\title{
Developing and implementing appropriate health communication messages for community based management of fevers
}

Citation for published version (APA):

Abbey, M. (2016). Developing and implementing appropriate health communication messages for community based management of fevers: Improving access to care for children under five in the Dangme West District, Ghana. [Doctoral Thesis, Maastricht University]. Datawyse / Universitaire Pers Maastricht. https://doi.org/10.26481/dis.20161125ma

Document status and date:

Published: 01/01/2016

DOI:

10.26481/dis.20161125ma

Document Version:

Publisher's PDF, also known as Version of record

Please check the document version of this publication:

- A submitted manuscript is the version of the article upon submission and before peer-review. There can be important differences between the submitted version and the official published version of record.

People interested in the research are advised to contact the author for the final version of the publication, or visit the DOI to the publisher's website.

- The final author version and the galley proof are versions of the publication after peer review.

- The final published version features the final layout of the paper including the volume, issue and page numbers.

Link to publication

\footnotetext{
General rights rights.

- You may freely distribute the URL identifying the publication in the public portal. please follow below link for the End User Agreement:

www.umlib.nl/taverne-license

Take down policy

If you believe that this document breaches copyright please contact us at:

repository@maastrichtuniversity.nl

providing details and we will investigate your claim.
}

Copyright and moral rights for the publications made accessible in the public portal are retained by the authors and/or other copyright owners and it is a condition of accessing publications that users recognise and abide by the legal requirements associated with these

- Users may download and print one copy of any publication from the public portal for the purpose of private study or research.

- You may not further distribute the material or use it for any profit-making activity or commercial gain

If the publication is distributed under the terms of Article $25 \mathrm{fa}$ of the Dutch Copyright Act, indicated by the "Taverne" license above, 


\section{Developing and implementing appropriate health communication messages for community based management of fevers}

Improving access to care for children under five in the Dangme West District, Ghana
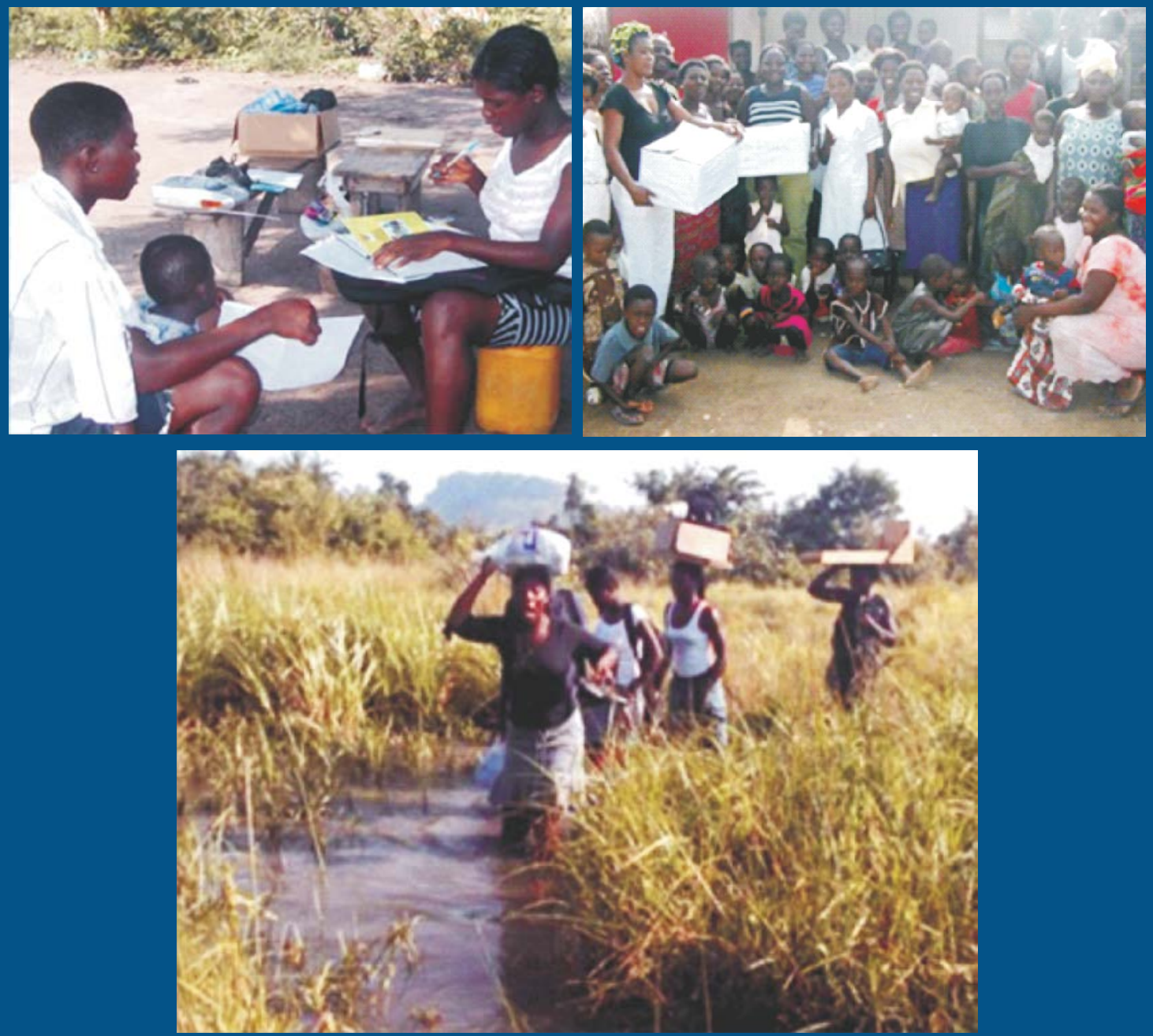



\section{Developing and implementing appropriate health communication messages for community based management of fevers}

Improving access to care for children under five in the Dangme West District, Ghana

\section{DISSERTATION}

To obtain the degree of Doctor at Maastricht University,

on the authority of the Rector Magnificus, Prof. dr. Rianne M. Letschert, in accordance with the decision of the Board of Deans, to be defended in public on Friday 25th November 2016, at10:00 hours

By

Mercy Abbey 


\section{Developing and implementing appropriate health communication messages for community based management of fevers}

Improving access to care for children under five in the Dangme West District, Ghana

\section{DISSERTATION}

To obtain the degree of Doctor at Maastricht University,

on the authority of the Rector Magnificus, Prof. dr. Rianne M. Letschert, in accordance with the decision of the Board of Deans, to be defended in public on Friday 25th November 2016, at10:00 hours

By

Mercy Abbey 


\section{Promotor}

Prof. dr. H.W. van den Borne

\section{2nd Promotor}

Prof.dr. L. K. Bartholomew-Eldredge (University of Texas, Houston, USA) (†)

\section{Co-Promotor}

Dr. Matilda Pappoe (University of Ghana)

\section{Assessment Committee}

Prof. dr. N.K. de Vries (chair)

Dr. A. Krumeich

Prof. dr. G. Parcel (University of Texas, Houston, USA)

Prof. dr. R. Ruiter

Dr. M. van Vugt (University of Amsterdam)

Printed By: Datawyse | Universitaire Pers Maastricht

ISBN: 9789461596376

\section{Copyright: Mercy Abbey}

All rights reserved. Any excerpts from this thesis may be used for scientific, educational, policy or programming purposes provided the source is acknowledged.

This dissertation has been prepared at the School for Public Health and Primary Care: CAPHRI, Department of Health Promotion, Maastricht University. CAPHRI participates in the Netherlands School of Primary Care Research (CaRe). 


\section{Contents}

Preface

Chapter 1 General Introduction

Chapter 2 Community perceptions and practices of treatment seeking for childhood pneumonia: A mixed methods study in a Rural District, Ghana

Chapter 3 Salient beliefs of primary care givers about prompt care seeking from Community Health Workers for a child with fever: An elicitation study in a rural district in Ghana

Chapter 4 Development of theory and evidence based program to promote community treatment of fevers in children under five in a rural district in Southern Ghana: An Intervention Mapping Approach

Chapter 5 Assessment of the adherence of Community Health Workers to dosing and referral guidelines for the management of fever in children under five years: a study in Dangme West District, Ghana

Chapter 6 Factors related to retention of Community Health Workers in a community based management of fevers in children under- five years in the Dangme West District of Ghana

Chapter 7 Treating fever in children under five: Care giver perceptions of Community Health Worker Services in Dangme West District, Ghana

Chapter 8 General Discussion and Conclusions 147

Valorization 163

Summary 169

References 175

Acknowledgements 195

Curriculum Vitae 201 


\section{Preface}

In response to the call by the World Health Organization (WHO) and the United Nations Children's Fund (UNICEF) to integrate pneumonia treatment at the community level, a cluster randomized controlled trial on treating malaria and pneumonia in children under five was implemented in the Dangme West District in Ghana between 2006 and 2009. The trial was implemented within the framework of a programme titled: "Improving access and quality of the management of malaria and pneumonia in Ghana" that was funded by the UNDP/WHO/Special programme for Tropical Diseases Research (TDR) and the Knowledge Enriches Programme of the Netherlands Foundation for the Advancement of Tropical Research (WOTRO). The programme comprised three projects:

1. Developing and implementing appropriate health communication messages for home and community management of fever in children under five in southern Ghana.

2. Home management of fevers (malaria and pneumonia) in children under five: A cluster randomized controlled trial in southern Ghana.

3. A cost analysis, and cost effectiveness study of home management of fevers in children under five in southern Ghana.

The present thesis is about project 1: Developing and implementing appropriate health communication messages for community based management of fever in children under five in the Dangme west district of Ghana. Projects 2 and 3 are topics of two other theses.

In brief, for the main trial, 660 persons, averaging two per community or village were selected by their communities and trained by professional health staff to manage fever in children aged 2 months to 59 months. The trained persons were referred to as Community Health Workers (CHWs). They worked in their homes, treated fever and referred the severely ill children to 
the nearest health facility. In addition CHWs counseled care givers on medication administration and referral compliance (where necessary). Medicines provided were free of cost to the sick children.

To promote the use of the $\mathrm{CHW}$ services, project 1 designed and implemented a health communication program that served as the platform for awareness creation and demand generation to drive appropriate uptake of the $\mathrm{CHW}$ services by the community. Our intervention methods included audio taped recorded messages and a role model story in the form of drama recorded on video. The communications program was implemented in all communities served by the $\mathrm{CHW}$ in the district. The messages were targeted at household care givers/parents of children under five and other stakeholders. Key messages delivered covered the rationale for the trial, the availability of trained CHWs in the communities, the need for prompt and appropriate treatment seeking for fevers in children under five and the expected role of the different target audiences.

\section{The Video:}

The video tape was a 30 minute drama made up of short scenes acted by community members in the local dialect Dangme. Each scene ended with lessons and morals based on the expected role of the target groups. Some of the key characteristics of scenarios acted out were: Children are dying of many illnesses especially fever, the importance of going to $\mathrm{CHW}$ immediately if the child has fever, the need for husbands to support their wives in seeking treatment for the sick child and free medications offered by CHWs for treating the sick children.

\section{The Audio Tape}

Two audio cassettes were produced with recorded messages in the local dialect. The first provided information on the overview of the project; informing community members about the job of the $\mathrm{CHWs}$, the role of the community members and urging them to use the services of the $\mathrm{CHWs}$. The second audio tape message provided information on drugs and the need for compliance. 


\section{Terms and Definitions}

\section{Integrated Management of Childhood illness (IMCI)}

A holistic approach to management of common childhood illnesses, developed by WHO and UNICEF in 1995. The approach aims at improving health worker skills, strengthening health systems and engaging and improving community and family practices to deal with the main causes of mortality and morbidity in children under 5 in resource constrained settings.

$\mathrm{IMCl}$ strategy includes interventions that promote child growth and development, prevent illness and allow illness proper management when it appears. These interventions should take place at facility level or at home at community and family level. There are 2 levels where $\mathrm{IMCl}$ should be implemented: Health facilities level (facility $\mathrm{IMCl}$ ) and community level (Community IMCl or Community Case management).

\section{Integrated Community Case Management (iCCM)}

Integrated community case management (iCCM) is a health service delivery approach in which trained community health workers provide basic diagnostic and treatment services for a subset of common childhood illnesses at the community level. Community $\mathrm{IMCl}$ activities focus on improving availability and quality of health education, community-based services, and essential commodities to treat conditions like malaria, Acute respiratory illnesses (ARI), and diarrhea.

\section{Pneumonia}

Pneumonia is a severe acute respiratory infection, a condition where fluids fill the lungs and disrupt how oxygen is absorbed. Breathing can become very difficult, especially for young children. Other symptoms can include intense coughing, a high fever, and chills. As pneumonia progresses, children can experience convulsions, unconsciousness, feeding problems, and without timely treatment, often death from respiratory failure. 


\section{Malaria}

Malaria is an acute febrile illness caused by parasites that are transmitted to people through the bites of infected female Anopheles mosquitoes. Initial symptoms such as fever, headache, chills and vomiting may be mild and difficult to recognize as malaria. However If not treated within 24 hours, P. falciparum malaria can progress to severe illness, often leading to death. In its severe state, children can experience breathing difficulty, convulsions, cough, high fever and feeding problems.

\section{Community Health Workers}

Community Health Workers (CHWs) are members of the community chosen by their community to be trained to provide health care and or community development services usually for children less than five years old within the communities where they live. They can be men or women with little or no formal education. Their work may be with pay or on voluntary basis. They are trained for short periods and may provide treatment for one or more disease or health problem. They are called by various names including: Village health volunteers, community based agents.

\section{Home Management of Malaria (HMM)}

Home management of malaria (HMM), is a strategy to ensure early recognition of and prompt and appropriate treatment of malarial illness in children under five years of age within the home or the community. Essentially, HMM provide anti-malaria medication for the treatment of fever, presumed to be malaria. The presumptive approach relies solely on clinical symptoms and signs to establish diagnosis and initiate treatment.

\section{Rapid Diagnostic Tests (RDTs) for malaria}

Malaria rapid diagnostic tests (RDTs) assist in the diagnosis of malaria by detecting evidence of malaria parasites (antigens) in human blood. RDTs permit a reliable detection of malaria infections particularly in remote areas with limited access to good quality microscopy services. Rapid diagnostic tests (RDTs) for malaria is critical in shifting from presumptive to test base approach to management of suspected malaria cases especially in peripheral health facilities without facilities for microscopy 



\section{Chapter 1}

General Introduction 



\section{General Introduction}

Malaria and pneumonia continue to be major public health problems in many parts of the world. Despite global and national control efforts, these two disease conditions have remained leading causes of morbidity and mortality among children under five, particularly in sub-Saharan Africa (SSA), causing an estimated 1.4 million child deaths each year [1]. These two diseases often have overlapping clinical manifestations including fever, cough, and difficult and fast breathing that make them indistinguishable in the absence of proper diagnostic equipment. In Ghana, malaria and pneumonia contribute $25 \%$ and $20 \%$ of child mortality respectively [2].

Current control strategies for malaria and pneumonia include early diagnosis and prompt treatment within 24 hours after onset of first symptoms. Prompt appropriate treatment can reduce illness progression to severe stages, and thus decrease mortality [3, 4]. Artemisinin based combination therapy (ACT) is generally recommended as first-line treatment for uncomplicated Plasmodium falciparum malaria and amoxicillin for the treatment of pneumonia in Ghana. Despite the availability of these effective treatments, access was largely limited to public health facilities and many of the children affected in rural areas therefore died at home or in the community with little or no prior contact with health care professionals at the health facilities $[5,6]$. Factors contributing to this inadequate access are many and include on one hand: lack of policy and supply issues [7] and on the other, poor geographic and financial access to health care facilities. In addition, care giver perceived poor attitudes of health care providers, care giver understanding of the illness, and the practice of self-medication [3, 8-10].

To improve access to care, community-based interventions for common childhood illnesses have been introduced to complement formal health care services. An example of the early strategies is the Home 
Management of Malaria (HMM), introduced in the 1990s to provide treatment close to homes or within communities especially in areas that lacked diagnostic facilities [11]. Under the HMM strategy, fever in children was treated presumptively as malaria using anti malarials such as chloroquine (CQ) $[12,9,11,13]$.

A number of trials on HMM recorded substantial reductions in childhood mortality and severe morbidity. For instance, a trial in Ethiopia reduced mortality by $40 \%$ [14] and in Burkina Faso, prompt treatment of children with uncomplicated malaria with pre-packaged anti-malarials reduced progression to severe malaria by $50 \%$ [13]. Although the HMM approach provided prompt treatment for malaria, one main challenge was that children with non-malaria febrile conditions or illnesses such as pneumonia (with symptoms similar to malaria), were often inappropriately treated with anti-malarials only, resulting in delayed treatment for pneumonia $[15,16]$.

In 2004 the World Health Organization (WHO) and the United Nations Children Fund (UNICEF) supported recommendations for community level treatment of pneumonia as part of integrated community case management (i-CCM) [17] based on evidence that a $70 \%$ reduction in under five mortality could be achieved if all cases of childhood pneumonia were managed the community level [18]. The i- CCM approach enables treatment for multiple common childhood illnesses including malaria, pneumonia and diarrhoea [19]. This change in strategy also coincided with a change in malaria drug policy from the use of monotherapy - chloroquine (CQ) to artemisinin-based combination therapy (ACT) such as artesunate amodiaquine (AAQ) as firstline treatment for uncomplicated malaria [20]. In 2010 (after the completion of this study) there was a shift in malaria case management policy from the presumptive to test-based approach including the use of rapid diagnostic test (RDT) before initiating drug treatment. [21]. Using test based approach enables parasitological confirmation to differentiate malaria from other common causes of childhood febrile illnesses [22]. 
Such community-based intervention strategies have often depended on community health workers ( $\mathrm{CHWs}$ ) who have become an important part of the health care system in expanding access to health services in remote areas in many developing countries [23]. The term "community health worker" generally refers to lay persons selected and trained to carry out one or several functions related to community health care. CHWs are known by different names in different countries such as Village Health Volunteers (VHWs), Community Drug Distributers (CDDs), and Community Based Agents (CBAs). They are often of varied demographic backgrounds and may be young or old, men or women and with or without formal education [23]. A common definition proposed by the WHO is that: "Community health workers should be members of the communities where they work, should be selected by their communities, should be answerable to the communities for their activities, should be supported by the health system but not necessarily a part of its organization, and have shorter training than professional workers" [24].

Involving $\mathrm{CHWs}$ for the provision of some basic health programs has been in existence for many years [23] having its roots in the philosophy endorsed in the Alma Ata Declaration of 1978 that emphasized among other things, Universal primary health care (PHC) and 'bringing health care as close as possible to where people live and work' [24]. CHWs gained much prominence internationally with their involvement in PHC programs established by many countries post Alma Ata as a means of attaining "Health for All". Although some trials involving CHWs in health care delivery contributed to substantial reductions in childhood mortality and severe morbidity, $[13,14,25,26]$ the problem of high rates of $\mathrm{CHW}$ attrition varying between $3.2 \%$ and $77 \%$ [25-27] coupled with other program related factors such as poor selection criteria and training, inadequate financial motivation, lack of community support, heavy workload and socio-cultural environments $[26,28-31]$ have led to concerns about the sustainability of programs involving $\mathrm{CHWs}$. The negative effect of high rates of attrition on the 
continuity of established relationships between $\mathrm{CHWs}$, the communities they serve and the health system as well as increased costs involved in the selection and training of new $\mathrm{CHW}$ s have been noted $[23,26]$.

Factors affecting the uptake of health services provided by $\mathrm{CHWs}$ are varied and often interrelated. The interactions between these determinants brings about challenges in the efforts of policy makers, program staff and the $\mathrm{CHWs}$ themselves in the process of deploying $\mathrm{CHWs}$ in the health care system $[32,33]$. Determinants of uptake of CHW services can be categorized into three broad themes [33]: First, are factors of knowledge and competency that may either facilitate or impede the uptake of services offered by CHWs. Adequately trained $\mathrm{CHWs}$ equipped with the requisite skills are in a better position of rendering quality care services and also provide critical information on health issues to the communities they serve.

On the other hand, poor quality services subsequently lead to persistence of health problems which results in the eroding of the confidence that communities may have had in the abilities of $\mathrm{CHWs}$. Further, inadequate knowledge and information on the training and the role of $\mathrm{CHWs}$ and community members themselves also results in high expectations on the part of both CHWs and the communities [23, 24]. When CHWs do not fully appreciate their limits (and when program staff do not place significant emphasis on this) they may tend to over step their boundaries and may offer services for which they have not been trained. Such practices could lead to complications and consequently discontinued use of their services [12, 26, 30]. Additionally, when communities are not adequately sensitised on the specific role of CHWs, it may result in high expectations of the $\mathrm{CHW}$ and subsequently unmet health care needs of communities. Persistence of unmet health care needs will result in discontinued use of the services of CHWs [12, 33]. Similarly, the level of awareness generated during the reintroduction of $\mathrm{CHWs}$ to their communities may either generate or result in low demand of the services of the $\mathrm{CHW}[32,34]$. 
The second category of determinants of uptake of CHW services are related to structural and contextual barriers. Structural barriers that affect the uptake of $\mathrm{CHW}$ services are health system related and include proximity of health care facilities, poor referral systems and stock-out of medicines [33, 35]. Communities closer to health facilities prefer the services of formal health workers to the CHWs. CHWs are mostly trained to provide first aid services or trained to deal with non-severe forms of illnesses and refer the patient in instances where they are unable to provide care; thus referrals may be inferred by communities as a sign of incompetence which adversely affects subsequent patronage of the $\mathrm{CHW}$ services $[12,36]$. When $\mathrm{CHWs}$ are frequently out of stock of drugs and other medical consumables, community members may go health shopping and this in the long term results in low demand for CHW services [12, 36, 37]. Contextual factors are community or individual related factors that affect demand for $\mathrm{CHW}$ services and may include taboos and local customs related to health care and certain diseases, religious factors and community affiliations [33].

The third category of determinants of demand for $\mathrm{CHW}$ services is related to $\mathrm{CHW}$ as well as individual community member attributes. Community member poor health seeking behaviour will result in low use of CHW services and this transcends into the health system at large [33, 34]). Further, poor community attitudes toward CHWs affect the uptake of the services they provide $[33,34]$. Poor community attitudes may stem from poor stakeholder engagement, $\mathrm{CHW}$ social standing in the community, the $\mathrm{CHW}$ selection and reintroduction process. CHWs are ordinary community members selected and given the most basic of health care training, thus, naturally, certain sections of the population are reluctant in seeking care from $\mathrm{CHWs}$. Derogatory nick naming of CHWs may also be attributed to this $[12,33$, 38] Poor CHW attitudes may also result in low patronage of their services. For 
instance community members will not feel comfortable accessing care from $\mathrm{CHWs}$ who constantly nag and treat them with disrespect. Further, $\mathrm{CHWs}$ who are unable to adhere strictly to the patient - health worker confidentiality agreement will scare away prospective clients. The unavailability of CHWs when they are needed by community members also adversely affects the use of their services $[12,30,33,39]$.

In Ghana the Ministry of Health (MoH) introduced large numbers of community or village health workers in the late 1970 s as part of a substantial review and organization of $\mathrm{MoH}$ activities aimed at implementing $\mathrm{PHC}$ strategies [23]. However, as has been the case in other parts of the developing world, the initial enthusiasm for CHW programs died down [23] due to factors including poor program sustainability, poor performance in some cases and high $\mathrm{CHW}$ attrition rates.

In recent times, CHWs have been high on the agenda again internationally to help deliver essential health interventions; given the limited professional health care personnel in developing countries. Following the recommendation on community treatment of pneumonia, a cluster randomized controlled trial was implemented in the Dangme West district of Ghana between 2006 and 2009; with the primary aim of assessing the impact of the intervention on mortality among children under five in the study district.

\section{Overview of Trial}

The trial entailed selecting, training and equipping $\mathrm{CHWs}$ for treatment of fever in children aged 2-59 months; using either the antimalaria drug, artesunate amodiaquine ( $A A Q$ ) alone or in combination with an antibiotic - amoxicillin (AMX), (AAQ+AMX) for the treatment of pneumonia within the HMM strategy. Details of the overall trial design and implementation are described elsewhere [40]. In brief, $660 \mathrm{CHWs}$, averaging two per community or village were selected by their communities and received three day training from professional health staff. The CHWs 
managed fevers in children brought over to them by care givers in the communities they served. CHWs worked in their homes and treated uncomplicated cases and referred the severely ill children to the nearest health facility. In addition, CHWs counseled care givers on medication administration and referral compliance, as needed. Medicines provided to the sick children were free-of-cost to the children. CHWs worked on a voluntary basis and managed over 12000 sick children by the end of the project. The trial reduced all-cause mortality by $30 \%$ and $44 \%$ among the study groups who received an anti-malarial (artesunate amodiaquine) and those receiving an antibiotic (Amoxicillin) in addition to the anti-malarial respectively.

As a complement, a second component of the programme, (upon which the present thesis is based) focused on developing and implementing health communication messages in the communities for promoting early and appropriate home management of fevers for children under- five. This component is based on the premise that: selecting, training and deploying $\mathrm{CHWs}$ into communities alone is not enough to ensure adequate utilization of services by community members, and that demand creation activities are necessary to promote use of services. The corresponding communication program was designed and implemented in all communities where CHWs worked. Health promotion messages were designed and disseminated through oral presentations, audio tapes, mobile van and a locally-produced video drama. Communication activities reached over 16,844 care givers in the study district. Detailed description of the design, development and implementation of the communications program are reported in chapter four of this thesis (Abbey et al., in press).

The present thesis focuses on the communication component of the trial and comprises eight chapters describing program development and implementation as well as related studies conducted immediately before, during and immediate post project implementation. 


\section{Intervention Mapping}

In recent times, planning programs that are theory and evidence based have become the mainstay of effective health promotion interventions. On this basis, the program was developed using Intervention Mapping (IM); a protocol for systematically developing theory and evidencebased health promotion interventions [41]. IM has guided the development of health promotion programs for different health problems; recent examples include cervical cancer screening [42] promotion of regular use of clinical preventive services by women with physical disabilities [43] smoking [44] Obesity [45] chronic disease self-management [46] sexuality, HIV and AIDS $[47,48]$ hearing loss [49] antiretroviral treatment adherence [50]and physical activity [51].

\section{Overview of Intervention Mapping}

The IM protocol comprises of six steps and each of the six steps comprises several tasks; the completion of which leads to products that inform the subsequent step, and the completion of all steps creates a "blueprint" or "map" for the intervention. Briefly, the six steps of IM are: (1) Needs assessment, (2) formulation of change objectives matrices, (3) Selection of theory-based methods and practical applications , (4) creation of intervention components and materials, (5) development of an adoption and implementation plan, and (6) development of the evaluation plan.

Step 1 includes problem identification together with the behaviors and environmental factors that cause the problem, among whom, and in what context. During this step the program person also aims at gaining an understanding of the community in which the intervention is to be implemented.

In step 2, the specific sub-behaviours that make up the targeted behaviors or performance objectives are established and then crossed with personal and external determinants in matrices. This leads to a list of change objectives: concrete objectives for the intervention. 
In step 3, theory-based methods and practical applications are matched with the corresponding change objectives. Theory based methods are also selected and integrated into an appropriate program.

In step 4, the practical applications specified in step 3 are combined to further develop the program with attention to the intended participants and the context. Program producers (e.g. graphic artists and producers) perform their tasks and the program is pretested.

In step 5, which deals with adoption and implementation, the potential users of the program and people who should ensure the successful implementation are identified. Matrices are developed to reflect performance objectives; matched to methods and practical applications; and a composite program is developed.

In step 6, an evaluation plan is completed which enables an assessment of the various decisions made at each step of the process. The results from the assessment can be useful for informing future intervention development. It must be mentioned that although steps, 5 and 6 are finalized in the last stages of intervention development, they are none-the-less started at the initial stages simultaneously with step 1.

The application of the protocol to the intervention reported in this thesis is expounded upon in chapter four.

\section{The outline of this thesis}

Chapter 1 provides a general background to the research reported in this thesis. It provides information about the problem of high mortality and morbidity in children under five particularly in sub Saharan Africa and describes the main factors contributing to the problem including, delays in accessing effective treatment as a result of geographic distance, financial constraints and long waiting time at health facilities. It further describes efforts made to improve access to care and strategies recommended to reduce under-five mortality and severe morbidity. 
Chapters 2 and 3 present formative studies conducted to inform the Intervention mapping for development and implementation of programs to promote prompt and appropriate care seeking for fever in children under five. In line with IM, these formative studies were conducted to fill the knowledge gap on community perceptions, recognition and management of childhood pneumonia; as well as to determine the willingness of caregivers to use $\mathrm{CHW}$ services for the sick child. Furthermore, a belief elicitation study based on the Reasoned Action Approach(RAA) [52] was conducted among care givers to explore their salient beliefs regarding prompt care seeking for a child with fever from $\mathrm{CHWs}$.

Chapter 4 describes how the IM protocol was applied to systematically develop and implement a multi component program; designed with elements to influence behaviour of caregivers of children under five, community health workers, professional health care providers and the wider community, to promote prompt and appropriate care seeking for fever in children under the age of five.

Chapters 5, 6 and 7 each present studies conducted as part of the process evaluation efforts of various components of the intervention. Chapter 5 describes the performance of $\mathrm{CHWs}^{\prime}$ adherence to the protocol for assessing the sick child. Specifically, the study assessed the adherence of CHWs to dosing and referral guidelines by reviewing records of consultations between CHWs and children sick with fever as reported by the caregivers. Chapter 6 examined the attrition rate among $\mathrm{CHWs}$ on the project and factors influencing retention of the $\mathrm{CHWs}$ that participated in the trial using a mixed method approach.

Chapter 7 reports the rate of utilization and caregiver perceptions on program implementation. In addition, it examines what factors are related to the use of CHW services for fever in children under five in the Dangme West district using multiple data sources. 
Chapter $\mathbf{8}$ provides a general discussion of the main findings of the studies included in this thesis, examines relevant methodological issues as well as implications of the findings for policy, programmatic actions, and further research.

The process of developing and implementing the health communication program is shown in figure 1.

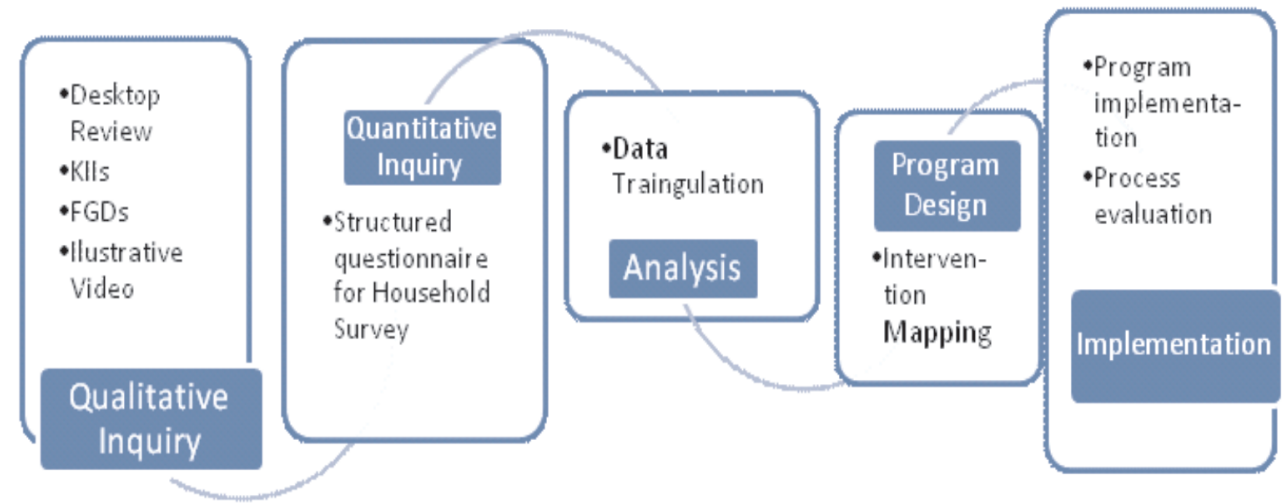

Figure 1: Developing and Implementing the Health Communication program for home and community management of fever in children under five in Dangme West District, Ghana.

\section{Ethical approval}

All the studies conducted were part of the larger study on Home and community management of fevers in children under five approved by the ethical review boards of the World Health Organization through the Special Programme for Research and Training in Tropical Diseases (TDR) and the Ghana Health Service. Permission was obtained from district health Administration authorities, village chiefs and informed consent from community members who participated voluntarily.

\section{Study Area}

The study was carried out in the Dangme West district in the Greater Accra region in Ghana. The district has an estimated land size of 1,700 square kilometres and an estimated mid-year population of about 109,000 . It is comprised of a total of 376 communities or villages. It lies in the coastal savannah; with isolated hills. The land is mostly flat and at sea level. The 
district is bounded on the North by the Akuapim Ranges; to the South by the gulf of Guinea, to the East by the River Volta and the Dangme East district and to the West by the Ga and Tema Metropolis.

Dangme West is largely rural. At the time of the study, the district was divided into four administrative sub-districts: Dodowa, Prampram, Ningo and Osudoku. There were four health centres, one per sub district. Few privately owned health facilities included four clinics, two maternity homes, two pharmacies and several over-the-counter medicine sellers (commonly called chemical sellers in Ghana). The Public Health facilities were situated in the sub district capitals. The district had no hospital therefore severe cases were referred to hospitals in neighbouring districts. Most health facilities were under staffed with the requisite qualified personnel and also diagnostic facilities were often not available.

Each community has a leader or chief who is supported by a group of elders or opinion leaders. Inhabitants are predominantly of the Ga-Adangme ethnic group. The language commonly spoken within these communities is largely referred to as Dangme with slightly different linguistic pronunciation of words. The other ethnic groups living in the communities include Ewes and Akans who by and large speak the local dominant language. Majority of the inhabitants profess Christianity. Many inhabitants lived more than $5 \mathrm{~km}$ away from the health facilities, and road networks were poor within the sub districts.

The dominant occupation is trading and subsistence farming. Other sources of livelihood included fishing, craftsmanship and few white color jobs. The district is mostly rural with wide spread poverty and many migrate in search of jobs. 
The overall aim of the study was to assess, design and implement a health program to promote early and appropriate home management of fevers in under-fives. Specific objectives were:

- To design messages for awareness creation among community members about the availability and role of $\mathrm{CHWs}$ in the communities

- To motivate community members to utilize $\mathrm{CHW}$ services in their communities

- To design appropriate program to promote CHW participation and retention in the project

- To assess the effectiveness of the messages disseminated among caregivers and

- To assess CHW adherence to protocol for assessing the sick child 



\section{Chapter 2}

\section{Community Perceptions and Practices of Treatment Seeking For childhood Pneumonia: A Mixed Methods Study in a Rural District, Ghana}

\section{Published as:}

Mercy Abbey, Margaret A. Chinbuah, Margaret Gyapong, L Kay Bartholomew, Bart van den Borne Community Perceptions and Practices of Treatment Seeking For childhood Pneumonia: A Mixed Methods Study in a Rural District, Ghana. BMCPublic Health. 2016 Aug 22;16(1):848. doi: 10.1186/s12889-016-3513-z. 


\section{Abstract}

Background: The World Health Organization recommends community case management of malaria and pneumonia for reduction of under-five mortality in developing countries. Care givers' perception and understanding of an illness influences the care the sick child receives. Studies in Ghana and elsewhere have routinely shown adequate recognition of malaria by care givers; similarly, evidence from Asia and some African countries have shown adequate knowledge about pneumonia. However, in Ghana, little has been documented about community awareness, knowledge, perceptions and management of childhood pneumonia particularly in the Dangme West district. Therefore this formative study was conducted to determine community perceptions of pneumonia for the purpose of informing the design and implementation of context specific health communication strategies to promote early and appropriate care seeking for childhood pneumonia.

Methods: A mixed method approach was adopted. Data were obtained from structured interviews ( $\mathrm{N}=501)$ and eight focus group discussions made up of 56 caregivers of under-fives and eight community Key Informants. Descriptive and inference statistics were used for the quantitative data and grounded theory to guide the analysis of the qualitative data.

Results: Two-thirds of the respondents had never heard the name pneumonia. Most respondents did not know about the signs and symptoms of pneumonia. For the few who have heard about pneumonia, causes were largely attributed to coming into contact with cold temperature in various forms. Management practices mostly were self-treatment with home remedies and allopathic care.

Conclusion: The low awareness and inadequate recognition of pneumonia implies that children affected may not receive prompt and appropriate treatment as their care givers may misdiagnose the illness. Adequate measures need to be taken to create the needed awareness to improve appropriate care seeking for childhood illnesses. 


\section{Introduction}

Malaria and pneumonia are leading causes of childhood morbidity and mortality in Sub Saharan Africa (SSA) killing approximately 1.4 million children every year [1]. Although effective drugs are available, many of the affected children do not receive treatment within the first 24 hour period after onset of symptoms [17, 53]; and many of them die at home [54].

To increase access to prompt and appropriate treatment for ill children, community-based interventions, mostly involving Community Health Workers (CHWs) have been introduced in areas that lacked access to formal health facilities [55]. CHWs are laypersons selected by their communities to render some basic health services within the communities, after undergoing short-term training [23]. Early examples of such communitybased service delivery strategies include the home management of malaria (HMM) which provided anti-malaria medication for the treatment of fever presumed to be malaria in children under five [4]. Though HMM led to prompt treatment of fever due to malaria, other febrile non-malaria illnesses or conditions (including pneumonia) were often inappropriately treated with anti- malarial only, resulting in delayed treatment for pneumonia [56].

In 2004, The World Health Organization (WHO) and the United Nations Children Fund (UNICEF) supported recommendations for community level treatment of pneumonia as part of integrated community case management (iCCM) activities in areas where malaria and pneumonia are endemic [17]. Several countries, including Ghana have subsequently adopted this strategy. CHWs in Ghana have been used successfully in community health service delivery programs (mostly pilot studies) targeting single diseases such as malaria. Previous attempts to train and deploy $\mathrm{CHWs}$ in management of childhood pneumonia were unsuccessful and 
therefore abandoned due to poor performance in differentiating malaria from pneumonia for appropriate treatment [57]. Treatment of childhood pneumonia has therefore been restricted mainly to health facilities. Following the recommendation on community case management of pneumonia, a pilot randomized controlled trial was implemented in the Dangme West district in Ghana to operationalize the strategy and to explore the effect of community management of pneumonia and malaria on underfive mortality in the study district.

The effectiveness of such community level interventions requires the utilization of the services by caregivers of the sick child. The utilization of such services by the caregivers may be influenced by the caregiver's perception and understanding of the illness [58], it is therefore pertinent to assess the caregivers' perceptions of childhood pneumonia and their treatment seeking practices for the sick child. Community perceptions of malaria and treatment seeking behaviour have been widely studied. For example, Studies in Ghana and elsewhere have shown that mothers had knowledge to recognize symptoms suggestive of malaria [3, 59-61]. Similarly, studies conducted on pneumonia in countries including Pakistan, Peru and Kenya showed that most caregivers were aware of and could easily recognize pneumonia signs and symptoms [62-64]. However, in Ghana, little has been documented about community awareness, knowledge, perceptions and management of childhood pneumonia particularly in the Dangme West district. Therefore, this study was conducted to determine community perceptions of pneumonia for the purpose of informing the design and implementation of context specific health communication strategies for appropriate care seeking behaviour for childhood pneumonia. In addition, it examines what factors are related to care givers' willingness or intention to use $\mathrm{CHW}$ services for fever in children under five in the Dangme West district. 


\section{Methods}

\section{Study Site}

The study was carried out in the Dangme west district of Greater Accra region in Ghana. At the time of the study, the district had an estimated land size of 1,700 square kilometres with a population of about 109,000 and 376 communities or villages. Available health facilities at the time of the study included four government owned health centres, six community clinics, two privately owned clinics, two private maternity homes, two pharmacies, and 42 registered drug retail shops. The district had no hospitals. Severe cases were referred to hospitals in neighboring districts. The indigenes are of the Ga-Adangme ethnic group and the dominant occupation is trading followed by subsistence farming.

\section{Study Design}

The study employed a mixed methods design to explore community perceptions and practices in the management of childhood fevers with emphasis on respiratory symptoms (especially pneumonia).

\section{Study Population and Sample}

\section{Key Informant Interviews and Focus Group Discussions}

We conducted a total of eight focus group discussions (FGDs), with seven female groups and one male group, made up of 56 parents and care givers of under-fives. A care giver was defined by household members as persons having the primary responsibility of caring for an under-five child. This person could be a male or female biological parent or guardian of the child. In this paper, the words parent(s)/caregiver(s) are used interchangeably. We carried out in-depth, key Informant Interviews (KIIs) with three Traditional Birth Attendants (TBAs), one herbalist, three chemical shop attendants and one community leader as key Informants. We defined a Key Informant as a community member seen by peers as an authority, an opinion leader or a well-known community member having adequate 
knowledge to discuss issues related to the inhabitants; including health issues and health seeking behaviour in the community. The numbers of FGDs and KIls were deemed sufficient when subsequent discussions and interviews yielded little or no new information [65].

\section{Household Survey}

In addition to the KIls, we conducted a household survey of a representative sample of 501 care givers. Details of the sample were accessed via the database of the Dodowa Health and Demographic Surveillance System (DHDSS). This database comprises of information on socio demographic characteristics of the district population; such as age, sex, marital status and total number of children per woman. Other variables are a unique identification code for each care giver, community of residence and house address.

The respondents were selected through a multistage sampling technique as follows: 15 communities were randomly selected from each of the four sub districts. All houses within the selected communities with underfives were selected, and from each selected house, only one eligible care giver from a household was selected for interview. If there was more than one eligible care giver, only one was chosen by simple random sampling.

\section{Procedures: Interviews and Focus Groups}

We purposively recruited key Informants and FGD participants with the assistance of a community mobilization officer who lived in the community. Research team members screened recruits for eligibility and selection prior to the day of discussion. The discussions were held in quiet places within the communities and in the local language, Dangme, to allow participants to express themselves more easily and to elicit local terminology that could be useful in designing messages for the intervention. A social scientist who spoke Dangme fluently conducted the Key Informant interviews and moderated the focus groups. She was assisted by a note taker who was 
proficient in Dangme and the first author who only had basic knowledge of the language. A list of topics, complemented with a video on Acute Respiratory illnesses (ARI) for training health workers in $I \mathrm{MCl}$ was used to guide the discussions. Topics discussed included care giver perceptions of common childhood illnesses in their communities, breathing difficulties among children, recognition of childhood pneumonia and its treatment seeking practices. (Assessment of pneumonia was based on $\mathrm{IMCl}$ criteria i.e. the presence of cough, difficult or fast breathing with or without fever). The video sections showed a child suffering from pneumonia showing fast breathing and chest in drawing. The use of the video was to help participants see the illness symptoms and to generate more terms related to the illness from the participants [66]. The discussions were audio recorded with consent from participants. Each discussion lasted about one hour to one hour thirty minutes.

The qualitative data was reviewed to extract repeated ideas or themes that were apparent. Themes that emerged from the key informants and focus group discussions were not only grouped into categories but were further used to design the survey instrument.

The household survey assessed care giver perceptions, and practices in the management of fevers and breathing difficulties with emphasis on pneumonia in children under five. Information sought from the respondents included care givers' perceptions of common childhood illnesses in the communities, perceptions of severe childhood illnesses, recognition of the symptoms and causes of pneumonia, its treatment seeking practices, and the local name for pneumonia. Other variables covered demographic characteristics of the care givers and whether or not care givers were willing to utilize $\mathrm{CHW}$ services for treatment of fever in under-fives if made available and actions taken at home for childhood fevers.

A team of eight trained research assistants (Six interviewers and two serving as supervisors) conducted face to face interviews with care givers in their homes. Interviews were held in the local languages using a 
questionnaire with both open and closed ended questions. Several role play sessions of translating questions from English to the local languages and back translation from the local language into English to check accuracy and consistency, as well as field pretesting among the data collection team ensured adequate practice prior to actual field data collection. Supervisors helped to resolve any emerging challenges during the field data collection and also checked filled questionnaires for completeness. Data collection lasted four weeks for both qualitative and quantitative survey.

\section{Data Analysis}

The household data was coded, categorized, entered in SPSS and exported and then analyzed in STATA. Descriptive and inference statistics were the primary tools used to explore and interpret findings of the quantitative survey data. To examine the factors that determine the use or otherwise of $\mathrm{CHW}$ services, logistic regression was conducted using a probit model, a technique that uses the maximum likelihood estimation to investigate the probability of an event occurring or not. The dependent variable in this study is the intention to use the services of the CHWs or not. The explanatory variables considered for the investigation include the age of the care giver, sex, religion, education, constraints (financial, unfriendly staff, and proximity to the $\mathrm{CHW}$ ), marital status and birth parity (number of children) of the respondents.

The tape-recorded FGDs and KIIs were transcribed verbatim, supplemented with field notes and any identifying information removed to ensure participant anonymity [65]. We adopted the grounded theory approach to the data analysis. The first author and the moderator of the interviews read all transcripts several times to familiarize with the data, identify key themes and develop a coding scheme. The transcripts were analyzed and coded. We compared coded themes and discussed discrepancies until agreement was reached. We then grouped segments of the interviews under the relevant codes and further analyzed the data by sub themes. 


\section{Results}

Results are presented by methods. We report first on results of the quantitative study then the qualitative. Key findings reported are demographic characteristics, perceptions on pneumonia and treatment practices, intention or willingness to use $\mathrm{CHW}$ services and treatment for childhood fever.

\section{Demographic characteristics of respondents}

The care givers were predominantly female, and aged between 25-34 years, as shown in Table1. A quarter of the respondents had no formal education, while most of the rest had basic education. They were mostly Christians (87.6\%) and married (87.8\%).

\section{Perceptions on pneumonia}

The care givers' knowledge about pneumonia is shown in Table 2. The results suggest that, perceptions and understanding of illnesses that affect underfives and adequate knowledge about their causes, effects and treatments are context specific. Most respondents were inadequately informed about pneumonia, its signs, symptoms, causes and treatment. Only a third of respondents $31.94 \%$ (160/501) indicated they had ever heard the name pneumonia. Of those who reported having ever heard of pneumonia, majority $58.13 \%$ (93/160) did not know any symptoms of pneumonia as shown in Table 2. Only 5.62\% (9/160) mentioned a word in Dangme for pneumonia and each name varied. 
Table 1: Demographic Characteristics of Care givers in Selected Households in Dangme West District, Ghana

\begin{tabular}{|c|c|c|c|}
\hline \multicolumn{2}{|c|}{ Variable } & \multirow{2}{*}{$\frac{N(501)}{53}$} & \multirow{2}{*}{$\frac{\%}{10.6}$} \\
\hline Sex & Male & & \\
\hline \multicolumn{4}{|c|}{ Age (Years) } \\
\hline & $16-24$ & 105 & 20.9 \\
\hline & $25-34$ & 234 & 46.7 \\
\hline & $35-44$ & 103 & 20.6 \\
\hline & $45-54$ & 35 & 7.0 \\
\hline \multicolumn{3}{|c|}{ Religion } & 4.8 \\
\hline & None & 23 & 4.6 \\
\hline & Christianity & 439 & 87.6 \\
\hline & Muslim & 32 & 6.4 \\
\hline & Traditionalist & 5 & 1.0 \\
\hline & Missing & 2 & 0.4 \\
\hline \multicolumn{4}{|c|}{ Education } \\
\hline & None & 144 & 28.7 \\
\hline & Primary & 138 & 27.5 \\
\hline & JSS/ Middle School & 184 & 36.7 \\
\hline & Secondary/SSS & 21 & 4.2 \\
\hline & Tertiary & 11 & 2.2 \\
\hline & Vocational/Technical & 3 & 0.6 \\
\hline \multicolumn{4}{|c|}{ Ethnicity } \\
\hline & Ga Adangme & 341 & 68.1 \\
\hline & Ewe & 123 & 24.6 \\
\hline & Akan & 15 & 3.0 \\
\hline & Dagomba/Gonja/Mamprusi & 15 & 3.0 \\
\hline & Others & 5 & 1.0 \\
\hline & Missing & 2 & 0.4 \\
\hline \multicolumn{4}{|c|}{ Marital status } \\
\hline & Never Married & 11 & 2.2 \\
\hline & Married & 440 & 87.8 \\
\hline & Divorced/separated/widowed & 50 & 10.0 \\
\hline \multicolumn{4}{|c|}{ Occupation } \\
\hline & Unemployed & 83 & 16.6 \\
\hline & Farmer & 124 & 24.8 \\
\hline & Artisan & 81 & 16.2 \\
\hline & Trader & 181 & 36.1 \\
\hline & Others & 31 & 6.2 \\
\hline & Missing & 1 & 0.2 \\
\hline
\end{tabular}


Table 2: Reported knowledge on pneumonia among caregivers in Dangme West district, Ghana

\begin{tabular}{|c|c|c|c|c|c|c|}
\hline \multirow[t]{2}{*}{ Variable } & \multicolumn{2}{|c|}{ (Yes) } & \multicolumn{2}{|c|}{ (No) } & \multirow{2}{*}{$\begin{array}{c}\text { Don't } \\
\text { know (n) }\end{array}$} & \multirow{2}{*}{$\%$} \\
\hline & $\mathrm{n}$ & $\%$ & $\mathrm{n}$ & $\%$ & & \\
\hline Heard of pneumonia $(\mathrm{N}=501)$ & 160 & 31.94 & 341 & 68.06 & - & \\
\hline \multicolumn{7}{|c|}{ Signs and symptoms of pneumonia ( $N=160)$} \\
\hline Fever & 18 & 11.25 & 49 & 30.63 & 93 & 58.12 \\
\hline Fast breathing & 18 & 11.25 & 49 & 30.63 & 93 & 58.12 \\
\hline Difficulty breathing & 19 & 11.88 & 48 & 30.00 & 93 & 58.12 \\
\hline Cough & 23 & 14.38 & 44 & 27.50 & 93 & 58.12 \\
\hline
\end{tabular}

Causes $(\mathrm{N}=160)$

$\begin{array}{lllllll}\text { Sleeping on bare cemented or cold floor } & 59 & 36.87 & 26 & 16.25 & 75 & 46.88\end{array}$

$\begin{array}{lllllll}\text { Exposure to cold weather } & 56 & 35.00 & 29 & 18.12 & 75 & 46.88\end{array}$

$\begin{array}{llllllll}\text { Sleeping close to electronic and fan } & 28 & 17.50 & 57 & 36.61 & 75 & 46.88\end{array}$

$\begin{array}{llllllll}\text { Eating cold food/drinking very cold water } & 13 & 8.12 & 72 & 45.00 & 75 & 46.88\end{array}$

Treatment for pneumonia $(\mathrm{N}=160)$

$\begin{array}{llllll}\text { Take the sick child to the health facility } 92 & 92.50 \quad & - & - & 68 & 42.50\end{array}$

Can pneumonia be prevented? ( $\mathrm{N}=160)$

$\begin{array}{lllllll}\text { Yes } & 97 & 60.63 & 2 & 1.25 & 61 & 38.12\end{array}$

Preventive measures/ ways to prevent

pneumonia $(\mathrm{N}=160)$

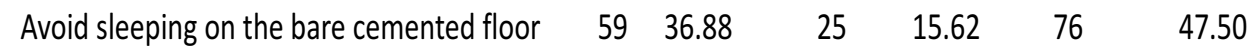

$\begin{array}{lllllll}\text { Avoid exposure to cold weather } & 54 & 33.75 & 30 & 18.75 & 76 & 47.50\end{array}$

$\begin{array}{lllllll}\text { Avoid eating cold food/ very cold water } & 14 & 8.75 & 70 & 43.75 & 76 & 47.50\end{array}$

$\begin{array}{lllllll}\text { Avoid sleeping with fan on } & 28 & 17.5 & 56 & 35.00 & 76 & 47.50\end{array}$ 


\section{Intention or willingness to use $\mathrm{CHW}$ services}

Majority, 96.6\% affirmed their willingness to utilize the $\mathrm{CHW}$ services for their children if such services are made available in their communities. The probit regression showed that age, education, religion, sex and occupation are not important predictors of the intention (willingness) of care givers to use services of the CHWs for childhood fever. Marital status and birth parity do however significantly influence a care giver's decision to use services of the CHWs (Table 3). Married respondents were more likely than the unmarried to use services of the CHWs $(P<0.001)$. The use of these services also increases with an increasing parity $(P<0.001)$.Financial challenges and proximity to the CHW's are some reasons why respondents may not use the services of $\mathrm{CHWs}$.

Table 3: Probit regression results for intention to use services of CHWs and background characteristics

\begin{tabular}{|c|c|c|c|c|c|}
\hline Intention to use the services of $\mathrm{CHW}$ & Coefficient & $\begin{array}{l}\text { Standard } \\
\text { Error }\end{array}$ & $\mathbf{z}$ & $\mathbf{P}>\mathbf{Z}$ & \\
\hline Age of respondent & 0.016 & 0.015 & 1.06 & 0.29 & \\
\hline Female (Reference: Male) & 0.582 & 0.302 & 1.75 & 0.081 & \\
\hline Married (reference: not married) & 0.917 & 0.25 & 3.67 & 0.000 & $* * *$ \\
\hline $\begin{array}{l}\text { Birth Parity (Number of Children) } \\
\text { Education (Reference: No education) }\end{array}$ & 1.416 & 0.233 & 6.09 & 0.000 & $* * *$ \\
\hline Primary & 0.055 & 0.385 & 0.14 & 0.887 & \\
\hline JHS & -0.448 & 0.348 & -1.29 & 0.199 & \\
\hline Secondary plus & -0.593 & 0.532 & -1.11 & 0.265 & \\
\hline \multicolumn{6}{|c|}{ Reason for not using ( Reference: financial) } \\
\hline Unfriendly staff & 0.124 & 0.374 & 0.33 & 0.74 & \\
\hline Distance/proximity & 0.808 & 0.326 & 2.48 & 0.013 & $* *$ \\
\hline \multicolumn{6}{|l|}{ Religion ( Reference: None) } \\
\hline Christian & -0.683 & 0.68 & -1 & 0.315 & \\
\hline Moslem & -0.539 & 1.434 & -0.38 & 0.707 & \\
\hline \multicolumn{6}{|c|}{ Occupation (Reference: Unemployed) } \\
\hline Farmers & -0.0689 & 0.386 & -0.18 & 0.859 & \\
\hline Artisans & 0.0412 & 0.390 & 0.11 & 0.916 & \\
\hline Traders & 0.4860 & 0.352 & 1.38 & 0.167 & \\
\hline Formal sector of the economy & -0.2545 & 0.693 & -0.37 & 0.713 & \\
\hline Employed (other jobs) & -0.2769 & 0.591 & -0.47 & 0.639 & \\
\hline _cons & -0.6888 & 0.886 & -0.78 & 0.437 & \\
\hline
\end{tabular}

*** Significant at $1 \%, \quad * *$ significant at $5 \%$, 


\section{Treatment seeking practices for fever}

The respondents gave a clear description of various treatment practices for fever. As shown in Table 4, the child is usually given a tepid sponging (61.9\%) to bring down the temperature, followed by selfadministered home treatment with remnants of orthodox medicine kept from a previous ailment or herbal remedies. The common medication administered at home were mostly analgesics such as paracetamol (92.4\%) and anti-malarial, mainly chloroquine (33.1\%). Majority, (93.4\%) would normally initiate treatment on the same day or within 24 hours from when symptoms are observed.

Table 4: Care giver management of fevers in under $5 s$ in Dangme west district $(\mathrm{N}=\mathbf{5 0 1})$

\begin{tabular}{lrrrr}
\hline Variable & \multicolumn{2}{c}{ Yes } & \multicolumn{2}{c}{ No } \\
& $\%$ & $(\mathbf{n})$ & $\%$ & (n) \\
\hline Action taken at home/Treatment given for child's fever & 61.9 & $(310)$ & $38.1(191)$ \\
Tepid sponging of the child & 58.5 & $(293)$ & $41.5(208)$ \\
Use of left over medicine available at home & 20.6 & $(103)$ & $79.4(398)$ \\
Seek care from over-the-counter medicine seller & 13.0 & $(65)$ & $87.0(436)$ \\
Seek care from a health facility & 4.2 & $(21)$ & $95.8(480)$ \\
Give herbal medicine & 2.2 & $(11)$ & $97.8(490)$ \\
Give enema at home & 0.0 & $(501)$ & $0.0(501)$ \\
\hline Seek care from a CHW & & &
\end{tabular}

\section{Background characteristics of FGD participants}

Participants in the FGDs comprised of young mothers, older mothers, grandmothers and fathers. The young mothers were aged between 21 and 32 years and had one to three children, some were married. Many of these 
mothers have primary and/or Junior secondary school education while a few of them have no formal education. They had lived in the community most of their lives. Most of these younger mothers were traders or artisans. A few were unemployed.

Older mothers were aged between 35 and 47 years. Most were married while some were divorced or single parents. Almost all the older mothers had little or no formal education; and had lived in the community since birth. The grandmothers were engaged in either farming or trading or both, were averaged between 50 and 77 years, and had lived in the community most of their life time.

Men who were engaged in the FGDs were aged between 20 and 43 years and were mostly married. All male participants were employed, and had lived in the community between 10 and 38 years. Most of them were farmers and the rest artisans. All of them had some formal education with the highest being secondary education.

Key issues explored from the various study participants in the qualitative interviews yielded similar responses therefore the findings are presented together and under three main themes: Community perception of common childhood illnesses; perceived causes of difficulty in breathing and or pneumonia and treatment seeking for these illnesses.

\section{Care giver perceptions of common childhood illnesses among under-fives.}

Key Informants and care givers perceived malaria, 'hiowe' or 'ablam' (convulsion), 'haem-lar-dum' or 'hedola' (hot body/fever) diarrhea and measles as the common causes of under-five mortality in the district. Other conditions perceived as non-life threatening were, stomach pains, skin rashes, cough and worm infestation.

On the whole "difficulty in breathing or breathing difficulties" was rarely mentioned spontaneously as one of the common illnesses among children in the district. Further probing revealed that difficulty in breathing in children was often associated with 'soso' (common cold) or "blocked nose", 'hoha' (asthma) and convulsion. 
However, after FGD participants and Key Informants viewed the video of a child with high respiratory rate, cough and lower chest in-drawing, that indicated severe pneumonia (WHO's IMCl classification), majority of the discussants generally described the child in the video as having breathing problems. Very few (about 11\% of 56 of FGD participants) and an herbalist spontaneously identified the child as suffering from pneumonia. A male participant in one of the FGDs exclaimed "...oh that is pneumonia; it is common among adults but not the children".

In another FGD session, a female participant also explained, "... That is pneumonia; because pneumonia causes a child to cough and breathe like this." When probed further, majority said they have never heard the word "pneumonia" before, adding that it was their first time of hearing it. Others, who reported they have heard about pneumonia, indicated the radio, school and clinic as their source of information.

It appeared that there was no single word or expression used to describe "pneumonia" in the local dialect. Various expressions used in the Dangme dialect to describe the condition included "emumu-sue-no" or "emumu-siueo-nowie" (meaning "gasping for breath") and "emumu-dei-no" or "enge-mumu woe mla mlamla" (meaning "the child is breathing faster than normal"). The expressions given by respondents in the household survey included: "... kasa hio" (meaning "illness of the rib area"); "fie se ehem" (meaning "cold air has entered into his/her body").Additionally, the herbalist, who identified the child as suffering from pneumonia, suggested the name for pneumonia in the local dialect as "Mumunya tam hio" (meaning, "out of breath" illness).

The variety in common expressions among the participants suggest inadequate exposure/knowledge or understanding of pneumonia except for those who have ever seen someone suffer from it or someone who had been diagnosed of it as told by one female participant. She said "I went to visit my 
relative on admission to the hospital and she told me the Nurse told her that she had pneumonia...she was not breathing properly but I don't know a name for it in Dangme".

\section{Perceived causes of breathing difficulties and or pneumonia}

Most participants perceived causes of breathing difficulties in children as common cold, headache, cough, asthma, hot body and 'hidden measles' (this is when a child has other symptoms of measles without the skin rash), eating 'Bad food,' (junk food) and being infested with worms and measles.

The perception of care givers who have heard about pneumonia differed. The general belief was that exposing a child, to cold temperature or windy weather conditions could result in the child getting pneumonia. The most common factors mentioned in all discussion groups included "sleeping on the bare cemented floor". For instance, one female participant said "What I know is that pneumonia is caused by sleeping on the bare cemented floor; because the bare floor is cold, if the child is not adequately clothed and sleeps on it for a long time, the cold penetrates the body and causes pneumonia."

Another belief expressed by a male discussant was that, "Sleeping directly under a fan can cause a child to have pneumonia; I mean the continuous exposure of a child to the air from an electric fan over a long period of time makes the child sick with pneumonia."

Furthermore, other views sampled attributed the cause of pneumonia to ingesting cold drinks or food; they indicated that, "One gets pneumonia from drinking cold water, eating cold food or chewing ice cubes." The Herbalist also added that, "... In the past, when there was no iced water children did not get pneumonia."

Poor hygiene practice was also mentioned as one of the factors that could cause the child to get pneumonia; as explained by a male participant, "When a child picks anything from the ground and puts it in his mouth, there can be contamination which can cause the child to have pneumonia. Crawling children get it easier than toddlers." 


\section{Treatment seeking practices for difficulty in breathing and pneumonia}

Overall, treatment practices that were mentioned by participants can be grouped into Self-treatment and Hospital treatment.

Self-treatment

Self-treatment refers to a situation where a person determines what medicine, as well as the dosage to use for an ailment without consultation with a qualified health personnel. The Self-treatment practiced by community members were in the form of home remedies including the use of Shea butter, honey and herbal treatments. Discussants believe Shea butter has medicinal properties and can be used both externally and internally. Some uses mentioned include massaging the sick child's rib area with the Shea butter, particularly by a woman who has ever given birth to twins. The belief is that such persons possess special supernatural abilities that make the massage more effective and facilitates the healing process. Another approach is to make a mixture of Shea butter, herbs and/or honey for the massage. For internal usage, ingesting or inhaling melted Shea butter is believed to clear the nasal congestion and restore proper breathing as explained by one female participant in FGD; "Catarrh also causes the child to have difficulty in breathing so when my child gets "catarrh" I normally put shea butter into the nose and give him some to eat then the blockage opens and the child begins to breathe properly."

Another common form of treatment mentioned was massaging the child with Robb methylated ointment and hot water. This is particularly done for children with pain in the rib cage area. A less common practice indicated by few care givers is to give the child water drained from soaked uncooked rice, or honey to treat the difficulty in breathing as cited by one grandmother in FGD; "We soak rice in water and give the cloudy water to the child to drink. This cleans up the child's system and health is restored." 
Herbs in different forms were reportedly used for treatment of pneumonia in children. Some are boiled or made into powder and mixed with certain substances obtained from a herbalist for use as described by one male participant "The herbs are boiled and given to the child to drink or given as enema. This flushes out the illness through the passing of stool."

The herbalist also revealed that, "There is one called "Ti" which is also smeared on the child's body. "Ti" is black powdered substance processed from a combination of herbs and other ingredients made into powder and this is given to the child who has fast breathing problems for remedy."

\section{Hospital treatment}

The other major form of treatment for difficulty in breathing was sought at the hospital as some considered it difficult for home treatment. This approach was common among care givers within and closer to the district capital where access to facility treatment was easy and convenient. Some Care givers expressed that they would usually initiate some form of treatment at home but most invariably, the sick children ended up in the clinic. One of such views pertained to treatment for asthma as mentioned by one female participant; "For asthma, first, we give honey and $M \& B$ (an anti-biotic) at home. If the child does not respond well to the medicine, then we send the child to the clinic for further treatment."

Others seek medication for breathing difficulties directly from drug shops in the community as narrated by one drug shop attendant:

"... people do come here (drug shop) complaining about breathing problems. They would say for example, the way my child is breathing, the child is having asthma. Normally when they behave like that we advise them to take the child to the hospital first because there are different drugs for asthma so when they visit the hospital and the drug is prescribed for them they come back to buy." 


\section{Decision making on treatment seeking for the sick child}

Discussants indicated that, decisions on treatment seeking are most often taken in a consultative manner. The immediate caregiver consults relatives or neighbours for ideas on the best course of treatment for the illness. It often involved seeking the opinion or assistance of significant others who are considered knowledgeable in managing the child's illness. Such persons included grandparents of the child, other older relatives and neighbours as explained by a female participant: "I don't know any medicines for any illness and since my parents are older than I am and they know what is wrong with the child they take the decision on what medicine to give to the child."

Nonetheless, there are instances where the decision rests on the care giver present at the time when the illness is observed as pointed out by one male participant: "My wife is the one who takes care of the children when I am not in the house, but when I am in the house I take the decision on what to do."

\section{Discussion}

This study aimed to assess caregivers' awareness and perceptions of pneumonia, its causes, signs and symptoms and their treatment seeking practices for children with the symptoms of pneumonia. The mixed method approach proved useful in confirming perceptions expressed in the quantitative and qualitative responses. In-depth interviews and focus group discussions provided explanation of the quantitative responses, which validated knowledge gathered from the responses as true reflections of opinions and beliefs of the respondents.

The study showed that care givers had an awareness of various common childhood illnesses prevailing in their communities; however, pneumonia did not emerge as one of the known common childhood diseases in their communities. The biomedical symptoms indicative of pneumonia including fast breathing, difficult breathing and cough were not mentioned spontaneously or associated with pneumonia even when prompted. 
The seeming low awareness of pneumonia among the rural dwellers of Dangme West district is consistent with earlier findings of studies conducted in Eastern Uganda among mothers and traditional healers [67] but in contrast to the findings in Kenya [63], Pakistan [62], Peru [64] and Western Uganda [68], where participants had heard about the illness and were easily able to identify the signs and symptoms. It can therefore be posited that such problems of low awareness are community specific, and may be dependent on the linguistic interpretation of diseases and how they may be perceived within the communities. This became evident from the video illustration of the sick child, where participants identified and associated pneumonia with varied local terminologies but could not agree on a known local name; as such, there are some care givers that have heard the term "pneumonia" but do not understand what it is. Similarly, findings from Eastern Uganda showed that participants had local names for the symptoms but no specific name for pneumonia [67] which is in contrast to study findings in Kenya [63]and Pakistan [62] that reported knowledge of specific local names for pneumonia and its symptoms among study participants. There may also be a possibility that the people of Dangme West district, a primarily rural area have had very little education or information on pneumonia and its symptoms.

This lack of ability among care givers in the present study to identify pneumonia symptoms could result in possible delays in seeking appropriate health care for the sick child and result in avoidable deaths; as noted by others [15].

Treatment practices for breathing difficulties and or pneumonia, cited by care givers in the present study and also reported in other studies in Pakistan [62] and Uganda, [67] concur and resonates with common practises for managing childhood illnesses where many care givers in Sub Saharan Africa try different home remedies and resort to facility treatment after selftreatment efforts have failed and or illness worsens $[3,69]$. On the other hand, a study in Kenya found no known home treatment for pneumonia but rather emphasized hospital treatment [63]. 
We note an interesting observation in the relationship between causes, prevention and treatment of Pneumonia in the current study and that of Peruvian mothers: Care givers in Dangme west district employed mostly herbal, hospital treatment or some home remedy to treat pneumonia, mothers studied in Peru had one peculiar form of treating pneumonia. As they had more knowledge on the causes of pneumonia, they considered doing the opposite of the causative factor, as a form of treatment [64]. For instance, "If cold temperature was indicated as one important cause of pneumonia, then making the child sweat or providing heat will bring health." As a result, Peruvians explored practices like sauna, spa and thermo therapeutic methods as a way of treating some ARIs.

In the Ghanaian study, a similar approach can be seen; though the respondents in Ghana, unlike their Peruvian counterparts, rather perceived the opposite of the causes of pneumonia as a way of preventing the illness altogether. For example, if sleeping on the bare cemented floor caused pneumonia, then they mentioned 'avoiding sleeping on bare cemented floors' as a preventive measure. This is evident in Table 2 where the various causes of pneumonia mentioned was the same as the various preventive measures, which were actually the reverse of its causes. From the responses, it could be deduced that if care givers in the present study were convinced that bacteria or virus causes pneumonia, then they would seek appropriate protection and care.

This study found proximity to a CHWs' location as a significant factor for the willingness to utilize the $\mathrm{CHW}$ for the child's fever ( $p$-value $=0.013$ ). This means that $\mathrm{CHW}$ services have a high probability of being used if they are located closer to the communities they serve and this can be explained by the fact that proximity to the service provider has advantages including reduction in cost for transportation, waiting time and elimination of other costs associated with health seeking at health facilities; similar to findings reported by others $[10,22,39]$. 


\section{Limitations}

Assessing actual behaviour of study participants would have been more ideal than exploring perceptions of participants since this may have revealed their actual practice. The use of a triangulation of quantitative and qualitative methods with different participants however strengthened our findings from the different community perspectives explored. The use of the video showing real children with pneumonia proved useful. It enriched the discussions as it elicited more information from participants compared with the use of the discussion guide alone [66]. The study findings could be largely generalized to the district due to the probability sampling method used in selecting respondents for the household survey.

\section{Conclusion}

Majority of care givers in this study were unable to recognize or identify symptoms indicative of pneumonia. Most could not appreciate its dangers or identify it as a deadly childhood disease and as a result take appropriate steps to manage a child affected by it. Intense education at the home and community level, through appropriate behaviour change communication methods and targeted at various stakeholders is necessary to increase awareness and to improve care seeking behaviour. As a result of this formative study, particularly due to the low awareness of pneumonia, and given that care givers could not distinguish between pneumonia and malaria, we changed our original intent of specifying malaria and pneumonia in our campaign messages. We refined the message to reflect that fever can be a sign of several illnesses and that a child observed to have fever, should be taken immediately to the $\mathrm{CHW}$ or a health facility for appropriate care.

This strategy was more amenable to promoting prompt and appropriate care seeking rather than requiring care givers to attempt a diagnosis at home before seeking appropriate care for the sick child. 


\section{Chapter 3}

Salient beliefs of primary care givers about prompt care seeking from Community Health Workers for a child with fever: An elicitation study in a rural district in Ghana

Submitted as:

Mercy Abbey, Amerley Ollenu, L Kay Bartholomew, Bart van den Borne: Salient beliefs of primary care givers about prompt care seeking from Community Health Workers for a child with fever: An elicitation study in a rural district in Ghana. 



\section{Abstract}

Background: This study was undertaken to elicit the salient beliefs about seeking care for the febrile child from Community Health Workers in order to inform potential strategies for increasing access to prompt and appropriate care; by promoting utilisation of $\mathrm{CHW}$ services for the reduction of childhood mortality in a rural Ghanaian district.

Methods: This study was part of a cross sectional formative survey among 501 household care givers of children under five. In line with the Reasoned Action Approach theory, the study sought care givers' salient beliefs about facilitators and barriers, circumstances and perceived norms that would influence their use of Community Health Worker services for childhood fevers.

Results: Responses on salient consequences of seeking treatment from Community Health Workers for children with fever were mainly positive; $47.7 \%$ of respondents cited the advantage of 'effective treatment', and $82.2 \%$ stated there were no bad outcomes from seeking immediate care for the child's fever from CHWs. Most respondents (96\%) asserted 'no one' will object to them seeking treatment from $\mathrm{CHWs}$ for children with fever and the biological parents $(55.1 \%)$ were reported to be the primary referents. The predominant facilitating factor in seeking immediate care for children with fever as stated by respondents were nearness to a health facility (55.7\%) and financial inaccessibility and unaffordability of medication (46.3\%) as the inhibiting factors.

Conclusion: The findings suggest that factors including prompt treatment, proximity and cost are key elements that could ensure a successful uptake of services. 


\section{Introduction}

In Sub-Saharan Africa (SSA), an estimated $80 \%$ of deaths in children under five are caused by acute febrile illnesses like malaria and pneumonia. Globally, malaria and pneumonia are major public health challenges; however the disease burden is greatest in Sub Saharan Africa [1] where these two diseases together cause nearly 1.4 million deaths in children under five years old [70]. In Ghana, malaria and pneumonia are leading causes of childhood mortality and morbidity; malaria accounting for $25 \%$ and pneumonia $20 \%$ of under-five deaths [2]. Control strategies include early recognition and prompt treatment, (initiated within 24 hours of symptom onset) to avert development into severe complications as this can be rapid and fatal [71]. Despite availability of effective treatment, many sick children particularly in rural SSA die at home with minimal or no previous contact with health care providers $[72,73]$. Factors contributing to this include delays on the part of household care givers in seeking prompt and appropriate care for the sick child, care givers' understanding of the illness, preferences for selftreatment and alternative care, limited female decision-making autonomy to seek care, poor geographic access, perceived poor attitudes of professional health care providers towards clients and financial barriers[54,59,74].

To reduce mortality from febrile illnesses, integrated community case management (i-CCM) of childhood illnesses including malaria and pneumonia has been introduced to provide easy access to treatment in areas with difficult access to health care facilities [72].

The success of such interventions requires the active involvement of care givers who play a key role in seeking care for children under-five. Consequently, an in depth understanding of care givers' treatment-seeking behavior for febrile children is important for program planning and implementation. Behavioral interventions are more likely to be successful when they are based on an empirical understanding of the factors associated with the behavior of interest among target populations $[41,75]$. Hence, "the 
more a program planner understands the factors underlying a person's decision to perform or not perform a given behavior, the more likely it is that the planner will design an effective intervention." [75]. Theory-based formative research is needed to gain this insight.

\section{Conceptual Framework}

In the current study, we used the Reasoned Action Approach (RAA) which is the latest version of the Theory of Planned Behavior [76]. This theory has been used to predict and explain a wide range of behaviors. According to the theory, people's behavior depends on their intention to perform it. This intention is determined by a person's attitude, which describes their overall positive or negative feelings about personally performing the behavior (RAA expands the concept to include experiential or affective attitude which refers to people's feelings towards performing the behavior and instrumental or cognitive attitude which refers to peoples thought processes towards performing a behavior); perceived norms which refers to perceptions about how important referent persons view the behavior in question (subjective norm is also constructed in two ways: descriptive norm which describes what others are doing and injunctive norms, describes others' expectations); and perceived behavioral control (PBC) which refers to perceptions of their ability to perform the behavior under different circumstances(RAA also expands PBC to reflect people capacity or agency to perform the behavior and their perceived autonomy or control over performing the behavior). The more favourable these determinants are, the stronger a person's intention to perform the behavior or the more likelihood of them actually performing the behavior.

Attitude, perceived norms, and perceived behavioral control are based on the beliefs that people have. Hence, interventions do not target behaviors and intentions to change behaviors directly, but they target the determinants and underlying beliefs [41]. Therefore, it is important to gain more insight into these beliefs. RAA states that a salient belief elicitation 
study among the target group is needed to adequately intervene or bring about a change in a situation. Such an elicitation procedure is essential to determine salient consequences, referents and circumstances that form the belief structure underlying the intention to take a child with fever to the $\mathrm{CHW}$. This is a necessary step for gaining an understanding of the behavior, which enables programme planners to target appropriate beliefs in interventions.

In spite of its importance, the elicitation aspect of the theory has not received much attention among researchers. $[77,78]$. A recent review in the domain of physical activity showed that only 47 out of 150 studies had conducted an elicitation study [79]. There is a dearth of documentation on theory-based formative research to guide interventions aimed at influencing appropriate care-seeking behaviors in general and in increasing use of $\mathrm{CHW}$ services in particular in the Dangme west district of Ghana. Therefore, this study was conducted to investigate care givers' salient beliefs about seeking care for the child with fever from trained $\mathrm{CHWs}$ in order to inform potential strategies for increasing access to prompt and appropriate care to reduce morbidity and mortality among children under five in the study district.

\section{Methods}

\section{Study Site}

The study was conducted in Dangme West, a rural district in the Greater Accra Region of Ghana. It has a population of about 109,459 and 376 communities. The district is divided into 4 sub districts - Dodowa, Prampram, Ningo and Osudoku. At the time of the study, there was no district hospital. Each sub district was served by one government health center, a few rural clinics and other privately owned health facilities. The main occupation included trading, subsistence farming, fishing, petty and artisan work.

\section{Study Design}

This study was part of a household cross sectional survey on community perceptions and practices of treatment seeking for pneumonia in children under five in the Dangme West district. Descriptions of the study site and sampling procedure have already been reported [80]. 
In the present study we conducted a belief elicitation among the 501 care givers sampled for the formative study. A care giver was defined as the person whom household members regarded as having primary responsibility of caring for a child under five. The care givers were randomly selected through a multi-stage sampling technique.

\section{Instrument}

In line with the RAA, we selected and stated the behavior of interest in terms of action, target, context and time [76]. The behavior selected for elicitation was "taking your child under five with fever to the $\mathrm{CHW}$ immediately you notice that the child has fever". The phrase: "taking your child" reflects action, "child under five" is the target, "with fever" is the context and "immediately" relates to the time-communicating the urgency with which action needs to be taken. This is in line with "prompt care seeking" defined by the World Health Organization (WHO) as adequate treatment received within 24 hours of onset of illness; recommended to prevent the illness from progressing from mild symptoms to severe complications [72].

Subsequently, as recommended for an elicitation approach, six openended questions were asked, two on each of the determinants of intention; to identify the underlying beliefs about: salient consequences (related to attitude), underlying beliefs about social referents (related to perceived norms) and beliefs underlying salient circumstances of performing the selected behavior (related to perceived behavioral control).

\section{Procedure}

Trained research assistants using a questionnaire with both closed and open ended theory based questions interviewed care givers one- on- one at the household level. Interviews were held in the vernacular after seeking consent and assuring respondents of confidentiality.

First, a scenario was narrated to study participants as follows: (Madam Lucy's child who is less than 5 years of age has fever. As soon as she 
noticed that her child has fever, she immediately took this child to the Community Health Worker who then assessed the child and gave her drugs for treatment. Now, if your child under 5 had fever and you took her immediately to the Community Health Worker for treatment as Madam Lucy did with her child...).

This was followed by the six open ended questions below.

What good things will happen as a result of taking your child with fever immediately to the community Health Worker for treatment?

What bad things will happen as a result of taking your child with fever immediately to the community health worker for treatment?'

Who do you think will approve of you taking your child with fever immediately to the Community Health Worker for treatment?

Who do you think will disapprove of you taking your child with fever immediately to the community Health Worker for treatment?

What will make it easy for you to take your child with fever immediately to the community Health Worker for treatment? and

What would make it difficult for you to take your child with fever immediately to the community Health Worker for treatment?

In addition, respondents were asked questions on their sociodemographic characteristics such as age, marital status, educational level attained, number of children, ethnicity and length of stay in the district.

The verbatim responses to open ended elicitation questions were reviewed by a team of social scientists and experienced local research assistants who were fluent in the Dangme dialect. A content analysis was then performed and major categories of responses identified for each question. The responses were then grouped according to themes or concepts and similarity of words. Two researchers independently coded the data and then compared and discussed any discrepancies related to their coding until an agreement was reached. Thereafter, the final responses were grouped to reflect the underlying beliefs about: salient consequences (related to attitude), social 
referents (related to perceived norms) and circumstances of seeking prompt care for child's fever from CHWs. The closed ended data were coded and entered in SPSS (SPSS Inc., IL, USA) separately by two data entry staff for analysis. Results are presented as frequencies.

\section{Results}

\section{Demographic background}

A total of 501 care givers were interviewed. The respondents were mostly women (89.4\%) with a mean age of 33 years. They were mostly married (87.8\%), and single (widowed, divorced or never married) (12.2\%); and had an average of 3 children (98.4\%). Majority were Ga-Adangme natives (68.1\%), Ewe's (24.6\%) and other ethnic groups (7.4\%). Religious affiliations were mainly Christian (87.6\%), Muslims (6.4\%) and Traditional worshipers (1.0\%). Their level of education was largely basic with a little over a third (36.7\%) having attained up to Junior Secondary School (JSS) or Middle school levels and $27.5 \%$ up to primary school level. Few had higher education; secondary (4\%) and tertiary education (2.2\%). Their main occupations were trading (29.3\%), farming (24.6\%), and artisans (29.5\%). The rest (16.6\%) were unemployed.

\section{Salient consequences}

The results of the salient consequences perceived by the respondents about the expected care seeking behavior show that care givers perceived more positive than negative outcomes as shown in Table 1 . The most cited advantage for seeking care immediately for child's fever from the CHW was that of "effective treatment." Respondents perceived that since $\mathrm{CHWs}$ were trained, they would provide effective treatment to cure the child's illness $47.7 \%$ (239). Another benefit mentioned was prompt treatment $27.7 \%$ (139) as there will be no need to wait in a queue to be served. Proximity to the $\mathrm{CHW}$ $13.2 \%(66$,$) was seen as another advantage; as it would reduce or eliminate$ costs associated with care seeking and transportation. (One respondent did not provide an answer.) 
Regarding disadvantages perceived, majority, 82.2\% (411) perceived no bad outcomes from seeking immediate care for the child's fever from $\mathrm{CHWs}$. The negative outcomes expressed were that, it would be a waste of their money if the drug given by the $\mathrm{CHW}$ did not work for their child $9.2 \%$ (46); or time wasted if the needed drugs were not available or if the $\mathrm{CHW}$ $\mathrm{him} /$ herself were not available at the time they were needed $1.4 \%$ (7) as shown in table 1.

Table 1: Salient Consequences of seeking care for a child with fever from CHWs in the Dangme West district

Consequences (behavioural beliefs)

$(\mathrm{N}=501)$

$\mathrm{n}$

(\%)

\section{Advantages/good things}

They are trained so will provide good/effective

239

treatment/Child's illness will be cured

Prompt treatment for child

$139 \quad 27.7$

Proximity/nearness of CHW

$66 \quad 13.2$

Reduced cost/No transportation

$56 \quad 11.2$

Missing/Blank

10.2

Disadvantages/bad things

Nothing bad

$411 \quad 82.0$

Money will be wasted if drug doesn't work

$46 \quad 9.2$

Child's condition may worsen If the CHW doesn't assess

$25 \quad 5.0$

the illness well /If the right dosage is not given

Time wasted if drugs not available/CHW not available

$\begin{array}{ll}7 & 1.4\end{array}$

Adverse effects

$\begin{array}{ll}7 & 1.4\end{array}$

Other

$4 \quad 0.8$

No comment

$\begin{array}{ll}1 & 0.2\end{array}$ 


\section{Social Referents or Normative belief}

Table 2 reports on the social referents mentioned by care givers. The results indicate that parents of the child were predominantly perceived as the referents for seeking immediate care for the child's fever with the CHW $55.1 \%$ (276). Other salient referents included the "other relatives and family members", 25.7\% (129) and grandparents of the child, $8.0 \%$ (40).

Although it was highly perceived among the respondents that "no one" (96\%) would disapprove of their seeking care from the CHW, in few cases, relatives, influential members of the community or people who were not particularly knowledgeable about the work of $\mathrm{CHWs}$, were regarded as possible referents who might disapprove of the behavior.

Table 2: Care givers' Salient Referents for seeking care for febrile children under 5 years from CHWs in the Dangme West District

\begin{tabular}{lrr}
\hline Social Referents (Normative belief) & \multicolumn{2}{c}{$(\mathrm{N}=501)$} \\
& $\mathrm{n}$ & $(\%)$ \\
\hline Who Approves & 276 & 55.1 \\
My husband/wife/parents of child & 129 & 25.7 \\
Other relatives/family members & 40 & 8.0 \\
Grandparents of child & 35 & 7.0 \\
Myself & 18 & 3.6 \\
Friends/everybody & 2 & 0.4 \\
The nurses & 1 & 0.2 \\
Landlord & & \\
Who Disapproves & 476 & 96.0 \\
No one & 7 & 1.4 \\
Anyone who doesn't know the abilities of the CHW & 6 & 1.2 \\
Neighbours/relatives who prefer the clinic & 5 & 1.0 \\
Family/anyone whose child does not respond to this treatment & 3 & 0.6 \\
Herbalist in my community & 2 & 0.4 \\
Evil person who hates progress & 2 & 0.4 \\
\hline Myself & & \\
\hline
\end{tabular}




\section{Salient Circumstances}

In all, distance to the location of the CHW expressed as "proximity" or "nearness" $55.7 \%$ (279) was perceived as the main facilitator for seeking care there for the child's fever. Respondents explained that proximity to the CHW enabled such advantages as elimination of transportation cost, no queuing before being attended to and therefore prompt treatment of child's illness.

Other facilitating factors mentioned included the "availability of money or affordability of the medication" $39.7 \%$ (199) and the availability of the CHW $1.4 \%$ (7).

On the other hand, a financial constraint, $46.3 \%(232)$ was seen to be a hindrance, albeit $38.5 \%$ (193) said nothing will bar them from seeking care from the $\mathrm{CHW}$. Some respondents saw social or relationship barriers expressed as: 'If I am not on good terms with the CHW 6.1\% (30), 'If CHW is unfriendly/not sociable' $2.8 \%$ (14), 'If CHW is not dedicated' or if the CHW is often unavailable or if the prescribed drugs are not available $2.8 \%(14)$, when needed. Other barriers were: physical accessibility -'If the CHW is far away' $2.2 \%$ (11); efficacy of the medication, 'If the drug doesn't work or CHW does not give proper medication' $1.2 \%$ (6) and if the physical environment of the CHW is dirty $0.2 \%(1)$. 
Table 3: Salient Circumstances for seeking care for febrile children from CHWs in the Dangme West District

Circumstances (Control beliefs)

$(N=501)$

n

Facilitators/ easy circumstances

Proximity(nearness)/no waiting time or queue/If no

transportation is required/child will get early treatment

Availability of money/affordability of drug $199 \quad 39.7$

If the CHW is usually available

If the drugs proves to be effective/child will get well

(Other) if I have time at home

If I have health insurance

$3 \quad 0.6$

The love I have for my child

$1 \quad 0.2$

\section{Barriers/difficult circumstances}

Financial constraint

Nothing

If I am not on good terms with the CHW

$30 \quad 6.1$

If $\mathrm{CHW}$ is unfriendly/not sociable

If CHW is not dedicated/CHW is not usually available/if drugs $\begin{array}{lll}14 & 2.8\end{array}$ aren't available

If the CHW is located far away

If the drug doesn't work/CHW doesn't give proper medication $6 \quad 1.2$ 


\section{Discussion}

The aim of this study was to explore care givers' salient beliefs about taking their children under five with fever to the $\mathrm{CHW}$ immediately they notice that their child has a fever. In line with the RAA, these beliefs concerned salient consequences, social referents, and salient circumstances.

\section{Salient Consequences}

Majority of care givers reported that they would seek immediate care from the CHWs. Reasons cited for this include beliefs that the CHWs would offer effective treatment because they were trained by professional health staff; that because CHWs resided in the community they would be easily accessible. Other reasons given were: perceived prompt attention they would receive from $\mathrm{CHWs}$, the efficacy of the medication, and the elimination or reduced financial cost in seeking care. Such beliefs could mean that care givers recognized the capability of the $\mathrm{CHWs}$ in providing effective and prompt care and were therefore motivated to use $\mathrm{CHW}$ services for the febrile child. In a study in Uganda, the overall use of CHWs was low although there was an increase among children receiving prompt and appropriate care from CHWs [81]. This is in contrast to findings from a number of trials conducted in some West African countries that reported higher utilization rates ranging between $86 \%$ and $97 \%$ for those who sought care the day of onset or the next day from CHWs [82] as opposed to this study where respondents reported that they would seek immediate care. This could imply that in practice, care givers may not seek appropriate care promptly even though they may know and report that they will seek immediate care. This is not surprising as management of fever at home is a common practice among care givers in Ghana and in many other African countries. Care givers either initiate treatment at home before seeking care elsewhere either from drug retail shops, traditional healers, private or government facilities thereby delaying appropriate treatment of the child's illness $[10,54,59,74,83,84]$. 
Also proximity, prompt attention, the efficacy of medication and the reduced cost were a source of attraction to utilization of $\mathrm{CHW}$ services. Similar findings have been reported by others where care givers are reported to have sought care from $\mathrm{CHWs}$ because the services were close by, good, and treatment cost was either reduced or free. [12, 14, 85-87].

Even though over $80 \%$ of the respondents in this study perceived no disadvantages in seeking care for the child's fever from CHWs, the few who did, mentioned the non-availability of $\mathrm{CHW}$ and his/her ability particularly with issues concerning prescribed drug (i.e., availability, potency, efficacy, correct dosage and side effects) and the eventual loss of money to care givers as possible consequences. These care givers may have had a negative previous experience with $\mathrm{CHWs}$ and/or prescribed drugs which may have affected their subsequent health behavior (i.e., not seeking care). Some studies have shown that care givers' experience with health care providers and the potency, efficacy and cost of drugs do affect intention and revisits to health care providers and facilities [88]. Even though the findings of Bazzano and others were related to the attitude of professional health care providers in health facilities and the difficulty in navigating such facilities; this could be extrapolated to $\mathrm{CHWs}$ whom community members view as trained workers and therefore have positive expectations about them providing good, courteous and effective treatment, as shown from table 1 above. Such perception may have to be pursued in the intervention phase.

\section{Social Referents}

The obvious mention of spouses (husband/wife) and/or both parents of the child as the salient referents by over $60 \%$ of respondents shows that spouses and parents of a child have a big role in approving care seeking; as well as family members especially grandparents (grandmothers and grand fathers who are family heads). These family heads are seen as custodians of family health so they must be consulted when seeking care [89]. This finding is 
typical in the study district because of the paternal inheritance system where the paternal family heads, fathers and male folks are the main decision makers in a household [90]. Other studies have shown that in some cultures female care givers will only seek care with approval of the dominant male figure in the household (family heads, grand fathers and fathers or other males) mainly because they provide money for accessing health care $[14,89]$. Such trends may be changing in these modern times where more women are engaged in gainful employment.

Almost all respondents reported that no one will disapprove of the decisions to utilize $\mathrm{CHWs}$ except where the people are not sure of the ability of the CHW and the efficacy of the drugs. This implies that the CHW must be well trained to ensure that they do proper assessment, provide appropriate treatment and counseling and play their prescribed roles. The mention of the herbalist as one who might disapprove is understandable in rural communities as they may be one of the rural communities' main sources of traditional medicine and consultation. Also the two people who said 'evil people who do not like progress' may disapprove of their behavior may be thinking in terms of the African world view, which believes that life consists of both the physical and spiritual, and the spiritual affects health positively or negatively [92]. This implies that health providers must also take into consideration other sources of health care in their provision of health care and not only think of the physical aspects of health.

\section{Salient Circumstances}

Proximity and the availability of the $\mathrm{CHWs}$ at the time they are needed were seen as the main factors that will facilitate care givers seeking care from CHWs. In addition, availability of money as well as efficacy of the drugs, effectiveness of treatment for the sick child and the possession of health insurance will facilitate their seeking prompt care.

Although most of these factors were already mentioned as advantages under the salient consequences; they are also perceived as facilitators in terms of salient circumstances. This underscores the 
importance that community people attach to the proximity of health care to them as well as nearness of the CHWs location to care givers. In addition the attitude and social relations of the $\mathrm{CHW}$ with community members would attract or hinder seeking care. Proximity is also linked to all forms of health care cost which continues to be a big barrier to many rural folk in accessing health care facilities. Transport cost, waiting time in long queues and travel time are all minimized or eliminated altogether with the availability of $\mathrm{CHWs}$ within communities.

From these discussions the training and proximity of $\mathrm{CHWs}$ as well as their social relationship to care givers, efficacy of drugs and elimination of health care costs of all forms are factors that will motivate care givers to seek prompt care for their under fives; and parents of the child and spouses were the significant others who would approve of the care seeking behavior. This means that health care intervention planners must ensure that these factors are properly taken into consideration.

To the best of our knowledge, there is no validated tool for measuring the determinants of "taking your child under five with fever to the CHW immediately you notice that the child has fever." The findings of the present study can be further tested among household care givers to help refine and validate them as an instrument that can be used to examine theoretical constructs of the RAA. This is needed to better understand Care givers' decision-making processes for accessing $\mathrm{CHW}$ services for childhood febrile illnesses which may contribute to the reduction of severe morbidity and mortality in children under five in Ghana and other countries with similar settings.

\section{Limitations}

The study was cross-sectional in nature; therefore we are unable to draw conclusions on whether the underlying beliefs cause subsequent behavior or whether they are merely related. Despite this limitation, some strengths of the study include the use of probability sampling to generate a 
representative sample of the primary household care givers in the district. Hence, the results obtained in the present study could be applied to the wider population particularly the priority audience in the district for whom the intervention is intended. The qualitative data gathered enabled access to terminologies and words in the local dialect that could be incorporated into design of effective intervention programs.

\section{Conclusion}

The application of the belief elicitation among the population of interest was helpful in providing insight into the salient beliefs of care givers the priority audience for the behavior of interest. The findings suggest that factors including prompt treatment, proximity, cost and inter-personal aspects of care are key to care giver's expectations. Therefore our intervention incorporated key findings as appropriate. For example, regarding proximity, we ensured that $\mathrm{CHWs}$ were selected within walking distance from care givers' residence. Thus some communities had multiple CHWs depending on the size of the community. To tackle the issue of cost of medication, the intervention was designed to provide free medication therefore all sick children treated for fever received medication free of charge. To deal with inter-personal aspect of care, we incorporated sessions into the $\mathrm{CHW}$ training curriculum to emphasize good interpersonal communication as a component of quality of care. 


\section{Chapter 4}

Development of theory and evidence based program to promote community treatment of fevers in children under five in a rural district in Southern Ghana: An Intervention Mapping Approach

In Press BMC PH:

Mercy Abbey, L Kay Bartholomew, Margaret A. Chinbuah, Margaret Gyapong, John O. Gyapong, and Bart van den Borne: Development of a theory and evidence based program to promote community treatment of fevers in children under five in a rural district in Southern Ghana: An Intervention Mapping Approach. 


\begin{abstract}
Background: This paper describes the development and implementation of a program to promote prompt and appropriate care seeking for fever in children under the age of five. Designed as a multicomponent program, the intervention comprises elements to influence behavior of care givers of children, community health workers, professional health care providers and the wider community.
\end{abstract}

Methods: Following the six fundamental steps of the Intervention Mapping protocol, we involved relevant stakeholders from commencement of planning to program end. The IM protocol also recommends various behavior change methods to guide intervention development.

Results: The intervention components implemented were successful in achieving program goals. For example the intervention resulted in the primary outcome of reductions in all-cause mortality of $30 \%$ and $44 \%$, among children treated with an antimalarial and those treated with the antimalarial plus an antibiotic respectively.

More Community Health Workers were retained on the program, with an attrition rate of $21.2 \%$ over a period of 30 months and the Community Health Workers rate of adherence to performance guidelines was high at $94.6 \%$.

Conclusion: We were able to systematically develop a theory- and evidence-based health promotion program based on the Intervention Mapping protocol. This article contributes to the response to recent calls for more detailed description of the development of interventions and trials. The intervention mapping approach can serve as a guide for others interested in developing community based health interventions in similar settings. 


\section{Introduction}

Mortality in children less than five years of age, remains an important public health problem especially in Sub- Saharan Africa (SSA) where almost half of the 7.7 million child deaths recorded globally occur each year [93-95]. Malaria and pneumonia alone cause about 1.4 million childhood deaths every year [1]. Effective treatment is available through interventions such as the use of antimalarials and antibiotics but prompt diagnosis and treatment remain essential.

It is estimated that a $70 \%$ reduction in under five mortality could be achieved if all cases of childhood pneumonia were managed at the community level [18]. Similarly, community case management (CCM) of malaria can reduce overall and malaria-specific childhood mortality by $40 \%$ and $60 \%$, respectively, and severe malaria morbidity by 53\% [72]. Yet, most developing countries with high mortality rates, have limited access to prompt and appropriate care for potentially deadly childhood diseases especially in rural areas [96]. Poor access contributes to care giver's failure to seek care and delays in seeking appropriate care which also contributes to the large number of child deaths [97]. Other reasons for delays in care seeking include geographic and financial barriers to access to health care facilities, poor knowledge and practice among care givers and care giver's perceptions that health care providers have poor attitudes towards them $[9,54,98,99]$.

Efforts to increase access to prompt and effective treatment of common childhood illnesses led to the introduction of community based interventions such as the Home Management of Malaria (HMM). Under this strategy children presenting with fever were treated presumptively with antimalarial drugs [11] usually by Community Health Workers (CHWs) who are lay persons selected by their communities and given basic training by professional Health Care staff to provide care for specific ailments. While this strategy expanded access to treatment of uncomplicated malaria; evidence showed misdiagnoses and inappropriate treatment of non-malaria febrile illnesses including pneumonia [16]. 
In 2004, the WHO and the United Nations Children's Fund (UNICEF) supported recommendations for the integrated community case management ( ICCM) of common childhood illnesses that included malaria, pneumonia and diarrhoea [72]. Following the recommendation, the Ghana Health Service initiated a randomized controlled trial in the Dangme West district to operationalize the approach of involving $\mathrm{CHWs}$ in the management of pneumonia at the community level and to assess the impact of the intervention on under - five mortality in the study district [38-40, 100]. As a part of this community-based research, we used a systematic planning approach [41] to develop the community intervention to promote CCM of pneumonia. In this report, we describe the development and implementation of this evidence - and theory-based intervention.

Many authors have argued for a systematic approach for development and reporting of theory and evidence based interventions [41, 101-103] Reporting in detail the design process and intervention implementation would promote the understanding of how effective interventions are made. Further, reporting in sufficient details would make it easy for other scientists and practitioners to replicate.

\section{Methods}

\section{Planning Method}

We used Intervention Mapping (IM) , a six step tool for the systematic planning of health promotion programs using theory, evidence from the literature and further research as needed [41] to develop a behavior change intervention to promote prompt and appropriate care for febrile children aged 2 to 59 months in the Dangme West district in Ghana. IM has guided the planning and development of health promotion programs for many different health problems. Recent examples include cancer screening [42], smoking [44], obesity [45], chronic disease self-management [46]; sexuality and HIV/AIDS [47, 48], hearing loss [49], antiretroviral treatment adherence [50] and physical activity [51]. Others have explicitly used Intervention Mapping to 
guide community-based participatory research (CBPR) [104]; to better understand the active change ingredients in interventions [105, 106].

Each of the six steps of IM comprises several tasks. The completion of the tasks in each step leads to products that inform the subsequent step, and the completion of all steps creates a "blueprint" or "map" for designing, implementing, and evaluating an intervention. Step 1, entails describing the problem, the behaviors and environmental factors that cause the problem, among whom, and in what context. This first step of IM is based on the PRECEDE Model and results in a simple logic model of the problem [107]. In step 2, the specific behaviors and environmental conditions required to solve the problem are described and their determinants explored to create a logic model of change. In step 3, planners choose theory-based change methods and practical applications matched to the behaviours and their determinants. In step 4, change methods are organized into a coherent, deliverable program leading to Step 5 where further work is done to ensure the program is feasible for communities to adopt and implement. Finally, in step 6 , an evaluation plan is completed.

\section{Planning Steps and Procedures}

Step 1: Formative Research and Logic Model of the Problem. In this step we defined the priority population and environmental change agents; reviewed reports of studies on community perceptions and care seeking for common childhood illnesses including malaria and pneumonia and the training, and use of CHWs. We also conducted formative research including individual indepth interviews with key informants, focus group discussions, and a survey among household care givers of under- fives in the district to assess community knowledge, attitudes, perceptions and management of fever in under-fives [80]. We also solicited the perceptions of professional health staff on involving CHWS in the management of childhood fevers (to be presented elsewhere). 
In the formative work, we defined a care giver as that person whom household members perceived as having primary responsibility of caring for an under-five child in the home. This person may or may not be the biological parent or blood relation of the child. In this paper, the words: Parent and care giver are used interchangeably.

Our eight focus group discussions among household caregivers and eight individual In-depth Interviews with community key informants focused on perceptions, knowledge, behavioursand management of childhood fevers with emphasis on respiratory illnesses (especially pneumonia) and care seeking.

Following in-depth interviews and focus groups, we administered a questionnaire in a cross sectional household survey among 501 care givers to corroborate our qualitative findings.

Further, we distributed a self-administered questionnaire to 15 professional health workers in the district health facilities to assess their perceptions about involving CHWs in the management of childhood fevers. We organized the Step 1 results in a logic model of the problem based on the PRECEDE model [107].

Step 2: Performance and Change Objectives. In step 2, we used the key findings of the formative study to define fever management behaviors for care givers and $\mathrm{CHWs}$, to describe determinants of the necessary behaviors and to develop a logic model of change (also called program or intervention theory). This step is based on the answers to the questions: "what do the participants of our program need to perform the health promoting behavior?"; "Why would the participants perform these behaviors?" The answers to the determinants questions were informed by behavioral theory with determinants including attitudes and other cognitions concerning the 
problem and the solutions. We then used the determinants and performance objectives to develop matrices of change objectives for care givers, the wider community, $\mathrm{CHWs}$ and professional health staff in the district health facilities.

Working from the logic model of change, we developed matrices that combined behaviors with determinants to produce change objectives. These matrices were the foundation for decisions about what theory-based change methods (also referred to as techniques) [108] will likely influence change in determinants of the targeted behaviors in both the at-risk group and agents in the environment. A theory--based change method is a defined process by which theories postulate, and empiric research provides evidence for, how interventions can influence change in the determinants of behavior of individuals, groups, or social structures. Determinants of behavior almost always include many factors other than knowledge and awareness; therefore, methods must include processes to influence factors other than simple knowledge. Theory-based methods are likely to be a major foundation of an intervention's active ingredients, because they have been matched directly to the change objectives.

\section{Steps 3 and 4: Change Methods and Practical Applications for the} Intervention. In steps 3 and 4 , we selected change methods for determinants specified in step 2 (Step 3) and then we organized the change methods into a coherent program of practical applications and delivery strategies (Step 4). For example, modeling with vicarious reinforcement, derived from Social cognitive Theory [109] is an example of a theoretical method, which can be applied to increase skills and self-efficacy [41]. A practical application is the delivery of a change method or set of change methods in ways that fit the needs and preferences of the priority group and the context in which the program will be conducted. For example, to apply modeling, a program might include role model stories or skill demonstrations in person, in print, or in a mediated format such as video or computer. We added relevant methods to the logic model of change developed in this step. 
Step 5: Adoption and Implementation. In step 5, we planned for initial program use and testing of the program's effectiveness. To increase the potential for program adoption, implementation and sustainability, we repeated the processes of considering needs, performance objectives, and determinants - but this time for the program adopters, implementers, and maintainers. Thus, working with potential adopters and implementers, we reviewed the national implementation guidelines for integrated management of Childhood Illnesses, discussed the scope and training of $\mathrm{CHWs}$ and adapted the existing training materials for $\mathrm{CHWs}$. Further we planned for the orientation and role of professional health staff in the district as well as community involvement in the program.

\section{Step 6: Planning the Evaluation.}

In step six we planned for process and impact evaluation of the program by reviewing the logic model of change, developing evaluation questions and deciding on indicators and measures. We then planned an evaluation research design and data collection methods.

\section{Results}

\section{Step 1: Formative Research, Needs Assessment and Logic Model of the Problem}

From the formative work, we developed Figure 1, a logic model of the problem of delayed and inappropriate treatment of fevers in children under five from our literature review and formative research. Beginning on the right side of the model; we designated the main health problem to be fevers in children under five. Moving to the left in the model, the key care giver behavior of concern is delayed and inadequate response to fevers in underfives. For example, studies report that care givers often begin treatment at home and may include use of a combination of herbs and or orthodox medicines, use of inadequate doses of left-over medicines, use of over-thecounter medicines and consultation with traditional healers [59, 74]. Care seeking in health facilities begins only after their initial treatments prove ineffective. 


\section{Figure 1: Logic model of the problem of delayed and inappropriate treatment of fevers in children under-five in Dangme West District}

Determinants

Personal Determinants: What theory-and evidence-based factors are causally related to the behaviour?

-Lack of awareness of pneumonia as cause of fever or need for urgent treatment -No CHWs for fever (but positive intention to use if available -Subjective norms in support of using $\mathrm{CHW}$

-Dependence on home remedies; traditional treatment

Personal Determinants: What theory-and evidence-based factors are causally related to the behaviour of agents in the environment who control the environmental factor?

-Community professionals do not prioritize immediate care of fever and education of caregivers on pneumonia
Behaviour (At-risk group)

and Environmental Factors

Health Problems

Caregiver Behaviour: What behaviours increase risk, incidence, -prevalence, burden?

-Poor management of fevers

at home

-Do not seek prompt appropriate care

-Do not seek appropriate care in the community

Health Problems: What is the priority health problem(s) in the population? -Fevers in children under five particularly those caused by malaria and pneumonia

Environmental Factors: What interpersonal, organizational, community and societal factors influence health directly or through influence on the behaviour of the at-risk group?

-No CHW program in the district to treat fevers

-Healthcare workers do not promote home management; entertain some fears about CHW treatment

Factors contributing to this lack of appropriate response to fevers were found to be inadequate understanding by parents that fever can be related to either malaria or pneumonia and that both need urgent care. Care givers reported that malaria is a serious disease, but the local language did not even have a word for pneumonia. Results from the household survey showed high intention to seek care for childhood fevers from trained $\mathrm{CHWs}$ and perceived benefits and behavioral control (confidence) [110] about their ability to take a sick child to a $\mathrm{CHW}$ if available as well as positive subjective norms regarding use of a CHW for childhood fever. 
Healthcare workers also have a role in the inadequate response to fever by caregivers. They do not promote home management; nor do they seem to have much knowledge about the concept of home and community management strategies. Health care providers expressed some resistance to CHWs because they might detract from their professional practices and "popularity". Some expressed the fear that CHWs might even 'extort' money from caregivers. Above all, the health workers were hindered by policies that privileged official interventions at the facility level for such illnesses. On the other hand, in community meetings, community members were fairly positive about the possibility of using $\mathrm{CHWs}$ for management of fevers. They wanted to know details such as how long medicines would remain available, who would pay $\mathrm{CHWs}$, what type of training $\mathrm{CHWs}$ would have and whether they would treat other illnesses and other age groups above five years. In the survey caregivers also expressed a fairly high intention to use $\mathrm{CHW}$ for child's fever if available.

\section{IM Step 2: Change Objectives}

In this step we converted the logic model of the problem to a logic model of change to depict health promoting behaviors and environmental conditions with their determinants and change methods. From this logic model of change, we developed matrices that combine performance objectives and determinants to provide the map for developing intervention strategies. Examples of partial matrices for care givers, $\mathrm{CHWs}$ and health care providers are provided in Tables 1,2 and 3. 
Table 1: Partial matrix of change objectives for Care Givers of Under- fives in Dangme West District Ghana

\begin{tabular}{|c|c|c|c|c|}
\hline $\begin{array}{l}\text { Performance } \\
\text { Objectives }\end{array}$ & \multicolumn{4}{|c|}{ Determinants (Specific targets of the communication) } \\
\hline $\begin{array}{l}\text { Objectives } \\
\text { The caregivers wi }\end{array}$ & $\begin{array}{l}\text { Attitude } \\
\text { II: }\end{array}$ & $\begin{array}{l}\text { Perceived Social } \\
\text { Norm }\end{array}$ & $\begin{array}{l}\text { Perceived R } \\
\text { Control/skills Self } \\
\text { efficacy }\end{array}$ & Reinforcement \\
\hline $\begin{array}{l}\text { Seek prompt } \\
\text { treatment from } \\
\text { CHW when child has } \\
\text { fever }\end{array}$ & $\begin{array}{l}\text { Expect that new } \\
\text { treatment and } \\
\text { responding early will } \\
\text { keep child from } \\
\text { dying }\end{array}$ & $\begin{array}{l}\text { Expect that husband } \\
\text { or influentials will } \\
\text { Il approve of going to } \\
\text { the CHW }\end{array}$ & $\begin{array}{l}\text { d Describes } \\
\text { confidence in taking } \\
\text { action if child has } \\
\text { fever }\end{array}$ & $\begin{array}{l}\text { Health care } \\
\text { providers make } \\
\text { positive remarks } \\
\text { about CHW } \\
\text { treatment and } \\
\text { referral }\end{array}$ \\
\hline $\begin{array}{l}\text { Go to } \mathrm{CHW} \text { before } \\
\text { acquiring any drug } \\
\text { or herb or using left } \\
\text { over drugs }\end{array}$ & $\begin{array}{l}\text { Expect that new } \\
\text { drug will work to } \\
\text { cure the child }\end{array}$ & $\begin{array}{l}\text { Recognize that the } \\
\text { community expects } \\
\text { a good mother to } \\
\text { respond } \\
\text { immediately to a } \\
\text { child who has fever } \\
\text { by going to the } \mathrm{CHW}\end{array}$ & $\begin{array}{l}\text { Perceive that the } \\
\text { recommended } \\
\text { program has no cost } \\
\text { at CHWs } \\
N\end{array}$ & \\
\hline
\end{tabular}


Table 2: Partial matrix of change objectives for CHWS in Communities in Dangme West District

\begin{tabular}{|c|c|c|c|c|c|c|}
\hline Performance & Determir & nants (Specifi & $\mathrm{c}$ targets of the $\mathrm{cc}$ & communication & & \\
\hline $\begin{array}{l}\text { Objectives for } \\
\text { CHWs } \\
\text { CHWs will: }\end{array}$ & $\begin{array}{l}\text { Outcome } \\
\text { Expectation }\end{array}$ & $\begin{array}{l}\text { Subjective } \\
\text { Norm }\end{array}$ & $\begin{array}{l}\text { Perceived } \\
\text { Control/skills } \\
\text { Self efficacy }\end{array}$ & $\begin{array}{l}\text { Perceived } \\
\text { severity } \\
\text { knowledge }\end{array}$ & knowledge & Reinforcement \\
\hline $\begin{array}{l}\text { Greet and } \\
\text { congratulate } \\
\text { mother for } \\
\text { coming } \\
\text { immediately }\end{array}$ & $\begin{array}{l}\text { Expect } \mathrm{t} \\
\text { caregive } \\
\text { will com } \\
\mathrm{CHW} \text { if } \mathrm{t} \\
\text { are frien } \\
\text { in their } \\
\text { approac }\end{array}$ & $\begin{array}{l}\text { that } \\
\text { ers } \\
\text { ne to } \\
\text { they } \\
\text { ndly }\end{array}$ & $\begin{array}{l}\text { Describe how } \\
\text { to greet and } \\
\text { welcome the } \\
\text { caregiver and } \\
\text { specifically } \\
\text { mention that } \\
\text { she responded } \\
\text { quickly }\end{array}$ & $\begin{array}{l}\text { Exp } \\
\text { the } \\
\text { imp } \\
\text { tas } \\
\mathrm{CH} \\
\text { ma } \\
\text { car } \\
\text { we }\end{array}$ & $\begin{array}{l}\text { plain that } \\
\text { e first } \\
\text { sportant } \\
\text { sk of the } \\
\text { HW is to } \\
\text { ake the } \\
\text { regiver feel } \\
\text { elcome }\end{array}$ & $\begin{array}{l}\text { Caregivers and } \\
\text { community } \\
\text { respect CHW }\end{array}$ \\
\hline $\begin{array}{l}\text { Assess child } \\
\text { under } 5 \text { (and } \\
\text { siblings who } \\
\text { are presented } \\
\text { at the same } \\
\text { visit) and treat } \\
\text { for fever }\end{array}$ & $\begin{array}{l}\text { Describe how } \\
\text { new } \\
\text { treatment \& } \\
\text { responding } \\
\text { early will } \\
\text { keep child } \\
\text { from dying }\end{array}$ & $\begin{array}{l}\text { Expect their } \\
\text { role in the } \\
\text { community } \\
\text { to be one of } \\
\text { respect }\end{array}$ & $\begin{array}{l}\text { Shows } \\
\text { confidence in } \\
\text { assessing child }\end{array}$ & $\begin{array}{l}\text { Understand } \\
\text { that child can } \\
\text { die if action } \\
\text { is not taken } \\
\text { promptly for } \\
\text { fever }\end{array}$ & $\begin{array}{l}\text { Describe } \\
\text { their role in } \\
\text { the } \\
\text { community } \\
\text { as one that } \\
\text { can help the } \\
\text { children stay } \\
\text { healthy and } \\
\text { survive }\end{array}$ & $\begin{array}{l}\text { Caregivers and } \\
\text { community } \\
\text { respect CHW } \\
\text { e }\end{array}$ \\
\hline
\end{tabular}


Table 3: Partial matrix for professional health staff in facilities in Dangme west district

\begin{tabular}{|c|c|c|c|c|c|}
\hline Performance & \multicolumn{5}{|c|}{ Determinants (Specific targets of the communication) } \\
\hline Objectives for & Attitude & Perceived Social & Perceived & knowledge & Reinforcement \\
\hline professional & & Norm & Control/skills & & \\
\hline health staff & & & Self efficacy & & \\
\hline \multicolumn{6}{|l|}{ Health care } \\
\hline providers will: & & & & & \\
\hline
\end{tabular}

\begin{tabular}{|c|c|c|c|c|c|}
\hline $\begin{array}{l}\text { express } \\
\text { appreciation to } \\
\text { caregivers that } \\
\text { CHWs treat } \\
\text { children with } \\
\text { simple fever in } \\
\text { the community. } \\
\text { Compliment } \\
\text { caregivers for } \\
\text { promptly } \\
\text { responding to }\end{array}$ & $\begin{array}{l}\text { Express } \\
\text { importance of } \\
\text { CHW work } \\
\text { Recognize } \\
\text { importance of } \\
\text { prompt } \\
\text { reactions by } \\
\text { caregivers by } \\
\text { going to CHW if }\end{array}$ & $\begin{array}{l}\text { Recognize that } \\
\text { other } \\
\text { communities } \\
\text { work with CHW }\end{array}$ & $\begin{array}{l}\text { Feel confident in } \\
\text { treating CHWs as } \\
\text { equal partners in } \\
\text { treating fever in } \\
\text { children at the } \\
\text { community level }\end{array}$ & $\begin{array}{l}\text { Understand that } \\
\text { s project is a } \\
\text { research project } \\
\text { to test the } \\
\text { effectiveness of } \\
\text { home and } \\
\text { community based } \\
\text { management of } \\
\text { fevers in children } \\
\text { using these new } \\
\text { drugs }\end{array}$ & $\begin{array}{l}\text { Praise } \\
\text { caregiver for } \\
\text { responding } \\
\text { promptly to } \\
\text { referral by } \\
\text { CHW. }\end{array}$ \\
\hline referral by $\mathrm{CHW}$ & $\begin{array}{l}\text { child has fever } \\
\text { Recognize } \\
\text { importance of } \\
\text { attending } \\
\text { promptly to the } \\
\text { referred case }\end{array}$ & & & $\begin{array}{l}\text { Describe the role } \\
\text { of the } \mathrm{CHW} \text { in } \\
\text { community based } \\
\text { management of } \\
\text { fever. }\end{array}$ & $\begin{array}{l}\text { promptly } \\
\text { going with } \\
\text { child with } \\
\text { fever to } \mathrm{CHW}\end{array}$ \\
\hline
\end{tabular}




\section{Steps 3 and 4: Theory-Based Change Methods and Program Development}

In step 3 we used the logic model of change and the matrices to make final selections of theory-based change methods, practical applications and delivery. We designed program materials to correspond to the parameters of use indicated in step 3 and in reference to the change objectives in step 2. For example we tailored the video delivered role model story to reflect the different participants of our program [109]. These included a coping role model female care giver, a husband supporting his wife in taking their sick child to the $\mathrm{CHW}$, a $\mathrm{CHW}$ being appropriate with rewarding behavior and a professional Health staff praising care givers for responding promptly to referral by $\mathrm{CHW}$; in line with the social cognitive theory. In another example, the audio taped message presented persuasive arguments about why to adhere to a prescribed treatment schedule and referral request. To ensure effective communication and enhance acceptability of the program messages, we were guided by the principle of cultural similarity [111] in selecting program implementers from the communities with similar socio cultural background as the program beneficiaries. We pre-tested program materials among professionals as well as community members to ensure contents were technically correct and culturally sensitive.

The program comprised components to influence behavior of four groups: parents/caregivers, CHWs, professional health staff, and the significant others in the community. (See Table 4). For the parent/caregiver component, we delivered messages through videotaped drama, audio taped messages via a public address (PA) system attached to our project vehicle and 
through oral presentations in face -to -face community meetings or durbars (Durbar is a gathering of community chief(s), elders and community members especially in rural areas, for important meetings). Theory based methods used to influence determinants included modeling, persuasion and vicarious reinforcement. Messages for those considered as significant others or opinion leaders in the community were delivered through the same channels as for care givers and also through similar methods to influence the determinants. For CHWs, delivery was through educational video presentations (adapted from the IMCl training Video) and training activities. Methods used to influence determinants included modeling, skills training, information and demonstration and for the professional health care workers, we delivered messages through orientation meetings and to influence determinants, we used information dissemination, discussion, and modeling. Table 4 describes the change methods, delivery and sample messages for each component of the program. 
Table 4: Selected Examples of Determinants, Theoretical Methods, and Delivery for the Four Program Components

\begin{tabular}{|c|c|c|c|c|c|c|}
\hline \multirow{2}{*}{$\begin{array}{l}\text { Determinants (Theory Based Change } \\
\text { Methods and Messages ) }\end{array}$} & \multicolumn{6}{|c|}{ Program Materials, Practical Applications and Delivery } \\
\hline & $\begin{array}{l}\text { Community } \\
\text { Introductions } \\
\text { (Durbars) }\end{array}$ & $\begin{array}{l}\text { Videotaped } \\
\text { Drama }\end{array}$ & $\begin{array}{l}\text { Audio } \\
\text { tape }\end{array}$ & $\begin{array}{l}\text { Mobile } \\
\text { Van }\end{array}$ & $\begin{array}{l}\mathrm{CHW} \\
\text { training } \\
\text { and } \\
\text { protocol }\end{array}$ & $\begin{array}{l}\text { Health } \\
\text { Care } \\
\text { provider } \\
\text { Orientation }\end{array}$ \\
\hline \multicolumn{7}{|c|}{ PARENTS AND CAREGIVERS COMPONENTS } \\
\hline $\begin{array}{l}\text { Perceived Severity (Role Models, } \\
\text { Persuasion, Instruction: fever can be a } \\
\text { sign of severe illness - malaria and } \\
\text { pneumonia and other illnesses) }\end{array}$ & $\sqrt{ }$ & $\sqrt{ }$ & $\sqrt{ }$ & $\sqrt{ }$ & & \\
\hline $\begin{array}{l}\text { Attitudes (Modeling, arguments, } \\
\text { persuasion: Take child with fever } \\
\text { immediately to the CHW. This can keep } \\
\text { your child from dying). }\end{array}$ & $\sqrt{ }$ & $\sqrt{ }$ & $\sqrt{ }$ & $\sqrt{ }$ & & \\
\hline $\begin{array}{l}\text { Subjective Norms (Role models, } \\
\text { Persuasion: Husbands encourage your } \\
\text { wives to take child with fever to CHW } \\
\text { promptly) }\end{array}$ & $\sqrt{ }$ & $\sqrt{ }$ & $\sqrt{ }$ & $\sqrt{ }$ & & \\
\hline $\begin{array}{l}\text { Knowledge (Modeling, information: } \\
\text { CHWs are friendly) }\end{array}$ & $\sqrt{ }$ & $\sqrt{ }$ & $\sqrt{ }$ & $\sqrt{ }$ & & \\
\hline $\begin{array}{l}\text { Perceived behavioural control/Skills } \\
\text { What to do and how to do it ( Modeling, } \\
\text { information: Sponge child with fever, } \\
\text { give paracetamol (if available) and take } \\
\text { child immediately to CHW) }\end{array}$ & $\sqrt{ }$ & $\sqrt{ }$ & $\sqrt{ }$ & $\sqrt{ }$ & & \\
\hline $\begin{array}{l}\text { Reinforcement (modeling, vicarious } \\
\text { reinforcement, feedback: New drug from } \\
\mathrm{CHW} \text { is powerful and it is free. friends and } \\
\text { neighbors take child with fever to } \mathrm{CHW} \text { for } \\
\text { treatment }\end{array}$ & $\sqrt{ }$ & $\sqrt{ }$ & $\sqrt{ }$ & $\sqrt{ }$ & & \\
\hline
\end{tabular}




\begin{tabular}{|c|c|c|c|c|c|c|}
\hline \multirow{2}{*}{$\begin{array}{l}\text { Determinants (Theory Based Change } \\
\text { Methods and Messages ) }\end{array}$} & \multicolumn{6}{|c|}{ Program Materials, Practical Applications and Delivery } \\
\hline & $\begin{array}{l}\text { Community } \\
\text { Introductions } \\
\text { (Durbars) }\end{array}$ & $\begin{array}{l}\text { Videotaped } \\
\text { Drama }\end{array}$ & $\begin{array}{l}\text { Audio } \\
\text { tape }\end{array}$ & $\begin{array}{l}\text { Mobile } \\
\text { Van }\end{array}$ & $\begin{array}{l}\text { CHW } \\
\text { training } \\
\text { and } \\
\text { protocol }\end{array}$ & $\begin{array}{l}\text { Health } \\
\text { Care } \\
\text { provider } \\
\text { Orientation }\end{array}$ \\
\hline \multicolumn{7}{|c|}{ COMMUNITY MEMBERS } \\
\hline $\begin{array}{l}\text { Perceived Severity (Role Models, } \\
\text { Persuasion, Instruction: fever can be a sign } \\
\text { of severe illness - malaria, pneumonia and } \\
\text { other illnesses) }\end{array}$ & $\sqrt{ }$ & $\sqrt{ }$ & $\sqrt{ }$ & $\sqrt{ }$ & & \\
\hline $\begin{array}{l}\text { Attitudes ( Modeling, arguments, } \\
\text { persuasion: family members and } \\
\text { neighbours encourage /support Caregivers } \\
\text { to take child with fever to } \mathrm{CHW} \text { ) }\end{array}$ & $\sqrt{ }$ & $\sqrt{ }$ & $\sqrt{ }$ & $\sqrt{ }$ & & \\
\hline $\begin{array}{l}\text { Reinforcement (modeling, vicarious } \\
\text { reinforcement, persuasion: CHWs work is } \\
\text { voluntary, please show appreciation for } \\
\text { services) }\end{array}$ & $\sqrt{ }$ & $\sqrt{ }$ & $\sqrt{ }$ & $\sqrt{ }$ & & \\
\hline \multicolumn{7}{|c|}{ COMMUNITY HEALTH WORKERS } \\
\hline $\begin{array}{l}\text { Reinforcement (Modeling, instruction: } \\
\text { Sequence of CHW being appropriate with } \\
\text { rewarding behaviour) }\end{array}$ & & $\sqrt{ }$ & & & $\sqrt{ }$ & \\
\hline $\begin{array}{l}\text { Outcome Expectations ( modeling, } \\
\text { instruction: Caregivers will come to } \mathrm{CHW} \text { if } \\
\text { they are friendly in their approach) }\end{array}$ & $\sqrt{ }$ & & & & $\sqrt{ }$ & \\
\hline $\begin{array}{l}\text { Subjective norms ( Modeling, information: } \\
\text { Health Care Providers, project staff and } \\
\text { community members recognise the } \mathrm{CHW} \\
\text { role in the community to be one of respect) }\end{array}$ & $\sqrt{ }$ & $\sqrt{ }$ & & & $\sqrt{ }$ & \\
\hline $\begin{array}{l}\text { Skills/ Self-efficacy(modeling, information: } \\
\text { skills training, information: CHWs are well } \\
\text { trained to assess sick child) }\end{array}$ & $\sqrt{ }$ & $\sqrt{ }$ & & & $\sqrt{ }$ & \\
\hline $\begin{array}{l}\text { Perceived severity (Modeling, instruction: } \\
\text { child with fever can die if action is not taken } \\
\text { promptly for fever) }\end{array}$ & $\sqrt{ }$ & $\sqrt{ }$ & & & $\sqrt{ }$ & \\
\hline
\end{tabular}




\begin{tabular}{|c|c|c|c|c|c|c|}
\hline \multirow{2}{*}{$\begin{array}{l}\text { Determinants (Theory Based Change } \\
\text { Methods and Messages ) }\end{array}$} & \multicolumn{6}{|c|}{ Program Materials, Practical Applications and Delivery } \\
\hline & $\begin{array}{l}\text { Community } \\
\text { Introductions } \\
\text { (Durbars) }\end{array}$ & $\begin{array}{l}\text { Videotaped } \\
\text { Drama }\end{array}$ & $\begin{array}{l}\text { Audio } \\
\text { tape }\end{array}$ & $\begin{array}{l}\text { Mobile } \\
\text { Van }\end{array}$ & $\begin{array}{l}\text { CHW } \\
\text { training } \\
\text { and } \\
\text { protocol }\end{array}$ & $\begin{array}{l}\text { Health } \\
\text { Care } \\
\text { provider } \\
\text { Orientation }\end{array}$ \\
\hline $\begin{array}{l}\text { Knowledge (Modeling, Information: CHW } \\
\text { role in the community can help the children } \\
\text { stay healthy and survive) }\end{array}$ & n & $\sqrt{ }$ & & & $\mathrm{V}$ & \\
\hline \multicolumn{7}{|c|}{ PROFESSIONAL HEALTH CARE PROVIDERS } \\
\hline $\begin{array}{l}\text { Attitudes ( information, discussion, } \\
\text { modeling: The role of CHWs in community } \\
\text { management of fevers is important) }\end{array}$ & & & & & & $\sqrt{ }$ \\
\hline $\begin{array}{l}\text { Self-efficacy (Information, modeling: Health } \\
\text { care workers are knowledgeable and self - } \\
\text { efficacious professionals in working with } \\
\text { CHWs in treating child with fever) }\end{array}$ & & & & & & $\sqrt{ }$ \\
\hline $\begin{array}{l}\text { Reinforcement (Information, modeling: } \\
\text { Health care workers praise caregivers in } \\
\text { responding promptly to referral by } \mathrm{CHWs} \text { ) }\end{array}$ & & & & & & $\sqrt{ }$ \\
\hline $\begin{array}{l}\text { Knowledge ( information, discussion: Health } \\
\text { care workers discuss problems encountered } \\
\text { in the work of CHWs that are not resolved } \\
\text { during support visits, with project staff) }\end{array}$ & & & & & & $\sqrt{ }$ \\
\hline
\end{tabular}

\section{Step 5: Adoption and Implementation}

\section{Program implementation}

Two different groups performed implementation activities: Community members implemented the community communication activities while personnel from the Ghana Ministry of Health conducted trainings for prospective $\mathrm{CHWs}$. Four persons recruited from the communities and trained over two days implemented the community communications. The four persons, two per team, in consultation with community heads and opinion leaders, developed a schedule to cover date, time and an appropriate venue for the events. 
The program implementers recruited participants through various means including using the community gong gong beater (local town crier), the project vehicle with a public address system and by going door to door at households. Program delivery followed a standard routine. Typically, after observation of appropriate local protocol, (greetings, prayers, introduction of team members, opinion leaders present and $\mathrm{CHW}(\mathrm{s})$ for the particular community), implementers gave a general overview of the project and an explanation of the meeting format. They then showed the video with interludes at the end of each scene for interaction with the participants to ensure learning objectives of the scene were achieved. The implementers showed the video at least once and sometimes twice in every community in the district where there was a working $\mathrm{CHW}$. Meeting attendance ranged from 15-70 (depending on the size of the community). Community activities reached a total of 16,844 participants. These comprised 6,018 (35.7\%) males and 10,826 (74.3\%) females. Opinion leaders, including community chiefs, elders, executives of the local council, pastors and heads of organised women's group attended the video sessions. The program Implementers played the audio messages at vantage points in the community from the project vehicle. To attract the audience, the team played popular music until enough people have gathered before the messages were disseminated.

\section{Community Health Workers}

CHWs in groups of about 30 participants were trained for three days. Training was competence - and practice- based and was conducted in the local language. Trainers taught $\mathrm{CHWs}$ to assess sick children brought to them, provide treatment for those with uncomplicated fever, referred those presenting with signs of severe illness to health facilities and to counsel on medication and or referral compliance. A total of $660 \mathrm{CHWs}$ graduated and were re-introduced to their communities. During the short ceremony of introduction, CHWs were presented with the necessary tools and supplies for their work in the presence of their community members. 


\section{Step 6: Evaluation}

We conducted a process and outcome evaluation for each component of the program using both qualitative and quantitative data collection methods. Detailed results of these evaluations are reported elsewhere and briefly summarized here:

The primary outcome of the trial indicated a reduction in all-cause mortality of $30 \%$ and $44 \%$ in children treated for uncomplicated fever with artesunate amodiaquine (AAQ) alone and those treated with $A A Q$ in addition to amoxicillin (AMX) respectively. The reduction was in comparison to children who received standard care that includes treatment at home, by traditional healers, from drug retail shops, or from the formal health sector. Though both results were significantly different in comparison to standard care, there was no significant difference between the one drug and two drug treatments [40].

For the $\mathrm{CHWs}$, we examined attrition and retention among $\mathrm{CHWs}$ and its related factors. $\mathrm{CHW}$ attrition rates were abstracted from the project database and factors related to attrition analysed from focus group discussions conducted among $\mathrm{CHWs}$ who remained till the end of the project. In summary, the study found a relatively moderate rate of attrition of $21.2 \%$ over the intervention period of 30 months [38]. This fairly low rate was attributed to the high level of community involvement in various processes of the intervention leading to high community approval and support. Reasons for attrition included lack of remuneration, a possible weak sense of social responsibility, and negative attitude of some care givers.

In assessing the adherence of $\mathrm{CHWs}$ to guidelines for the management of fever in under-fives, we reviewed $\mathrm{CHW}$ documentation of sick child consultations over the trial period. The study showed that $\mathrm{CHWs}^{\prime}$ adherence to treatment guidelines was high 94.6\%; whereas adherence to referral guidelines was inadequate and inconsistent. [100]. 
Our post intervention community survey among 562 care givers and focus group discussions among 84 care givers assessed community utilization, perceptions and related factors of Community Health Worker services. The results indicated that a majority, 93.06\% (523/562) of care givers had knowledge about $\mathrm{CHWs}$ in their communities. More than half, $59.4 \%$ of care givers had used CHW services at least once for management of fever in their under-fives. Further, Caregivers who were exposed to the communication intervention were about four times more likely to use the services of the $\mathrm{CHWs}$ compared to those who were not exposed $(\mathrm{OR}=3.79$, $95 \% \mathrm{Cl}(2.62,5.49)),(\mathrm{P}<0.001)$ [39].

\section{Discussion}

We described, in this paper, how we designed and implemented a multicomponent program, to influence the determinants of the behavior of caregivers of children under five, $\mathrm{CHWs}$, professional health workers and community leaders regarding management of childhood fevers through theoretically based methods. These methods included modeling, persuasion and skills training; and strategies including video and audio recordings and training.

We applied the IM framework [41] which proved useful for the systematic development, implementation and process evaluation of our program. We used theory, evidence from the literature, formative research, and community participation in the design and implementation that led to the realization of our program goals. Whether the same goals would have been obtained without a systematic process is doubtful. As expected, the outcome of each step of IM provided the relevant materials that fed into the subsequent step. For example from the formative study results in step 1, we gained insight into the problem of a community knowledge gap on pneumonia as a potentially deadly disease and the seeming absence of a local name for it. Also the inadequate response to fever as well as the factors related to the problem at the individual and external levels. 
In step 2, the results of step 1, supported with additional evidence from theories of behavior, for example, the Theory of planned behavior [110] and the social cognitive theory [109] were useful for providing information for developing the matrices of change objectives. We were guided by these first two steps in the selection of appropriate theoretical methods for behaviour change in step 3. In step 4, we translated methods into practical applications ensuring that they matched our various groups. For example to effectively employ modeling, we ensured that the necessary parameters of use were present [109]. For attitude change, we ensured messages were presented in a persuasive manner through arguments [41], Ch. 3). For steps 4 and 5, we ensured adequate community involvement in the development, pretesting and finalisation of programs and in step 6 , we designed both outcome and process evaluation of the intervention. Though the steps are consecutive, we applied them in an iterative manner, moving backward and forward between the tasks and steps as we gained more information and insight [41] (Ch. 1).

The formative study was useful for gaining more insight and an understanding of the factors associated with community perceptions, knowledge, and management of pneumonia. From the results of the formative assessments, it became apparent that our intervention or message focus should be on fevers rather than on pneumonia or disease specific messages; given that community knowledge about pneumonia was inadequate and further that they had no local name for pneumonia. Fever is a well-known common overlapping symptom for both malaria and pneumonia $[20,56]$ therefore it was appropriate to use "fever" in our program to represent both malaria and pneumonia or to refer to febrile illnesses in general; Moreover, the community was not required to diagnose the type of febrile illness at their level given that the two diseases of focus (malaria and pneumonia) are not easily distinguishable in the absence of appropriate diagnostic tools $[20,56]$. 
Our use of video tape recorded messages and drama facilitated the coverage of a wider audience in a shorter time and with standardised messages than the commonly used health education strategy of to face - to -face oral presentations commonly used in the Dangme West communities. Oral deliveries are more prone to dilution by the implementers as compared with audio or video tape recorded messages. Further, the video shows were appropriate because its target audience captures those who did not own TV sets and could have missed out on the messages if they were aired by television stations. The video shows were not encumbered by lack of electric power in the rural communities and the shows facilitated immediate post video show audience surveys. Given the low literacy level among the care givers, face to face interviews was better suited. The strategy of playing music via the mobile van also served as a form of entertainment and attracted many to gather around to listen and dance, making it easy to recruit participants and to sustain their interest for the activity.

We continuously involved relevant stakeholders in various aspects of the program, an approach that fostered a sense of ownership among the community. It also enabled us to obtain feedback on processes during program development and implementation. Working with a local drama troupe to produce the drama/video role model story ensured that the characters and issues were of cultural relevance and created identifiable (credible) characters dealing with familiar day to day issues. These processes involving the dramatization of issues made it more acceptable to the community because they could easily relate to the people and the issues.

\section{Limitations}

In adopting the systematic approach of IM, we found the process to be time consuming, though useful. Conducting the formative study, which was necessary to gain the needed information to adequately specify the problem with its contributing factors, took almost six months to complete the entire process. However, other studies have reported much longer durations, 
including 12 months and more [42, 112, 113]. Gans and colleagues emphasized that developing a culturally sensitive successful program requires dedication of adequate time and other resources by researchers for the formative stage [112]. Similarly, Suzuki and colleagues also found the application of IM to be complex and time intensive; none the less, they concluded that "the final program product was relevant and useful to its participants, and the extensive planning and assessment largely determined that success." [43].

\section{Conclusion}

Through the application of IM, we were able to establish a logical planning process for the design, implementation, and evaluation of a communitybased program for the management of childhood fevers in a rural district in Ghana. The systematic and detailed planning could account for the success in achieving our program goals. Thus, our description of the process provides insights that may be replicated by other scientists interested in planning theory and evidence -based interventions in community settings. 


\section{Chapter 5}

\section{Assessment of the adherence of}

Community Health Workers to dosing and referral guidelines for the management of fever in children under five years: a study in Dangme West District, Ghana

Published as: Margaret A Chinbuah, Mercy Abbey, Piet Kager, Margaret Gyapong, Justice Nonvignon, Philipina Ashitey, Jonas Akpakli, Aba Appiatse, David Kubi, John Gyapong: Assessment of the adherence of Community Health Workers to dosing and referral guidelines for the management of fever in children under five years: a study in Dangme West District, Ghana. Int Health 2013; 5: 148-156 



\section{Abstract}

Community Health Workers (CHWs) manage simple childhood illnesses in many developing countries. Information on referral practices of $\mathrm{CHWs}$ is limited. As part of a large cluster randomized trial, we assessed the adherence of CHWs to dosing and referral guidelines.

Records of consultations of children 2-59 months with fever, managed by $\mathrm{CHWs}$ were analyzed. Appropriate use of drugs was defined as the provision of the correct drug pack(s) for the child's age group. Symptoms requiring referral were categorized into: danger signs; respiratory distress and symptoms indicating other illnesses. Multivariate logistic regression examined symptoms most likely to be noted as requiring a referral and those associated with a provision of written referral.

Most children 11 659/12 330 (94.6\%) received the appropriate drug. Only $161 / 1758$ (9.2\%) children who according to the guidelines required a referral were provided a written referral. Not drinking/breast feeding, excessive vomiting, unconsciousness/lethargy, difficult breathing, fast breathing, bloody stool, sunken eyes and pallor were symptoms significantly associated with being identified by $\mathrm{CHWs}$ as needing referral or receiving a written referral.

CHWs adherence to dosing guidelines was high. Adherence to referral guidelines was inadequate. More effort needs to be put into strengthening referral practices of $\mathrm{CHWs}$ within comparable community programs. 


\section{Introduction}

Childhood morbidity and mortality rates in Africa remain relatively high and mortality is contributed to by diseases such as malaria (16\%), pneumonia (18\%) and diarrhoea (18\%) [1]. Many health systems have been unable to reach communities where childhood mortality occurs most, therefore as part of efforts to improve child survival, lay persons commonly called Community Health Workers (CHWs) with little or no previous education in health have been trained to manage these diseases within their own communities [114116]. CHW programmes have resulted in increased appropriate case management for diseases like malaria and or pneumonia $[20,117,118]$ with reduction in the severity of morbidity reduction in childhood mortality [14, $85,117]$.

In general care provided by $\mathrm{CHWs}$ has been limited to uncomplicated illness. Children assessed to have signs of severe illness or other diseases that CHWs have not been equipped to treat must be referred to appropriate health facilities. Few studies have reported on adherence of $\mathrm{CHWs}$ to referral guidelines. A study in Kenya reported that $17 \%$ of severely ill children were not referred by CHWs [119]. Another study in Zambia reported a non-referral rate of $6.8 \%$ by $\mathrm{CHWs}$ [20]. Ghana's experience with $\mathrm{CHWs}$ in recent years has been focused on uncomplicated illness especially malaria primarily because malaria is the leading cause of childhood morbidity and mortality after the neonatal period $[82,86]$. These studies focused on the ability of CHWs to manage uncomplicated illness and provided little information on their ability to correctly identify symptoms requiring referral and on the provision of written referrals. As part of a cluster randomized trial, to be reported in detail elsewhere, we trained lay persons (whom we called community based agents but are hereafter referred to as CHWs) to treat children 2-59 months old with fever with either an antimalarial drug, artesunate amodiaquine alone 
( $A A Q$ arm) or together with an antibiotic drug, amoxicillin (AAQ+AMX arm) within the Home Management of Malaria strategy. The aim of the trial was to determine the added impact of adding an antibiotic to an antimalarial in the treatment of fever among children on childhood mortality. Here, we report on the adherence of the $\mathrm{CHWs}$ to the dosing and referral guidelines.

\section{Methods}

\section{Study site}

The trial was conducted between January 2006 and December 2009 in Dangme-West, a rural coastal district in Ghana. It is $1700 \mathrm{~km}^{2}$ in size, has 376 communities and a total population of about 110,000 . Inhabitants are made up mostly of farmers, fishermen and petty traders. There are a number of fish farms and crop farms. In 2006, there were four government health centers and six community clinics but no district hospital. Only one health centre had a functioning laboratory and none had x-ray facilities. In 2009, this health centre was upgraded to a district hospital. Before 2009, malaria was treated presumptively and severely ill children were referred to hospitals in neighboring districts. Private care was available through two private clinics, two maternity homes, two pharmacies and forty-two drug retail shops. Under Ghana's national health insurance system, children under-five years with acute illnesses are exempted from user fees. Currently non-insured children pay Ghc 8.00-8.50 (USD 5.6-6.0) for consultation treatment with artesunate amodiaquine or amoxicillin respectively.

\section{Study design}

This study assessed the adherence of $\mathrm{CHWs}$ to dosing and referral guidelines. The study population comprised trained CHWs, children 2-59 months old with fever as reported by the care givers. Records of consultations of these children were included in this analysis. 
Trial and intervention in brief: This was a cluster randomized stepped-wedge controlled open trial that measured the impact on childhood mortality, of the use of an antimalarial versus an antimalarial plus an antibiotic for the treatment of fever among children 2 to 59 (inclusive) months within the Home Management of Malaria (HMM) strategy. Within this strategy fever in children in areas where diagnostic facilities are lacking are considered as being due to malaria and treated accordingly. All communities in the district, many of which were more than $5 \mathrm{~km}$ away from health facilities, were grouped into 114 clusters of approximately 100 children. Using stratified randomization and cluster allocation performed in Microsoft Excel 2007, clusters were randomized in two phases to receive $A A Q$ or $A A Q+A M X$. Trained CHWs dispensed artesunate amodiaquine (AAQ), alone or with amoxicillin (AMX) after assessing children taken to them by their care givers. Information, Education and Communication (IEC) messages and drama were developed during the first preparatory year of the trial in cooperation with social scientists and an anthropologist. IEC targeted community leaders, members and care givers. Health staff were trained in order to receive and record $\mathrm{CHW}$ referrals but did not participate in the trial.

Preparation: Existing national and Integrated Management of Childhood Illness (IMCI) guidelines were used to develop CHW reference material, data collection forms for recording the sick child encounter (SCE), referring the child, recording drugs dispensed and a reference manual [120, 121]. The SCE form was semi-pictorial in order for CHWs to identify easily appropriate fields for capturing symptoms presented by the sick child. SCEs were the source of data and CHWs were to use a new SCE form per consultation. Written referrals were provided in duplicate (two on one sheet), one to be retained by the $\mathrm{CHW}$ and one to be given to the care giver to take to the health facility. Drugs, each pack containing a full treatment course, were pre-packaged and colour coded for different age groups. Artesunate amodiaquine treatment was given once per day for 3 days, packaged in an 
orange drug-pack for children 2-11 months and in a pink drug-pack for children 12-59 months. Stickers with a crawling child and a pre-school child were put on the boxes to facilitate easy identification. Dispersible tablets of amoxicillin in three different aluminium foil blister packs were given twice per day, also for 3 days $[122,123]$. The first dose was given under $\mathrm{CHW}$ supervision.

Training: Lay persons, all of whom had had no training in formal health care were selected from communities they lived in, which were often more than $5 \mathrm{~km}$ away from a health facility. Eighty-one of the $660 \mathrm{CHWs}(12.7 \%)$ had been engaged in a community trial the year before, but none had dispensed artesunate amodiaquine or amoxicillin before. None had any formal education in health care.

Using treatment guidelines developed for this study, $\mathrm{CHWs}$ were given a three day training on assessing, treating, referring a child appropriately, on counselling caregivers on how to give the drugs to their child, on signs of worsening illness and on when to return and taught to keep basic records. This was their main training however, trained field supervisors provided additional support, correcting CHWs but not forms during fortnightly supervisory visits. CHW participation in the trial was voluntary and without financial remuneration. They received a Tee-shirt and blood pressure checks once and their transport fares were remunerated during review meetings. Training was conducted in commonly spoken local dialects for CHWs from clusters randomized to the same intervention arm.

Assessment of the children: Table 1 outlines $\mathrm{CHW}$ responsibilities and expected actions to be carried out at the CHW's home during the clientprovider encounter. A history was taken focusing on the presence and duration of fever and other symptoms. In line with the main objective of the trial, children reported by care givers, eligible to receive study drugs were provided $A A Q$ or $A A Q+A M X$ on account of the fever. In both $A A Q$ and $A A Q+A M X$ clusters, children with symptoms of severe illness (danger signs) required immediate referral; and children with fast breathing ( $\geq 50$ breaths per minute for children less than 12 months old, and $\geq 40$ breaths per minute 
for children 12-59 months old) or had symptoms of other childhood illnesses which would need additional attention at a health facility were to be noted on the form as requiring referral. Figure 2 shows the flow chart of these actions. All actions were to be taken by $\mathrm{CHWs}$ except drugs which were dispensed per intervention arm. The drug pack(s) provided were to be indicated and care givers of such children were to be provided with a written referral and counseled to go to the health centre. CHWs were not to refer verbally but to fill forms in duplicate, one to be attached to the child's SCE form, and another to be given to the care giver to

Table 1: Key Actions in the assessment of children to be undertaken by all CHWs related to referral

\begin{tabular}{|c|c|c|c|}
\hline Category & Symptom & How information was to be obtained & Action \\
\hline \multirow{4}{*}{$\begin{array}{l}n \\
\frac{n}{60} \\
\frac{0}{n} \\
\frac{1}{d} \\
\text { do } \\
\frac{c}{\pi} \\
0\end{array}$} & Not drinking & offer water / observe breastfeeding & Refer \\
\hline & Vomits & Ask caregiver & Refer \\
\hline & Convulsion & Ask caregiver & Refer \\
\hline & Lethargic/unconscious & $\begin{array}{l}\text { Observe child/Ask caregiver } \\
\text { Clap near child's ears }\end{array}$ & Refer \\
\hline \multirow{4}{*}{ 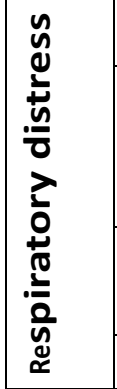 } & Difficulty in breathing & Observe child / Ask caregiver & Refer \\
\hline & Fast breathing & $\begin{array}{l}\text { Count respiration rate for one minute } \\
>50 \mathrm{~b} / \mathrm{m} \text { in children for } 2-11 \text { months* } \\
>40 \mathrm{~b} / \mathrm{m} \text { in children for } 12-59 \text { months* }\end{array}$ & Refer \\
\hline & Chest in-drawing & $\begin{array}{l}\text { Observe under ribs for indentation on } \\
\text { inhalation. }\end{array}$ & Refer \\
\hline & Stridor & Listen to child's chest for noisy breathing & Refer \\
\hline \multirow{7}{*}{ 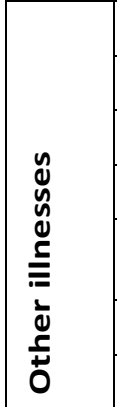 } & Diarrhoea & More than 5 days & Refer \\
\hline & Bloody stool & Ask if blood in stool & Refer \\
\hline & Sunken eyes & Observe child and ask & Refer \\
\hline & Skin pinch & Pinch abdomen/ observe skin recoil & Refer \\
\hline & Weight loss & Observe and ask & Refer \\
\hline & Palmar pallor & Observe child's palm & Refer \\
\hline & Swollen feet & Indent feet with thumbs & Refer \\
\hline
\end{tabular}


show to staff at the health facility. Health facilities were not required to provide feedback to $\mathrm{CHWs}$ as this was deemed extra work but were asked to retain the referral form for later collection. Children reaching health facilities were treated or referred to neighbouring district hospitals as per national guidelines.

Monitoring and supervision: Community meetings held after $\mathrm{CHWs}$ received their training, announced the commencement of the intervention, Community members were informed that drugs were provided at no cost and urged to comply with all $\mathrm{CHW}$ instructions. $\mathrm{CHWs}$ received a box with relevant forms and drugs. Completed SCE forms and referral forms were kept in a file in the box. CHWs were visited fortnightly by field supervisors who replenished drugs and forms. They used a standardized checklist to assess completed forms and, if needed, CHWs were advised and corrected (not the forms). CHWs who consistently made errors in filling forms were visited by a member of the study team and retrained on the specific issue noted. Public Health facilities within the district were visited fortnightly and the study referral forms retrieved. Review meetings held yearly for trained $\mathrm{CHWs}$ were used to retrain $\mathrm{CHWs}$ in assessing and referring children and dealing with other issues pertaining to the trial.

Analysis: Data from completed SCE forms were entered into Epidata and analyzed using SPSS 16 for Windows (Chicago: SPSS Inc). Adherence to dosing regimen was determined by comparing the child's age to the drug pack(s) dispensed. Adherence to referrals was assessed by determining the proportion of cases for whom CHWs had indicated on the form appropriately when a symptom for referral was present and those who had provided written referrals. Indications for referral were also grouped into: (i) $I \mathrm{MCl}$ defined danger signs (unable to drink or breast feed, vomiting everything, convulsions, lethargy/coma), (ii) other respiratory distress symptoms (fast breathing, difficult breathing, chest in-drawing, stridor/wheeze), (iii) symptoms of other illnesses requiring a referral (diarrhoea for more than 5 days, bloody stool, sunken eye, slow return on skin pinch, gross weight loss, palmer pallor and swollen feet) (Table 1) Chi squared test for two sided $p$ values at 0.05 level were used for determining statistical significance. Logistic 
regression models were used to identify characteristics that enhanced $\mathrm{CHW}$ adherence to referral instructions. Covariates included $\mathrm{CHW}$ age, sex, education, occupation, training phase and intervention arm and symptoms. Clustering at the level of the $\mathrm{CHW}$ was accounted for by applying random effects modeling methods resulting in robust standard errors.

Figure 1: Flow chart of $\mathrm{CHW}$ guide for assessing, treating or referring a child.

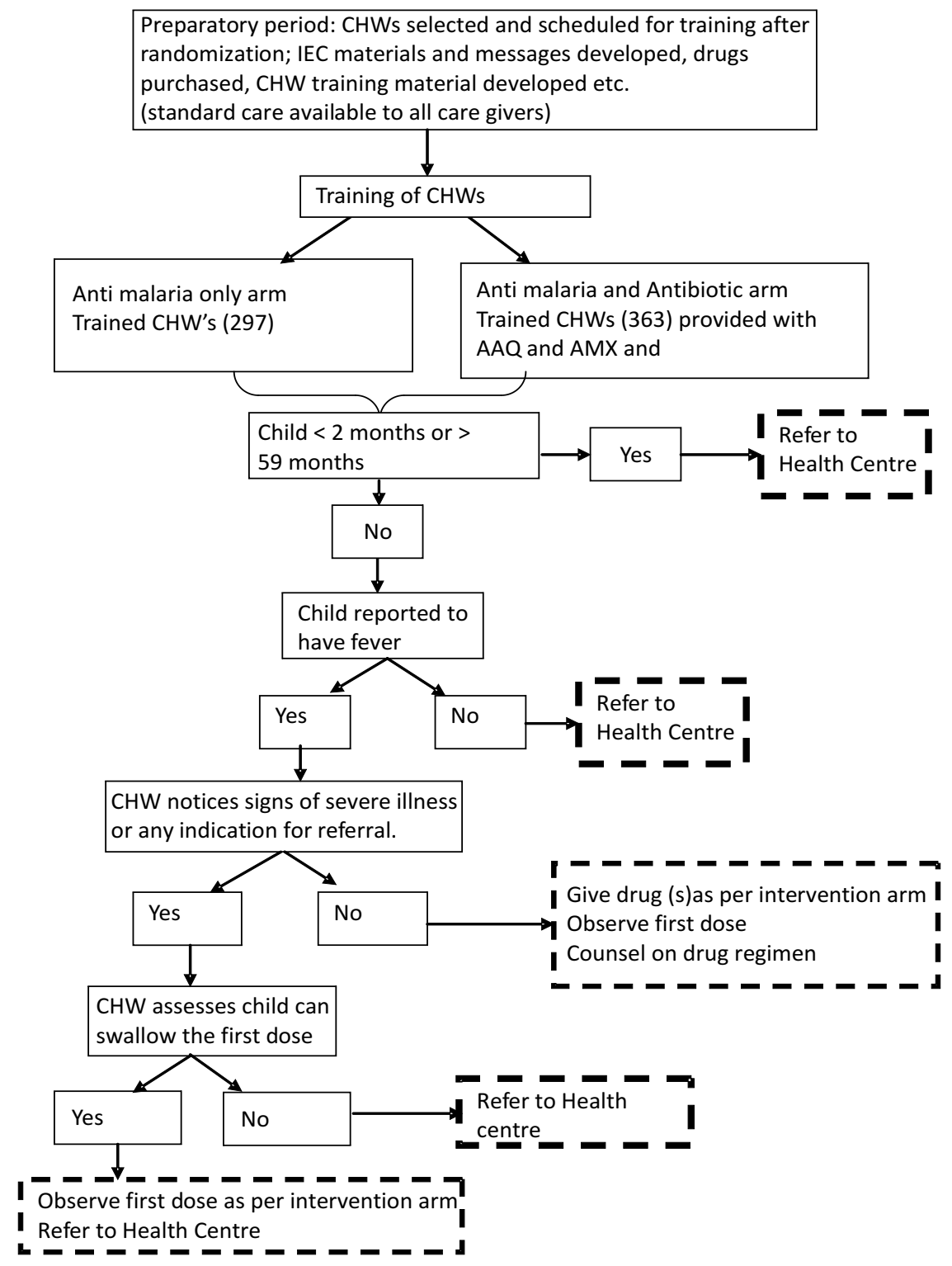




\section{Results}

There were 660 trained CHWs, 297 in AAQ clusters and 363 in AAQ+AMX clusters; 348 (52.7\%) male and 312 (47.3\%) female, with ages varying from 15 to 83 years with a median age of 30 years and an Inter Quartile Range (IQR)=18. From April 2007 when $\mathrm{CHWs}$ began attending to children, there were 13451 sick child consultations, the male to female ratio of the children was 52.7:47.1; and the median age was 25 months (IQR = 25).

In this analysis, 643 (4.8\%) consultations were excluded because of: missing data on age (424), over or under age (90), no evidence of fever (87) and poorly filled forms (42). Of the remaining 12808 (95.2\%) febrile episodes, 5990 (46.8\%) occurred in the AAQ clusters and 6818 (53.2\%) in the $A A Q+A M X$ clusters. Other demographic characteristics of the $\mathrm{CHWs}$ are shown in table 2. AAQ and AAQ+AMX were correctly dispensed in most instances; 5543/5622 (98.5\%) and 6116/6515 (93.9\%) respectively. Table 3 shows details of drugs dispensed by age categorization and by intervention arm. There were some differences in adherence by age group and drug type. Significantly more children in the AAQ clusters 5543/5622 (98.6\%) received the right drug for age group compared with 6116/6594(92.8\%) in the AAQ+AMX clusters (adjusted p<0.001). Overall,in 11 659/12330 (94.6\%) febrile episodes, the study drugs were correctly dispensed.

Table 2 Demographic characteristics of trained CHWs by intervention

\begin{tabular}{|l|l|l|l|}
\hline CHWs & $\begin{array}{l}\text { (AAQ) } \\
\text { N=297 } \\
\text { no. (\%) }\end{array}$ & $\begin{array}{l}\text { (AAQ+AMX) } \\
\mathbf{N}=363 \\
\text { no. (\%) }\end{array}$ & $\begin{array}{l}\text { Total } \\
\text { N=660 } \\
\text { no. (\%) }\end{array}$ \\
\hline Minimum to Maximum age & 15 to 76 years & 15 to 83 years & 15 to 83 years \\
\hline CHWs with no Education & $4(1.4)$ & $4(1.1)$ & $8(1.2)$ \\
\hline Primary Education & $10(3.5)$ & $15(4.3)$ & $25(3.9)$ \\
\hline Secondary Education & $268(94.4)$ & $322(92.3)$ & $590(93.2)$ \\
\hline Tertiary Education & $6(2.1)$ & $12(3.4)$ & $18(2.8 *$ \\
\hline Unemployed & $25(8.5)$ & $39(11.0)$ & $64(9.9)$ \\
\hline Self employed & $230(78.5)$ & $267(75.2)$ & $497(76.7)$ \\
\hline Professional/clerical work & $21(7.2)$ & $31(8.7)$ & $52(8.0)$ \\
\hline Students & $17(5.8)$ & $18(5.1)$ & $35(5.4)$ \\
\hline $\begin{array}{l}\text { Minimum-Maximum number of } \\
\text { children attended to by a CHW }\end{array}$ & 1 to 179 & 1 to 291 & 1 to 291 \\
\hline
\end{tabular}


Table 3: Appropriateness of drug(s) given by $\mathrm{CHWs}$ by child age group and intervention arms

\begin{tabular}{|c|c|c|c|c|c|c|c|c|}
\hline \multirow[t]{2}{*}{ Arm } & \multirow[b]{2}{*}{ Drug } & \multirow[b]{2}{*}{$\begin{array}{l}\text { Age } \\
\text { groups } \\
\text { in } \\
\text { months }\end{array}$} & \multicolumn{3}{|c|}{$\begin{array}{l}\text { Adherence of drugs } \\
\text { by Intervention arm }\end{array}$} & \multicolumn{3}{|c|}{ Adherence of drugs } \\
\hline & & & $\begin{array}{l}\text { Appropriate } \\
\text { drug (s) for } \\
\text { age } \\
\text { n (\%) }\end{array}$ & $\begin{array}{l}\text { Inappropr } \\
\text { iate drug } \\
\text { (s) for age } \\
\text { n (\%) }\end{array}$ & Total & OR & $\mathrm{Cl}$ & $P$ value \\
\hline \multirow[t]{2}{*}{ AAQ } & \multirow{2}{*}{$\begin{array}{l}\text { Artesunate } \\
\text { - } \\
\text { Amodiaqui } \\
\text { ne }\end{array}$} & $2-11$ & 1069 (96.7) & $37(3.3)$ & $1106(100.0)$ & 1 & & \\
\hline & & $12-59$ & 4474 (99.1) & $42(0.9)$ & $4516(100.0)$ & 3.7 & $1.08-6.58$ & $<0.001$ \\
\hline \multirow{5}{*}{$\begin{array}{l}\text { AAQ } \\
+ \\
\text { AMX }\end{array}$} & \multirow{2}{*}{$\begin{array}{l}\text { Artesunate } \\
\text { Amodiquin } \\
\mathrm{e}^{*}\end{array}$} & $2-11$ & 1180 (98.9) & $13(1.1)$ & $1193(100.0)$ & 1 & & \\
\hline & & $12-59$ & $5257(98.8)$ & $65(1.2)$ & $5322(100.0)$ & $\begin{array}{l}0.8 \\
9\end{array}$ & $0.42-1.88$ & 0.761 \\
\hline & \multirow{3}{*}{$\begin{array}{l}\text { Amoxicillin } \\
* *\end{array}$} & $2-11$ & $1223(99.0)$ & $12(1.0)$ & $1235(100.0)$ & 1 & & \\
\hline & & $12-35$ & 3370 (92.9) & $256(7.1)$ & $3626(100.0)$ & $\begin{array}{l}0.1 \\
3\end{array}$ & $0.07-0.23$ & $<0.001$ \\
\hline & & $36-59$ & $1863(95.2)$ & $94(4.8)$ & $1957(100.0)$ & $\begin{array}{l}0.1 \\
9\end{array}$ & $0.11-0.34$ & $<0.001$ \\
\hline \multirow{3}{*}{$\begin{array}{l}\text { AAQ } \\
+ \\
\text { AMX }\end{array}$} & \multirow{3}{*}{$\begin{array}{l}\text { Artesunate } \\
\text { - } \\
\text { amodiaqui } \\
\text { ne and } \\
\text { amoxicillin } \\
\text { Together }\end{array}$} & $2-11$ & 1178 (98.7) & $15(1.3)$ & $1193(100.0)$ & 1 & & \\
\hline & & $12-35$ & $3153(91.6)$ & $289(8.4)$ & $3442(100.0)$ & $\begin{array}{l}0.1 \\
4\end{array}$ & $0.08-0.24$ & $<0.001$ \\
\hline & & $36-59$ & 1785 (94.9) & $95 \quad(5.1)$ & $1880(100.0)$ & $\begin{array}{l}0.2 \\
4\end{array}$ & $0.14-0.41$ & $<0.001$ \\
\hline
\end{tabular}

Bivariate logistic regression adjusted for clustering at level of $\mathrm{CHW}$. * dosing adherence to $\mathrm{AAQ}=$ artesunate amodiaquine, ${ }^{* *}$ dosing adherence to $\mathrm{AMX}$ =amoxicillin. 


\section{Identification of symptoms requiring referral and provision of a}

written referral: Table 4 shows the various symptoms in children that required referral, the proportion for which referrals were noted and written referrals provided. Table 5 shows the number of referral symptoms a child had, the proportion cases for whom CHWs identified and indicated correctly on their forms, as requiring a referral and the proportion for whom a written referral was provided. Often CHWs did not recognize when a symptom required referral, thus more symptoms were present on the forms than written referrals provided. Of the 1758 (13.7\%) febrile episodes in which children had one indication for referral only $161 / 1758$ (9.2\%) were provided a written referral, with no significant difference by intervention arm adjusted for clustering at the level of $\mathrm{CHW}(\mathrm{p}=0.246)$. The provision of written referrals was analyzed as per categorization of the child's condition developed during analysis. Of 1423 children with at least one danger sign, 217 (15.2\%) were provided a written referral with no differences by intervention arm (adjusted $p=0.101$ ). Of the 1337 children with at least one symptom categorized as respiratory distress, 307 (23.0\%) were provided a written referral, however CHWs in the $A A Q+A M X$ arm were less likely to provide written referrals compared to $\mathrm{CHWs}$ in the $\mathrm{AAQ}$ arm (adjusted $\mathrm{p}=0.035$ ) and of the 544 children with at least one symptom indicating other illnesses 139 (25.6\%) were provided a written referral with no differences by intervention arm (adjusted $\mathrm{p}=0.076)$. 
Table 4: Children who presented with symptoms requiring referral, were identified correctly for referral, and received a written referral

\begin{tabular}{|c|c|c|c|c|}
\hline \multirow[b]{2}{*}{ 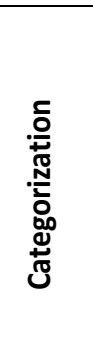 } & \multirow[b]{2}{*}{ Symptom } & \multicolumn{3}{|c|}{ Total ( all clusters) } \\
\hline & & $\begin{array}{l}\text { No. identified } \\
\text { (A) } \\
\text { A/N (\%) }\end{array}$ & $\begin{array}{l}\text { No. } \\
\text { noted for refe rral (B) } \\
\text { B/A (\%) }\end{array}$ & $\begin{array}{l}\text { No. given } \\
\text { written } \\
\text { referral (C) } \\
\text { C/B (\%) }\end{array}$ \\
\hline \multirow{4}{*}{ 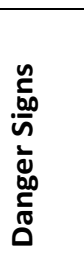 } & Unable to drink/BF & $881 / 12808$ (6.9) & $68 / 881$ (7.7) & $39 / 68$ (57.4) \\
\hline & Vomit everything & $461 / 12808$ (3.6) & $140 / 461(30.4)$ & $68 / 140(48.6)$ \\
\hline & Convulsion & $142 / 12808$ (1.1) & $52 / 142(36.6)$ & $28 / 52$ (53.8) \\
\hline & Lethargic/coma & 237/12808 (1.9) & $89 / 237(37.6)$ & $46 / 89$ (51.7) \\
\hline \multirow{5}{*}{ 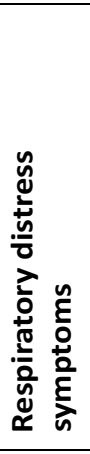 } & $\begin{array}{l}\text { Fast breathing (2- } \\
\text { 11) }\end{array}$ & $55 / 2407$ (2.3) & $21 / 55 \quad(38.2)$ & $14 / 21(66.7)$ \\
\hline & $\begin{array}{l}\text { Fast breathing (12- } \\
59)\end{array}$ & $858 / 10401$ (8.3) & $231 / 858 \quad(26.9)$ & $120 / 231$ (51.9) \\
\hline & Difficult breathing & 398/12808 (3.1) & $155 / 398$ (38.9) & $74 / 155$ (47.7) \\
\hline & Chest in-drawing & $55 / 12808 \quad(0.4)$ & $21 / 55(38.2)$ & $9 / 21(42.9)$ \\
\hline & Stridor/wheeze & $113 / 12808(0.9)$ & $49 / 113(43.4)$ & $24 / 49(49.0)$ \\
\hline \multirow{8}{*}{ 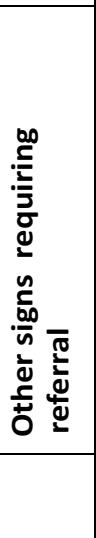 } & Diarrhoea $>5$ days* & $46 / 1634$ (2.8) & $12 / 46(26.1)$ & $7 / 12(58.3)$ \\
\hline & Bloody stool & $95 / 12808(0.7)$ & $35 / 95(36.8)$ & $17 / 35$ (48.6) \\
\hline & Sunken eyes & $170 / 12808$ (1.3) & $76 / 170(44.7)$ & $30 / 76$ (39.5) \\
\hline & Skin pinch & $52 / 12808 \quad(0.4)$ & $21 / 52(40.4)$ & $12 / 21(57.1)$ \\
\hline & Weight loss & $227 / 12808$ (1.7) & $72 / 227$ (31.7) & $33 / 72$ (45.8) \\
\hline & Palmer Pallor & $302 / 12808$ (2.4) & $142 / 302(47.0)$ & $82 / 142(57.7)$ \\
\hline & Swollen feet & $35 / 12808 \quad(0.3)$ & $17 / 35(48.6)$ & $7 / 17(41.2)$ \\
\hline & $\begin{array}{l}\text { Total (at least one } \\
\text { symptom) }\end{array}$ & $2716 / 12808(21.2)$ & $642 / 2716(23.6)$ & $308 / 642(50.0 \%)$ \\
\hline
\end{tabular}

*This assessment was done for only children who presented with diarrhoea. 
Table 5: The number of referral symptoms children requiring referral had, the proportion for whom referrals were noted and the proportion for whom written referrals were provided.

\begin{tabular}{|l|l|l|}
\hline $\begin{array}{l}\text { No of symptoms } \\
\text { requiring a referral }\end{array}$ & $\begin{array}{l}\text { No. noted for } \\
\text { referral }\end{array}$ & $\begin{array}{l}\text { No provided written referral } \\
\text { (A) }\end{array}$ \\
\hline 1 & $219 / 1758(12.5)$ & $82 / 219(37.4)$ \\
\hline 2 & $176 / 497(35.4)$ & $94 / 176(53.4)$ \\
\hline 3 & $134 / 254(52.8)$ & $80 / 134(59.7)$ \\
\hline 4 & $54 / 99(54.5)$ & $24 / 54(44.4)$ \\
\hline 5 & $28 / 51(54.9)$ & $9 / 28(44.4)$ \\
\hline 6 & $7 / 22(31.8)$ & $4 / 7(57.1)$ \\
\hline 7 & $10 / 12(83.3)$ & $7 / 10(70.0)$ \\
\hline 8 & $8 / 13(61.5)$ & $5 / 8(62.5)$ \\
\hline 9 & $5 / 7(71.4)$ & $3 / 5(60.0)$ \\
\hline 12 & $0 / 2(0.0)$ & - \\
\hline 15 & $1 / 1(100.0)$ & $0 / 1(0.0)$ \\
\hline
\end{tabular}

Review by CHWs: In 7554/12808 (59.0\%) febrile episodes, children were brought back to the $\mathrm{CHW}$ after 2 days for review during which care givers were asked whether the child had recovered or was still unwell. Most of these children $6352 / 7554$ (84.1\%) taken to the $\mathrm{CHW}$ for review after two days were 
well but $128 / 7554(1.7 \%)$ were still unwell. The need for referral was appropriately noted in 52/128 (40.6\%) of these children but few 43/128 (33.6\%) were provided a written referral. Significantly more written referrals were provided in $A A Q$ clusters $27 / 75,(36.0 \%)$ than in $A A Q+A M X$ clusters $16 / 53(30.2 \%)$, (adjusted $\mathrm{p}<0.001$ ). Of all children with an indication for referral, who returned to the $\mathrm{CHW}, 963 / 1022$ (94.2\%) were well.

Yearly assessment of written referrals: Between 2007 and 2009, $\mathrm{CHWs}$ provision of written referrals to relevant children reduced significantly from $108 / 495(21.8 \%)$ to $50 / 332(15.1 \%)$ respectively for children with at least one danger sign (adjusted $p<0.043$ ); from 156/494 (31.6\%) to 65/318 (20.4\%) respectively for children with respiratory distress (adjusted $p=0.007$ ) but the reduction from $54 / 160$ (33.8\%) to 39/137 (28.5\%) (Adjusted $p=0.420$ ) for children with other indicators for referral (was not significant).

Factors contributing to $\mathrm{CHW}$ adherence: In the multivariate logistic regression model in which we adjusted for clustering at the level of the $\mathrm{CHW}$, adherence to dosing guidelines was associated with the intervention arm to which the $\mathrm{CHWs}$ belonged. $\mathrm{CHWs}$ in the $\mathrm{AAQ}$ clusters were more compliant with the dosing regimen than those in $A A Q+A M X$ clusters (adjusted $p<0.001$ ). In similar multivariate models that adjusted for clustering at the CHW level, not breast feeding, vomiting everything, unconsciousness/lethargy, difficult breathing, , bloody stool, sunken eyes and pallor were symptoms and signs that CHWs significantly identified as requiring referral to a health facility. Apart from sunken eyes, these symptoms were also significantly associated with CHWs providing a written referral (table 6). Age, sex, education, the phase in which $\mathrm{CHWs}$ received training did not emerge as predictors of the provision of written referral (data not shown). 
Table 6: Multivariate analysis showing symptoms more likely to be noted as requiring a referral, and those more likely to receive a written referral from CHWs.

\begin{tabular}{|c|c|c|c|c|c|c|}
\hline \multirow{3}{*}{\begin{tabular}{|l|} 
\\
Unable to drink or \\
Breast feed \\
\end{tabular}} & \multicolumn{3}{|c|}{ Identified as requiring referral } & \multicolumn{3}{|c|}{ Provision of written referral } \\
\hline & \multirow{2}{*}{$\begin{array}{l}\text { Adjusted } \\
\text { Odds } \\
\text { Ratio } \\
0.437\end{array}$} & \multicolumn{2}{|c|}{$\begin{array}{l}\text { 95\% Cl for Odds ratio } \\
\text { Lower Upper }\end{array}$} & \multirow{2}{*}{$\begin{array}{l}\text { Adjusted } \\
\text { Odds } \\
\text { ratio } \\
1.493 \\
\end{array}$} & \multicolumn{2}{|c|}{$\begin{array}{l}95 \% \mathrm{Cl} \text { for Odds } \\
\text { ratio } \\
\text { Lower Upper }\end{array}$} \\
\hline & & 0.307 & $0.622^{*}$ & & 1.063 & $2.096^{*}$ \\
\hline Vomiting everything & 1.766 & 1.250 & $2.495^{*}$ & 3.456 & 2.256 & $5.294^{*}$ \\
\hline Convulsion & 0.731 & 0.397 & 1.344 & 1.353 & 0.601 & 3.042 \\
\hline Unconscious/ lethargy & 1.834 & 1.246 & $2.701^{*}$ & 1.834 & 1.046 & $3.214^{*}$ \\
\hline Difficult Breathing & 2.532 & 1.869 & $3.432^{*}$ & 2.860 & 1.893 & $4.320^{*}$ \\
\hline Fast Breathing & 1.286 & 0.920 & 1.798 & 4.058 & 2.987 & $5.513^{*}$ \\
\hline Chest In-drawing & 0.980 & 0.423 & 2.274 & 0.740 & 0.185 & 2.956 \\
\hline Stridor & 1.407 & 0.804 & 2.463 & 2.109 & 0.954 & 4.664 \\
\hline $\begin{array}{l}\text { Diarrhoea more than } 5 \\
\text { days }\end{array}$ & 1.475 & 0.786 & 2.765 & 16.646 & 6.791 & 40.803* \\
\hline Bloody stool & 1.622 & 0.932 & 2.823 & 2.699 & 1.275 & $5.713^{*}$ \\
\hline Sunken eye & 1.956 & 1.037 & $3.691^{*}$ & 1.122 & 0.498 & 2.528 \\
\hline Skin pinch & 1.506 & 0.502 & 4.518 & 1.255 & 0.180 & 8.733 \\
\hline Weight loss & 0.864 & 0.462 & 1.616 & 1.360 & 0.478 & 3.869 \\
\hline Pallor & 2.724 & 1.720 & $4.315^{*}$ & 5.308 & 2.901 & 9.709* \\
\hline Swollen feet & 1.011 & 0.368 & 2.776 & 0.421 & 0.077 & 2.299 \\
\hline
\end{tabular}

Reference point $=$ symptom in question not reported. ${ }^{*}$ Significant at 0.05 level 


\section{Discussion}

We report on the adherence of $\mathrm{CHWs}$ involved in a trial on management of fever among children 2-59 months old in Ghana. CHWs used the SCE form to take a history, examine, treat or refer a child and record results. We assessed symptoms based on what the $\mathrm{CHWs}$ recorded on the SCE forms. We could not assess their accuracy in recording symptoms. We did observe the examination of several children by the $\mathrm{CHWs}$ at the start of their functioning but could not regularly check later on due to limitations of staff and finances. We acknowledge that this is a limitation and agree that intensive supervision of $\mathrm{CHW}$ is very important. Based on ages recorded, $\mathrm{CHWs}$ performed well in providing the appropriate drug and dose according to age group, and this was probably enhanced by our use of pre-packed, colour coding, labelling with stickers and instructive inserts, factors known to improve drug prescribing [124, 125]. Performance regarding referral was inadequate both with respect to recognizing the need for referral, and to providing a referral, despite instructions on when and how to refer and a supply of referral forms.

Community Health Programmes (CHP) on the management of illness of children varies in several aspects. They may address single diseases e.g. malaria $[14,85,126]$ or pneumonia $[117,127]$ or have a broader approach on fever, respiratory infections, diarrhoea, malnutrition [20, 119]. They vary in activities expected from the $\mathrm{CHWs}$ (drug distribution only, health education, collecting information or diagnosis and treatment). The involved persons vary from trained health care workers to trained volunteers and mothers. They may be employed or receive some or no remuneration [117]. There are differences in duration of programmes, sustainability, supervision and quality control. Some CHPs are local, others regional even national. These variations make results of CHP as reported in the literature often difficult to 
compare and not generalizable, yet lessons can be learnt from experiences of others. Three studies $[119,128-129]$ specifically evaluate referral practices of CHWs, while others report other aspects of CHWs referral [130-132]. From these studies the following reasons for suboptimal performance of $\mathrm{CHWs}$ relating to referral practices emerge:

- algorithms and guidelines were too complicated;

- symptoms and signs on which to refer were ambiguous;

- CHWs may be unconvinced about the need for referral themselves;

- health staff criticise frequent referrals by CHWs;

- care givers protest against referral therefore $\mathrm{CHW}$ does not refer;

- CHWs, aware of high costs related to hospital care avoid referrals, or if referrals are given, care givers may not comply;

- knowledge about low satisfaction with care at the referral centre may be a threshold for CHWs to refer;

In the study of performance of CHWs in the management of ARI, diarrhoea and malaria in western Kenya by Kelly et al 2001 [119]. CHWs adequately treated $90.5 \%$ of malaria cases but often made mistakes assessing symptoms. Complexity of guidelines were important reasons for deficiencies. The authors give a series of simple guidelines and instructions for referral. In Uganda referral practices assessed within a Home Based Management of fever programme aimed at treating malaria [129]. The referral rate was low (8\%), but referral completion reached $87 \%$, although $30 \%$ of urgent referrals delayed more than 24 hours. Only 50\% of patients with pneumonia were urgently referred. Lack of money and waiting for the effect of the malaria drugs to show were main reasons for delay. They concluded that HBM needs to include pneumonia and also that lack of regular supervision may contribute to suboptimal performance. In Mali, verbal referral was twice as frequent as notification in the referral book, probably because the $\mathrm{CHWs}$ felt 
that the family would not comply [132]. In Sierra Leone, CHWs referred clients with indications for referral (RDT negative or RDT positive with signs of severe illness, or other illnesses) as directed, however, referral completion for children was very low (33/2024; $1.6 \%)$ but was much higher (15/17, 88.2\%;) when signs of severe malaria were present.

In our study the recruited CHWs had limited or no experience in health care and were given a three- day training. About $90 \%$ had secondary (the equivalent of junior high school) education, $1 \%$ no education and almost $3 \%$ had tertiary education. The average duration of CHWs service was 24.7 months. We did not evaluate actual consultations by $\mathrm{CHWs}$, and although they were supervised fortnightly by trained staff, the quality of their supervision was not assessed quantitatively. Guidelines and instructions were in English but training was in the dominant local languages. During review meetings, problems about the guidelines did not come forward. When asked about poor referral practice, $\mathrm{CHWs}$ said care givers resisted being referred. CHWs might have become complacent with time about referring as a result of perceived efficacy of the study drugs as $84 \%$ of the children that reported back ( $50 \%$ of the total), were well. It is unlikely that shortage of forms played a significant role as CHWs were restocked with the same number of referral forms as SCE forms and few CHWs needed to refer more children than they had SCE forms for. Of the 161 written referrals provided, $140(87.0 \%)$ were retrieved from the health facilities. Care giver compliance with referral advice will be presented elsewhere [128]. The formal health sector receiving referred patients did not consistently retain notes and did not report back and unfortunately personnel and finances did not allow us to redress this. In Mali a referral system that enabled feedback from the referral centre to CHWs worked well [130]. 
Although only a small percentage of children had an indication for referral, it is still important that CHWs properly identify and refer children with indications for referral in order to prevent illnesses from becoming worse and ultimately childhood mortality.To enhance management of patients with fever within CHP, diagnostic tools of RDTs for malaria (probably in the future for other diseases) have been introduced in WHO 2010 guidelines [21]. Carefully designed teaching instructions and regular supervision of $\mathrm{CHWs}$ and also of actual consultations and strategies to improve referral are required.

Conclusion: adherence of $\mathrm{CHWs}$ to dosing regimen by age group was $94.6 \%$. Only $13 \%$ of consultations involved children with symptoms and signs that required referral but $\mathrm{CHW}$ did not consistently note that these symptoms required a referral and the provision of written referrals was inadequate. CHPs need to develop strategies that enhance adherence to guidelines and instructions for referral. Socio-anthropological studies on deficiencies are needed. 



\section{Chapter 6}

\section{Factors related to retention of community}

health workers in a community based management of fevers in children underfive years in the Dangme West District of Ghana

Published as:

Mercy Abbey, L Kay Bartholomew, Justice Nonvignon, Margaret A. Chinbuah, Matilda Pappoe, Margaret Gyapong, John O. Gyapong , Constance Bart-Plange and Bart van den Borne: Factors Related to Retention of Community Health Workers in a Community Based Management of Fevers in Children under Five years in the Dangme West District of Ghana.Int Health doi:10.1093/inthealth/ihu007.International Health Advance Access published February 13, 2014 



\section{Abstract}

Background: In resource constrained settings of developing countries, promotion of community based health interventions through community health workers (CHWs) is an important strategy to improve child health. However, there are concerns about the sustainability of such programmes due to the high rate of attrition of CHWs. This study examined factors influencing retention of volunteer $\mathrm{CHWs}$ in a cluster-randomised trial on community management of under-five fevers in a rural Ghanaian district.

Methods: Data were obtained from structured interviews $(\mathrm{N}=520)$ and focus group discussions ( $\mathrm{N}=5$ ) with $\mathrm{CHWs}$. Factors influencing $\mathrm{CHWs}^{\prime}$ decision to remain or leave the programme were analysed using a probit model and focus group discussion results to elucidate our findings.

Results: Attrition rate among the CHWs was $21.2 \%$. Attrition was comparatively higher in younger age groups than the older ones: (26\% in $15-$ 25 age group, $18 \%$ in $26-45$ age group and $16 \%$ in $>46$ age group).The approval of a CHW by community $(p<0.001)$ and the CHW's immediate family $(p<0.05)$ showed significant in influencing the probability of remaining in the programme. Motivation for retention was related to the desire to serve their communities, humanitarian and religious reasons.

Conclusion: The relatively moderate rate of attrition could be attributed to the high level of community involvement in the selection process and other aspects of the intervention leading to high community approval and support. Attention for these aspects could help improve $\mathrm{CHW}$ retention in community based health interventions in Ghana and the lessons could be applied to countries within similar settings. 


\section{Introduction}

Community-based health interventions involving Community Health Workers (CHWs), is an important strategy for increasing access to health care in rural areas of developing countries where resources are most constrained [23]. Factors such as "brain drain" of professional health care providers, skewed distribution of available workers towards urban centres within developing countries and other challenges limiting availability of health services in remote areas have severely affected access to health care at the community level [133-135].

Currently, $\mathrm{CHWs}$ are used in Community Case Management (CCM) as recommended by the World Health Organization (WHO), United Nations Children's Fund (UNICEF) and other major partners, as a strategy to accelerate progress towards the attainment of the Health - related Millennium Development Goals (MDGs); particularly the MDG 4 of reducing mortality of children under 5 from 1990 levels by two-thirds by 2015 [72].

$\mathrm{CHWs}$ are members of the communities where they work, they are selected by, and answerable to their communities; They are also supported by the health system but are not necessarily a part of its organization and undergo shorter training than professional health workers [24].

Involving CHWs in health care delivery has contributed to substantial reductions in childhood mortality and severe morbidity $[13,14,20,25,26$, 136]. However the problem of high rates of $\mathrm{CHW}$ attrition varying between $3.2 \%$ and $77 \%[25,26,27]$ coupled with other programme related factors including poor selection criteria and training, inadequate financial motivation, lack of community support, heavy workload and socio-cultural environments $[12,26,28-31,114]$ have raised concerns about the sustainability of programmes involving CHWs. Literature has clearly documented the negative effect of high $\mathrm{CHW}$ attrition rates on the continuity of established relationships between $\mathrm{CHWs}$ on one hand and, the 
community they serve and the health system on the other hand. Such effects include the costs involved in selecting and training new $\mathrm{CHWs}$ as replacement $[25,26,114]$.

In Ghana CHWs have been engaged in various programmes [12, 30, 137] since the 1970s. However, there is little information on CHW attrition rates and factors contributing to this in community based interventions in Ghana. The purpose of this study was to examine the attrition rate among CHWs who participated in a cluster randomised controlled trial (RCT) on community management of fevers in children under five in the Dangme West District and the factors contributing to the retention of $\mathrm{CHWs}$; The trial implemented interventions that resulted in a reduction of all-cause mortality of $30 \%$ and $44 \%$ among children treated with an antimalarial and those treated with the antimalarial + an antibiotic respectively [40].

\section{Methods}

\section{Conceptual Framework}

The term "Attrition" was used in this paper to describe the loss of $\mathrm{CHWs}$ to the intervention, from the time of deployment until the end of the project. The framework for this study was adapted from concepts from the ecological behavior model [138] which emphasizes the influences of internal and external environmental systems on an individual's behavior. Internal factors comprise personal characteristics such as marital status, number of children, age, education and occupation which could influence a person's decision making towards involvement in community based interventions. In addition, Syed and colleagues indicate that factors including one's personal expectations of having opportunities to serve one's community, possibility of future jobs, financial gains and recognition in the community may encourage participation in community interventions [31]. while life events including births and deaths, ill health, marriage andmigration from the 
community as well as gaining other opportunities may influence attrition in a programme. The external factors of the behavior model relate to the immediate family, friends, resident-community and the broader environments of society and government; as well as programme characteristics including the selection process for CHWs, the quality of training, supervision and monitoring, remuneration and the relationship between formal health care workers and CHWs. [23, 30, 31, 139]. These various internal and external factors individually and in interactions may influence the $\mathrm{CHWs}$ decisions to remain in or quit a programme as shown in figure 1.

Figure 1: Conceptual Framework

\section{External \\ Factors}

Community

- Approval by community

-Approval by family and

friends

-Job opportunities

Society and Government

-Culture

-Policies

Program Related

-Selection

- Training

-Supervision

-Remuneration
Internal

Factors

Personal

- Age

- Gender

-Marital Status

- Number of Children

- Education

- Occupation

amongst

CHWs

Life Events

-Birth

-Marriage

- Illness

-Death 


\section{Study Site}

The study was conducted in Dangme West, a rural district in the Greater Accra Region of Ghana; with approximately 109,459 people living in 376 communities[10]. At the time of the study, the district had four government owned health centres and six community clinics, two private clinics, two private maternity homes, two pharmacies, and 42 licensed drug retail shops. Access to most of the health centres was poor, as many inhabitants lived more than $5 \mathrm{~km}$ away. The district is characterised by poor road networks which render some roads impassable during the heavy rain season.

\section{Overview of Intervention}

As part of a randomised controlled trial on community management of fevers in children under five in the Dangme West District, $660 \mathrm{CHWs}$ were engaged for a total of 30 months between January 2006 and December 2009. They assessed febrile children brought to them by their caregivers and either treated or referred those with danger signs to the nearest health facility. They also counselled caregivers on medication administration and referral compliance where needed and documented consultations with each sick child. The $\mathrm{CHWs}$ operated in their homes and were not required to undertake outreach activities. The study medicines - antimalarial medication (artesunate amodiaquine) ( $A A Q$ ) and antibiotic (amoxicillin) ( $A M X)$ were provided free of charge to the clients. In all, $\mathrm{CHWs}$ had consultations with approximately 12,500 sick children during the intervention[40]. (Detailed trial design and implementation are described elsewhere $[40,100])$.

Selection and Training of CHWs: A team comprising Project staff and health workers from the district paid initial visits to inform community leaders and to solicit support for the intervention. Subsequent meetings were held in each community in the district where community members openly discussed criteria for selection of the $\mathrm{CHW}$, nominated and voted openly for persons of 
their choice after the expected role of the prospective $\mathrm{CHW}$ had been explained by the project team. In some instances, individuals volunteered themselves and in few cases, the chiefs or other opinion leaders selected persons of their choice. On average two persons were selected per community depending on the size of the community.

Staff from the Ghana Health Service trained CHWs in batches over three-day sessions using a simplified version of the UNICEF/WHO guidelines for Integrated Management of Childhood Illnesses (IMCI). [140] Training was competence- and practice- based and was conducted in the local language of the $\mathrm{CHWs}$. On completion, $\mathrm{CHWs}$ received a certificate of participation and a box containing supplies for the job in simple graduation ceremonies witnessed by community members and their leaders. Further awareness of CHWs' skills and services and the expected role of community members were created through audio-visual messages designed and implemented by project staff in the communities. On a continuous basis, $\mathrm{CHWs}$ received two weekly supportive supervision and replenishment of stock from project supervisors.

Incentives: The CHWs worked on voluntary basis .The project paid CHWs transportation allowances for attendance at training and meetings and gave free T-Shirts donated by the National Malaria Control Programme. CHWs also benefitted from free blood pressure checks and medical advice during the refresher trainings. Project staff kept sustained social contact with the $\mathrm{CHWs}$ through visits when $\mathrm{CHWs}$ were taken ill. Staff also attended social events of cultural relevance such as naming ceremonies for babies born to $\mathrm{CHWs}$ or funerals for $\mathrm{CHWs}$ or their close relatives living in the CHW's community. Donations of small amounts of money (about USD 20) were usually made to them during such activities. At the end of the project, $\mathrm{CHWs}$ received a piece of wax print fabric as a token of appreciation for their participation. Although communities agreed during recruitment to provide $\mathrm{CHWs}$ with in-kind incentives, this did not work out in any of the communities. 


\section{Study Design}

This study applied a mixed method approach to examine $\mathrm{CHW}$ attrition and correlates of attrition. Attrition rates were abstracted from the CHW database built as part of the project. The database contained information on socio demographic characteristics of CHWs such as age, sex, educational level attained, marital status, occupation, and total number of children. Other details were: a unique identification code for each $\mathrm{CHW}$, the name and code of CHW's community of residence and house address derived from the Dodowa Health and Demographic Surveillance System (DHDSS).

The reasons for, or correlates of, attrition were analysed from data from face to face interviews and focus group discussions (FGDs). These were augmented with information from field reports and informal discussions with project staff. The face to face interviews were conducted among CHWs before their initial training using a semi structured questionnaire. Issues explored included: motivation for joining the programme, previous experience as volunteers in other programmes training expectations, as well as who approved and who disapproved their participation in the programme. Five FGDs were held at project end, between January and February 2010 among 13 male and 22 female "Stayers" ("Stayers" were CHWs who stayed till project completion). Key issues explored included CHWs' perceptions of their selection process, their experiences on the job, reasons for staying on and perceptions of reasons why others left. The discussions were held within the communities; and in the local language to allow participants to express themselves more easily. Discussions were tape recorded after obtaining consent from each participant. (Interview and focus group guiding questions are available as a separate file).

CHWs lost to attrition could not be interviewed because majority had relocated without prior notice and were difficult to reach. Further, we did not interview those lost to attrition though they remained in the communities due to time and financial constraints. Attempts made by Field Supervisors' to 
reach $\mathrm{CHWs}$ lost to attrition, and to understand why they withdrew from the project were by means of telephone calls and informal discussions with some $\mathrm{CHWs}$, family members, neighbors and colleague $\mathrm{CHWs}$ residing in the same communities as those $\mathrm{CHWs}$ lost to attrition.

\section{Data Analysis}

Data from the semi structured interviews were captured in EpiData software version 3 (The EpiData Association, Odense, Denmark); and analysed with SPSS 18 for Windows (SPSS Inc., IL, USA). Analysis was performed on a sample of $520 \mathrm{CHWs}$ for whom complete data was available.

A probit regression model was used to examine factors that are related to the decision to remain active in community based interventions or not. Following Jones [141], the model assumes that there is some unobservable continuous latent variable that determines the decision to remain active in community based interventions. Hence we developed a predictive regression (probit) model.

The dependent variable used was the loss of a $\mathrm{CHW}$ to attrition. This was a dummy variable taking on a value of 0 if the $\mathrm{CHW}$ was lost to attrition and 1 if the CHW stayed on till the end of the project. The explanatory variables included approval of the $\mathrm{CHW}$ by the $\mathrm{CHW}$ 's immediate family and the community. The total number of children, age, and number of years of schooling were all continuous variables. The latter was a transformation of the response of the $\mathrm{CHW}$ which were in the form of highest level of education, using the standard years of schooling in Ghana. Another explanatory variable called "volunteer" represents whether or not a $\mathrm{CHW}$ has ever been involved in similar community-based health programmes as a volunteer. The variable "occupation" had six categories i.e. unemployed, farmer/fisherman, artisan/trader, civil servant, student and self-employed. "Unemployed" was used as the base to which each of the other categories was compared. 
Focus Group Discussions: Analyses of the FGDs was an iterative process [65] beginning in the field; notes taken during the discussions were reviewed together with transcripts from the taped discussions. The taped discussions were transcribed verbatim and anonymised [65]. Descriptive summaries of each transcript were made to explore the depth of the data. Codes were developed based on concepts from the discussion guide, literature and new issues that emerged from the discussions [142]. Transcripts were first analysed separately, then jointly by two researchers with experience in qualitative research, comparing codes and themes until inter-coder agreement was reached. This was followed by mapping and interpretation of the themes across the entire set of transcripts.

\section{Results}

Attrition Rates: The attrition rate over the period of 30 months of intervention was $21.2 \%$ (140/660). Field records showed that 12 months into the project, about $63 \mathrm{CHWs}$ were lost to attrition, this number increased to 87 in 18 months and 126 in 24 months and by the end of the trial, about 140 were lost to attrition. The highest rate of $30.3 \%$ (54/178) was in Dodowa sub district and the second highest rate of 25.0\% (27/108) in Prampram sub district. These two respectively are the closest sub-districts to urban centres. Osudoku sub-district recorded the third highest attrition rate at $16.2 \%$ (30/185) followed by Ningo sub-district at 15.3\% (29/189).

Demographic Characteristics and Attrition: Results from the data showed a statistically significant difference between attrition and all demographic characteristics variables except sex of the CHWs as shown in Table 1 below. Attrition rate was lower in higher age groups compared with lower age groups, (25.9\% (55/212) in 15-25 age group, 18.2\% (57/314) in 26-45 age group and $16.5 \%(20 / 121)$ in $>46$ age group $)(\mathrm{P}=0.04)$ and higher in females (23.7\% [74/312]) compared to males (19.0\% [66/348]). Similarly, higher 
attrition rate was reported among single CHWs (28.3\% [64/226]) compared to married CHWs $(15.1 \%[63 / 416])(P<0.001)$. On education, the highest attrition was reported among $\mathrm{CHWs}$ with post-secondary education (38.9\% [7/18]) and lowest among Junior Secondary school leavers (15.7\% [67/427]) $(P=0.009)$.

Table 1: Attrition by demographic characteristics

\begin{tabular}{|c|c|c|c|c|c|c|}
\hline Variable & & $\begin{array}{l}\text { Active } \\
\text { CHWs }\end{array}$ & $\begin{array}{l}\text { CHWs lost } \\
\text { to attrition }\end{array}$ & $\begin{array}{c}\text { Total } \\
\mathrm{n}(100 \%)\end{array}$ & P-value & $\begin{array}{l}\text { (Pearson chi } \\
\text { square value) }\end{array}$ \\
\hline Sex & Male & & & & & \\
\hline & Female & 282(81.03) & $66(18.97)$ & 348 & NS & 2.2232 \\
\hline Age group & $15-25$ years & $238(76.28)$ & $74(23.72)$ & 312 & & \\
\hline & & $157(74.06)$ & $55(25.94)$ & 212 & & \\
\hline & $>46$ years & $257(81.85)$ & $57(18.15)$ & 314 & $\mathrm{P}=0.047 * *$ & 6.1045 \\
\hline & Missing & $101(83.47)$ & $20(16.53)$ & 121 & & \\
\hline Marital statu & S Single & $5(38.46)$ & $8(61.54)$ & 13 & & \\
\hline & Married & $162(71.68)$ & $64(28.32)$ & 226 & $P<0.001^{* * *}$ & 16.0171 \\
\hline & Missing & $353(84.86)$ & $63(15.14)$ & 416 & & \\
\hline $\begin{array}{l}\text { Educational } \\
\text { level }\end{array}$ & & $5(27.78)$ & $13(72.22)$ & 18 & & \\
\hline & No education & & & & & \\
\hline & Primary & $5(62.50)$ & $3(37.50)$ & 8 & & \\
\hline & Junior & $17(68.00)$ & $8(32.00)$ & 25 & & \\
\hline & $\begin{array}{l}\text { secondary } \\
\text { Senior }\end{array}$ & $360(84.31)$ & 67(15.69) & 427 & $\mathrm{P}=0.009 * * *$ & 13.6202 \\
\hline & $\begin{array}{l}\text { secondary } \\
\text { Post - }\end{array}$ & 126(77.30) & $37(22.70)$ & 163 & & \\
\hline & $\begin{array}{l}\text { secondary } \\
\text { Missing }\end{array}$ & $11(61.11)$ & $7(38.89)$ & 18 & & \\
\hline & & $1(5.26)$ & 18(94.74) & 19 & & \\
\hline
\end{tabular}

Notes: ${ }^{* * *}$ and ${ }^{* *}$ denote significant at $1 \%$, and $5 \%$ respectively; NS denotes not significant 
Probit Regression: Results of the probit estimation, reported in Table 2, show a significant positive relationship between the approval of a $\mathrm{CHW}$ by both community $(p<0.001)$ and the CHW's immediate family $(p<0.05)$ and the probability of remaining active. Older $\mathrm{CHWs}$ were less likely to be lost to attrition as compared to younger $\mathrm{CHWs}$ and $\mathrm{CHWs}$ working as artisans/traders were more likely to be lost to attrition.

Table 2: Probit regression results for determinants of $\mathrm{CHW}$ attrition

\begin{tabular}{|c|c|c|}
\hline Variables & Estimated Coefficients & Estimated Marginal Effects \\
\hline Family approved CHW & $0.60 * *(0.30)$ & $0.11 * * *(0.04)$ \\
\hline Community approved CHW & $0.84 * * *(0.27)$ & $0.26^{* * *}(0.09)$ \\
\hline Marital Status & NS & $0.06(0.04)$ \\
\hline No of Children & NS & $-0.00(0.01)$ \\
\hline Age of CHW & NS & $0.00 * *(0.00)$ \\
\hline Education Years & NS & $-0.00(0.00)$ \\
\hline Volunteer & NS & $-0.01(0.03)$ \\
\hline Farmer/Fisherman & NS & $-0.15(0.08)$ \\
\hline Artisan/Trader/Apprentice & $-0.62 * *(0.31)$ & $-0.15(0.08)$ \\
\hline Civil Servant & NS & $-0.21(0.14)$ \\
\hline Student & NS & $-0.18(0.13)$ \\
\hline Self Employed & NS & $0.02(0.13)$ \\
\hline Constant & $0.19(0.47)$ & \\
\hline \multicolumn{3}{|c|}{ Wald Chi-square $=23.68 ;$ number of observations $=513 ;$ Pseudo $R^{2}=0.0660$} \\
\hline
\end{tabular}


From the focus groups, the main reasons for attrition on the programme as perceived by "Stayers" were lack of remuneration, a possible weak sense of social responsibility and negative attitude of care givers. Nonpayment was a major concern for all $\mathrm{CHWs}$ contributing to the exit of those who were dissatisfied about non- payment for the sacrifices they made. Though they were informed about the unpaid nature of the job, some still hoped the situation might change in the future; as articulated by a CHW: "Those who stopped complained of money saying they are suffering for nothing..." this was aggravated by the community's broken promise to provide in-kind incentives as alluded to by one $\mathrm{CHW}$ : "... during the durbar the community agreed to give us (CHWs) some incentive but up to now nothing...".

Some perceived negative attitudes exhibited by caregivers may have accounted for the exit of some CHWs who were reportedly unable to tolerate it. There were complaints about rude behaviors on the part of care givers either demanding medication for ineligible children (older than 5 years) or impatient for $\mathrm{CHW}$ s to complete assessment of the sick child before providing treatment. For example one $\mathrm{CHW}$ explained that: "those who quit may not have patience, some people cannot tolerate the way some mothers shout at them."

A possible weak sense of social responsibility was expressed as another likely reason for attrition. The "Stayers" argued that most communities nominated and approved CHWs and they in turn openly accepted or declined their nomination. Thus, "Stayers" reasoned, if CHWs dropped out after having openly accepted their nomination, then perhaps they did not have genuine interest in the work to begin with.

Information from project field supervisors' records revealed that more than half of the $\mathrm{CHWs}$ lost to attrition had gained some employment or admission to further their education, which made them spend long hours 
outside the community or had caused them to relocate out of their communities. A few had difficulty coping with the work due to their inability to document consultations by themselves whenever they attended to a sick child. They needed to rely on their assistants who were not always readily available every time their services were needed. Reasons could not be attributed to the withdrawal of the rest for whom Field Supervisors' could neither reach nor find anyone to answer for their whereabouts.

On the other hand, perceived benefits and satisfaction derived from the realisation of expectations contributed to "Stayers" completing the project. They asserted that there was an observable reduction of childhood fever/malaria/death cases in their communities which they attributed partly to their efforts. These were reflected in statements such as: "There used to be a high rate of death among children who have fever, but now the rate has reduced in my community". For many, it was a religious, social or moral obligation to stay on; also, their self-professed love for children, coupled with a strong sense of commitment to prevent childhood deaths in their communities seemed to have kept them on the project in spite of not being paid, as expressed by one CHW: "The Bible says we should love our neighbour like we love ourselves', so whether the children vomit on me or not or I'm being paid or not I will still continue...."

Additionally, recognition by and cordial relationships with professional health staff, project staff and the community at large was further source of motivation to stay on as illustrated in such statements as: "I have become so popular and respected by the people in the community..." another remarked: 'When I go to the community clinic some of the Nurses recognise me ... and I'm very happy for that." Another CHW asserted: "I have become a friend to all children and mothers in the village. That is my benefit from this work". 


\section{Discussion}

The attrition rate of $21.2 \%$ over the 30 month intervention period appears moderate compared to other studies that reported $\mathrm{CHW}$ attrition rates of 30\% over 9 months in Senegal, $50 \%$ in Nigeria over 24 months [26] and 33\% in Kenya over 11 months [29].

Beyond this, the findings of this study relating to the factors in the framework for the study are largely consistent with the literature.

The finding that $\mathrm{CHWs}$ approved by their immediate families and the community were less likely to be lost to attrition compared to those who did not receive such approval, buttresses the well documented fact that community involvement is crucial for the success of $\mathrm{CHW}$ interventions [23]. In addition, the satisfaction derived from the recognition and appreciation of CHWs' work by health workers and the community, as was found in the FGDs, seemed to have been important in motivating and sustaining the CHWs; similar to findings elsewhere $[26,31,139]$.

The relatively high rate of attrition in the capital of our study district could be due to the availability of more alternative job opportunities for an income to satisfy daily needs, which are more likely in an urban than in a rural environment. Although information could not be sought from $\mathrm{CHWs}$ who dropped out, the "Stayers" seem to suggest that desertion was largely due to pursuit of income since there were no systematic incentives or payments for work done in the project albeit, this did not influence those who stayed.

Issues of $\mathrm{CHW}$ remuneration - whether $\mathrm{CHWs}$ should work as volunteers supported in kind or cash by their community, or paid - through government funds- has been a long standing challenge for community based programme implementers in many countries including Ghana [23, 26, 30,31]. Monetary incentives can increase retention and has been used successfully in some programmes [26]. However, most of the programmes that pay their CHWs either a salary or honorarium are known to face problems of sustainability [23], thus the need to build in some kind of appropriate 
mechanisms to ensure continued provision of service is crucial. Arguments have usually tilted against payment of $\mathrm{CHWs}$ due to the cost implication, especially when a large number of volunteers are involved.

Conversely, the use of non-monetary incentives has also been successful in some CHW programmes [26]; hence, community-based health interventions that rely greatly on community volunteers could consider providing some non-financial incentives to $\mathrm{CHWs}$ to encourage retention. Beside monetary and in-kind payments, community participation in the choice of a volunteer and other aspects of programme implementation cannot be ignored if CHWs need to be retained [26].

Regarding internal factors from the model, our results suggested age was significantly associated with attrition. Older $\mathrm{CHWs}$ were less likely to be lost to attrition compared with the younger CHWs. A study in Kenya also found that $\mathrm{CHWs}$ aged 40 and above were more stable in their home based care programme than younger CHWs [29]. Furthermore a study in the Solomon islands found that younger $\mathrm{CHWs}$ (less than 20 years of age) were more likely to drop out than older ones [139].

Gender was not found to affect attrition in our study. This could be attributed to the type of service the $\mathrm{CHWs}$ were required to provide providing medication for sick children less than five years old. In the study in Kenya where $\mathrm{CHWs}$ were providing nursing care such as bathing and cleaning soiled linens of people living with HIV and AIDS (PLWHA), male CHWs were reported to have considered such tasks as being in the domain of women hence higher attrition was found among the men [29].

\section{Limitations}

In order to explore reasons for attrition, it would have been ideal to interview CHWs who were lost to attrition in order to gain first-hand information from them. Although this was intended, it was not possible mainly because majority who left the programme did not give prior notice 
before doing so. Often, when Field Supervisors enquired of CHWs who were not at post, their relatives or neighbours told field supervisors that the $\mathrm{CHWs}$ had travelled and would be back but in most cases, they did not return. The opportunity to follow up after finding out that they had quit the job did not arise because they had either migrated out of the community/district or had left for further education or new employment and were generally out of reach. However, the insights given by the "Stayers" i.e. CHWs who stayed on the trial are helpful in understanding why others left; given that $\mathrm{CHWs}$ interacted with each other a lot both within their communities and also during periodic project meetings held, we believe the cordial relationship that existed among $\mathrm{CHWs}$ enabled them to share information with each other such that the reasons cited by "Stayers" for others leaving would be plausible. Following CHWs who were lost to attrition, would have provided in-depth information for understanding reasons for attrition. Future studies could address this shortfall.

\section{Conclusion}

The results from this study indicate that compared to several other studies on the involvement of CHWs working on a voluntary basis in a community-based management of childhood fevers, the intervention was successful in keeping majority motivated and in maintaining them in the programme, as shown by a relatively moderate attrition rate. Very likely, this was achieved because of the high level of community involvement in the selection of the volunteers leading to high community approval and because of approval and support of their immediate family members. Beyond community involvement, the limited scope of $\mathrm{CHWs}^{\prime}$ work may have also been a contributory factor. Attention for these aspects in the implementation 
of the project seemed to have been the key to retaining most of the $\mathrm{CHWs}$ in the project. However, inclusion of appropriate and adequate incentives, whether in kind or cash or in combination may have increased the motivation of the $\mathrm{CHWs}$ and further reduced attrition from the project.

This study served as a pilot study which, preceding the implementation of the national Home-Based Care (HBC) programme for childhood illnesses, which is currently being scaled up in other rural districts in the country. The HBC programme uses a model that is similar to the trial in using $\mathrm{CHWs}$ to implement the programme. Thus, the fact that the $\mathrm{HBC}$ is being integrated as part of the health system means that $\mathrm{CHWs}$ will work for periods exceeding that of the trial. Therefore, lessons from this study could be drawn to help in sustaining the use of $\mathrm{CHWs}$ in the $\mathrm{HBC}$ programme. Further, findings of this study could serve as baseline for future assessments of retention of CHWs in community based health programmes. 



\section{Chapter 7}

\section{Treating fever in children under five: Care giver Perceptions of Community Health Worker Services in Dangme West District, Ghana}

\section{Published as:}

Mercy Abbey, L Kay Bartholomew, Matilda Pappoe and Bart van den Borne "Treating fever in children under five: Care giver Perceptions of Community Health Worker Services in Dangme West District, Ghana": Int Health doi:10.1093/inthealth/ihv027. International Health Advance Access published April 29, 2015 


\section{Abstract}

Background: Integrated community case management of childhood illnesses is a key strategy to help reduce mortality in children under five; particularly those with difficult access to treatment. However the success of such strategies depends on community utilisation of services. This study assessed community utilization, perceptions and related factors of Community Health Worker services.

Methods: Data were gathered from a cross sectional survey among 562 care givers and focus group discussions among 84 care givers. Factors related to utilization of Community Health Workers for management of childhood fevers were analyzed using logistic regression and focus group discussions to explore care giver perceptions of $\mathrm{CHW}$ activities.

Results: Utilization of Community Health Workers for management of fever in under-fives was $59.4 \%$. Care givers who were exposed to the communication intervention were about four times more likely to use the services of the CHWs compared to those who were not exposed $(\mathrm{OR}=3.79$, $95 \% \mathrm{Cl}(2.62,5.49)),(\mathrm{P}<0.001)$. Farmers were $84 \%$ more likely to use $\mathrm{CHW}$ services for the sick child with fever compared to those who were unemployed (OR=1.84, 95\% Cl (1.00, 3.39) ( $p$-value=0.05). Care giver perceptions of the program were generally positive; most care givers expressed satisfaction with the Community Health Worker services, citing prompt treatment, friendliness and free medicines. Male involvement in the CHW program was comparatively low.

Conclusion: Dissemination of information among priority groups can enhance utilization of $\mathrm{CHW}$ services. Exploring the perspective of both men and women to gain in depth understanding on their views on male involvement will be useful for planning appropriate strategies to get more males involved in community based child health programs. 


\section{Introduction}

In Ghana, as in most parts of Sub Saharan Africa (SSA), childhood mortality rates are high, and majority of rural dwellers have poor access to facility-based health care. [20,54, 72]. Current efforts to improve availability and accessibility of health services include the integrated Community Case Management (iCCM) of childhood illnesses recommended by the World Health Organization (WHO) and the United Nations Children's Fund (UNICEF). $[18,143]$. Evidence indicates that community case management could potentially reduce childhood pneumonia and malaria-specific mortality in children under five by $70 \%$ [18] and $60 \%$ respectively; to address human resources and health care skill shortages, many countries are using volunteer Community Health Workers (CHWs) to deliver iCCM. [144] Malaria and pneumonia rank among the leading causes of mortality in children under-five in Ghana; contributing $25 \%$ and $20 \%$ respectively to the high mortality rate of 80 per 1,000 live births. [2] Studies have shown that CHWs appropriately trained and equipped with the needed tools, logistics support and adequate supervision can identify and appropriately treat childhood illnesses including malaria and pneumonia. $[13,14,17,20,96]$

Artemisinin-based combination therapy (ACT) such as artesunate amodiaquine is the recommended first-line treatment for uncomplicated malaria, and amoxicillin is recommended for pneumonia. Both of these drugs could be administered by CHWs in communities. However, by 2004, when the WHO and UNICEF, advocated for community-based case management of pneumonia, the official policy in Ghana was referral to a health facility for treatment. In response to the recommendations for community-based management of pneumonia, a randomized controlled trial was implemented in one rural district in Ghana between January 2006 and December 2009. By 2011, The Ministry of Health $(\mathrm{MOH})$ of Ghana began implementing 
community based care of malaria, Acute Respiratory Illnesses (ARI) and diarrhoea in children under five in selected districts throughout the country. [145]

During the trial, CHWs managed fever in children 2 to 59 months old. Additionally, project coordinators implemented a complementary health communication program targeted at household care givers/parents of children under five and other stakeholders to enhance awareness and utilization of CHWs. The program had a wide reach of about 16844 care givers of children under five (Abbey et. al. submitted). The 30 month trial reduced all-cause mortality by $30 \%$ and $44 \%$ among the study groups who received an anti-malarial (artesunate amodiaquine) and those receiving the anti-malarial in addition to an anti-biotic (Amoxicillin) respectively. [40]

This paper reports the rate of utilization and perceptions of $\mathrm{CHW}$ services by care givers of children under five. In addition, it examines what factors are related to the use of $\mathrm{CHW}$ services for fever in children under five in the Dangme West district. Information on utilization of $\mathrm{CHW}$ services and its related factors could inform the scale up of the current $\mathrm{CHW}$ program in Ghana.

\section{Methods}

\section{Study Setting}

The study site was Dangme West, one of ten Districts in the Greater Accra region of Ghana; with an estimated population of 109459 and 376 communities or villages. [10] Malaria transmission happens throughout the year, peaking during the rainy seasons in April and October. Each community has a leader or chief who is supported by a group of elders or opinion leaders. Inhabitants are predominantly of the Ga-Adangme ethnic group. The language commonly spoken within these communities is largely referred to as Dangme with slightly different linguistic pronunciation of words. The other ethnic groups living in the communities include Ewes and Akans who by and large speak the local dominant language. Majority of the inhabitants profess Christianity. 
The district is largely rural; divided into four administrative subdistricts: Dodowa, Prampram, Ningo and Osudoku. At the time of the study each sub district was served by a public health centre and few privately owned health facilities. These included four clinics, two maternity homes, two pharmacies and several over-the-counter medicine sellers (commonly called chemical sellers in Ghana). The Public Health facilities were situated in the sub district capitals. Many inhabitants lived more than $5 \mathrm{~km}$ away from health facilities, and road networks were poor within the district. Poverty was wide spread in the communities. Access to health facilities was poor. The inhabitants were predominantly subsistence farmers, fisher folks and petty traders.

\section{Overview of Intervention}

Details of trial design and implementation are described elsewhere. [146] In brief, $660 \mathrm{CHWs}$, averaging two per community or village were selected by their communities and trained by professional health staff. Selection of $\mathrm{CHWs}$ which was primarily done by the communities was influenced by the population density and size of the communities. The CHWs managed fevers in children aged 2 months to 59 months taken to them by their household care givers. CHWs worked in their homes and either treated or referred the severely ill children to the nearest health facility. In addition $\mathrm{CHWs}$ counseled care givers on medication administration and referral compliance (where necessary). Medicines provided were free of cost to the sick children. CHWs worked on voluntary basis and managed over 12000 sick children over a period of 30 months, between January 2006 and December 2009. [40] By the end of the trial, more $\mathrm{CHWs}$ were retained than those who left, with an attrition rate of $21.2 \%$. [38]

A complementary communications program was implemented in all communities. The messages were disseminated through oral presentations, audio tapes, mobile van and a locally produced video drama to enhance 
awareness and utilization of $\mathrm{CHW}$ services in the communities ( $\mathrm{M}$. Abbey et al in press). Key messages delivered covered the rationale of the study trial, the availability of trained CHWs in the communities for prompt and appropriate management of fevers in children under five and the importance of adhering to treatment and referral.

\section{Study design and population}

A cross sectional survey was conducted to assess utilization of $\mathrm{CHW}$ services for childhood fever and its related factors. Findings from this analysis were complemented by information from project records and those from focus group discussions (FGDs) held to explore community perceptions of the $\mathrm{CHW}$ program. The study populations were care givers of children under five living in the Dangme West district. A care giver was defined as any person - male or female - identified by household members as bearing the primary responsibility for an under five child in our study sample. This person may or may not be the biological parent or blood relation of the under-five child. The present study was conducted during the course of a larger study. In October 2009, approximately 700 children aged 2 to 59 months were selected through a random cluster sampling method to participate in a cross sectional survey. The present study recruited all care givers of the selected children for participation in the present study. Details of sample size determination and sampling strategy has already been reported elsewhere. [146]

A total of 12 FGDs involving a total of 84 Care givers were held between January 2010 and March 2010. Eight FGDs were held among females (55) and four among male (29) care givers. The groups were of the same sex with each group averaging seven participants. Eligibility criteria for inclusion in the FGDs were - must be a care giver of children under five, resident in the district during the period of project implementation. Project field supervisors recruited participants from the four sub districts 
prior to the day of the discussions. To capture variability in their experiences, the field supervisors purposively recruited care givers in communities with difficult access to facility services (communities farther away from the sub district capital where the public health facility is located) and care givers located closer to the public health facilities.

\section{Data Collection Cross-Sectional Survey}

Trained Research Assistants interviewed all Care givers who consented to participate in the survey with a pretested questionnaire that contained both open and closed ended questions. Data collection covered a period of four weeks in October 2009. Interviews were held in Dangme, the dominant language spoken in the communities. Information sought from the respondents included: Demographic characteristics of the care givers, whether or not care givers were aware of, or exposed to the $\mathrm{CHW}$ communications program ${ }^{1}$, Care givers' perceptions of the messages that were delivered and the main learnings from the messages. Other questions were: whether or not care givers utilized $\mathrm{CHWs}^{\prime}$ services for their under-five child sick with fever and care givers' perception of the $\mathrm{CHW}$ services.

\section{Variables}

The dependent variable used in this study was the utilisation of $\mathrm{CHW}$ services for a child under five years of age with fever. This variable was coded Zero if the care giver did not utilize $\mathrm{CHW}$ services for child's fever and One if the care giver utilised $\mathrm{CHW}$ services. The predictor variables were "Exposure to intervention", and demographic characteristics of respondents. These included: Education, coded into four categories: no education, primary, Junior Secondary School/Middle school, and secondary/higher education.

\footnotetext{
${ }^{1}$ Exposure to communications through any of the following means: oral presentations at community meetings, audio cassette messages or video drama messages.
} 
No education was used as the reference category. Marital status was categorised into two groups, married and single. Single is made up of those who have never married and those who are divorced, widowed, or separated. Single was used as the reference category. Ethnicity was coded into four categories, Akan, Ga-Adangme, Ewe and others. Ga-Adangme was used as the reference. Main occupation was coded into five categories: unemployed, farmer, artisan, trader and civil servant. Unemployed was used as the reference.

\section{Focus Group Questions and Procedures}

The purpose of the FGDs was to enable in-depth discussion of care givers' perceptions relating to the intervention. The FGDs were conducted between January and March 2010. The project team developed a discussion guide and complemented the guide questions with inductive leads, as topics emerged during the discussions. [65] The key topics introduced for discussion included participants' awareness of CHWs and their role in the communities, utilization and perception of $\mathrm{CHW}$ services, perceived benefits of the program and recommendations for improving the CHWs program. The FGDs were conducted by an experienced qualitative interviewer and an assistant who took notes. At the start of each session, the research team explained the aim of the study, assured confidentiality and anonymity and then obtained consent from participants to audio tape the sessions. Each discussion lasted about one hour to one hour thirty minutes and was held in Dangme, the commonly spoken language in the communities. 


\section{Data Analysis}

The data analyst double entered survey responses in EpiData statistical software version 3 (The EpiData Association, Odense, Denmark) and then imported the data into Stata ${ }^{\circledR} 12$ SE for analysis. The dependent variable was compared with socio-demographic characteristics of the care givers. A logistic regression analysis was carried out to identify predictors of utilisation of $\mathrm{CHW}$ case management of fever in children under five. We analysed data on 562 care givers for whom data was complete. The results are expressed as odds ratios with accompanying $95 \%$ confidence intervals.

The verbatim transcripts of the focus group discussions were translated from Dangme into the English language by the note taker and merged with notes taken during the discussion.

All identifying information was removed. [142] The data analyses approach was deductive, combining our pre-determined themes with those emerging from the FGD participants. The first author and a social scientist first analyzed transcript individually then jointly compared notes and resolved coding discrepancies. Results presented contain direct quotes from participants.

\section{Survey Results}

\section{Demographic characteristics}

Demographic characteristics of the respondents presented in Table 1 shows that most of the respondents were between $26-45$ years of age, $58.0 \%$ (326/562), 82.9\% (466/562) were married and 32.4\% (182/562) had no formal education. 
Table 1: Demographic Characteristics of Respondents

\begin{tabular}{|c|c|c|}
\hline Variables & $N=562$ & $\%$ \\
\hline \multicolumn{3}{|l|}{ Age } \\
\hline $15-25$ & 208 & 37.0 \\
\hline $26-45$ & 326 & 58.0 \\
\hline 46 plus & 28 & 5.0 \\
\hline \multicolumn{3}{|l|}{ Sex of respondent } \\
\hline Male & 6 & 1.1 \\
\hline Female & 556 & 98.9 \\
\hline \multicolumn{3}{|l|}{ No. of children } \\
\hline $1-3$ & 324 & 57.7 \\
\hline $4-6$ & 189 & 33.6 \\
\hline $7+$ & 48 & 8.5 \\
\hline \multicolumn{3}{|l|}{ Education } \\
\hline None & 182 & 32.4 \\
\hline Primary & 157 & 27.9 \\
\hline JSS /middle school & 201 & 35.8 \\
\hline Secondary/SSS & 22 & 3.9 \\
\hline \multicolumn{3}{|l|}{ Ethnicity } \\
\hline Dangme & 328 & 58.4 \\
\hline Akan & 4 & 0.7 \\
\hline Ewe & 191 & 34.0 \\
\hline Northern/others & 39 & 6.9 \\
\hline \multicolumn{3}{|l|}{ Marital Status } \\
\hline Never married & 96 & 17.1 \\
\hline Married & 466 & 82.9 \\
\hline \multicolumn{3}{|l|}{ Employment } \\
\hline Unemployed & 77 & 13.7 \\
\hline Farmer & 239 & 42.5 \\
\hline Artisan & 55 & 9.8 \\
\hline Trader & 183 & 32.6 \\
\hline Civil servant & 8 & 1.4 \\
\hline
\end{tabular}




\section{Care givers' Awareness, Knowledge and Utilization of CHW Services}

Table 2 presents care giver awareness of campaign messages, knowledge of $\mathrm{CHWs}$ in the communities, use of $\mathrm{CHW}$ services and care giver actions taken for child's fever.

On awareness or exposure to program campaign messages, $56.05 \%$ (315/562) of care givers indicated personal awareness through participation in the campaign activities. However, a majority, 93.06\% (523/562) of care givers reported that they had knowledge about $\mathrm{CHWs}$ in their communities. Though some did not participate personally in the campaign activities, they got to know about CHWs in their communities from other sources including their spouses, friends and other members of the community.

Overall, 59.4\% (334 /562) of the respondents in this study had used CHW services for child's fever at least once within the 30 month intervention period. A review of survey data overtime revealed a gradual progression in access to CHW services. An initial access rate of $26.4 \%$ (169/640) was recorded in April 2008. Thereafter an increase in CHWs access was recorded at $54.9 \%$ (502/914) by October 2008. However by April 2009 the access rate slightly fell at a ratio of $51.7 \%$ (415/802) and increased to $59.4 \%$ (334/562) by October 2009. Regarding fever, in the four weeks preceding the survey, $43.8 \%$ $(246 / 562)$ of care givers reported fever in their under -five children. Actions taken or treatments given for the child's fever ranged from traditional common knowledge approaches of treatment to orthodox methods of providing treatment.

The results show that first line of action by the respondents was that, when their children were observed to have fever, they were given tepid sponging 91.2\% (513/562), a little over a third of the respondents either used leftover medicine available at home $37.9 \%$ (208/562), sought care from an over- the -counter medicine seller $36 \%$ (202 /562), sought care from the CHWs $34.8 \%$ (196/562) and about a third 30.3\% (170/562) sought care from a health facility. 
Table 2: Awareness, Knowledge and Utilization of CHW Services among Caregivers $(\mathrm{N}=562)$

\begin{tabular}{|c|c|c|}
\hline Themes & Yes \% (n) & No $\%(n)$ \\
\hline \multicolumn{3}{|l|}{ Awareness \& Knowledge } \\
\hline Awareness of campaign messages on $\mathrm{CHW}$ programs & $56.05(315)$ & $43.95(247)$ \\
\hline Knowledge about CHWs in own community & $93.06(523)$ & $6.94(39)$ \\
\hline \multicolumn{3}{|l|}{ Utilization } \\
\hline Ever used CHW services for child's fever & $59.43(334)$ & $40.57(228)$ \\
\hline Child had fever 4 weeks prior to survey & $43.8(246)$ & $56.22(316)$ \\
\hline \multicolumn{3}{|l|}{ Action Taken/Treatment Given } \\
\hline Use of left over medicine available at home & $37.9(208)$ & $62.98(354)$ \\
\hline Sought care from over - the - counter medicine seller & $36.0(202)$ & $360(64.05)$ \\
\hline Sought care from a CHW & $34.88(196)$ & $65.12(366)$ \\
\hline Sought care from a health facility & $30.3(170)$ & $69.75(392)$ \\
\hline Tepid sponged the child & $91.28(513)$ & $8.7(49)$ \\
\hline Gave enema at home & $9.8(15)$ & $97.33(547)$ \\
\hline Gave herbal medicine & $6.6(37)$ & $93.41(525)$ \\
\hline Did nothing, waited for a while & $3.7(21)$ & $96.26(541)$ \\
\hline Use of other alternatives & $0.4(2)$ & $99.64(560)$ \\
\hline
\end{tabular}




\section{Perceptions of messages delivered and Main learnings}

Respondents were asked about their perceptions of the communications that were delivered to the community. Of the $56.05 \%$ who either saw or heard the communications, 55.8\% (314/562) reported that the messages delivered were appropriate. The same proportion found the messages understandable and acceptable. The main learnings from the communications include: $\mathrm{CHW}$ drugs are free of cost $42.1 \%$ (237/562), how to sponge a child with fever $41.2 \%$ (232/562), the benefit of taking a child with fever promptly to CHW for treatment $38.6 \%$ (217/562), CHWs provide prompt treatment $30.0 \%$ (169/562), CHWs live close to community members $26.6 \%$ (150/562) and care givers should administer the full dosage as prescribed by the CHW to the sick child $17.7 \%(100 / 562)$.

\section{Perceived Quality of Service}

Of the 59.4\% (334/562) care givers who ever utilized CHW services, $45.0 \%$ (253/562) perceived the quality of the services received as "good" while $13.7 \%$ (77/562) described the service as "excellent." The rest $0.71 \%$ (4/562) assessed the services as "fair". The majority, 58.9\% (331/562) indicated they would recommend the $\mathrm{CHW}$ who attended to them to other care givers. The main positive aspects of care mentioned by participants were: effectiveness of medication $40.75 \%$ (225/562), friendliness of $\mathrm{CHW}$ $34.7 \%$ (195/562), free medication 32.4\% (182/562) and easy accessibility of CHW 18.3\% (103/562). Few of the dislikes expressed by the participants were unavailability of CHWs when needed $1.25 \%$ (7/562) and unfriendliness of CHW 0.89\% (5/562). 
Logistic Regression of Utilization of CHW Service by Care givers of Children under five by Exposure

Table 3 presents results of utilization of $\mathrm{CHW}$ services by exposure to the communication intervention. The results indicate that Care givers who were exposed to the intervention are about four times more likely to use the services of the $\mathrm{CHWs}$ compared to those who were not exposed ( $\mathrm{OR}=3.79$, $95 \% \mathrm{Cl}(2.62,5.49)),(\mathrm{P}<0.001)$. In addition, the odds of using the $\mathrm{CHW}$ services is $16 \%$ higher for people with a higher number of children $(O R=1.16$, $95 \% \mathrm{Cl}(1.03,1.31))(p$-value $=0.05)$. Further, the results show that farmers are more likely to use $\mathrm{CHW}$ services for the febrile child compared to those who are unemployed $(\mathrm{OR}=1.84,95 \% \mathrm{Cl}(1.00,3.39)$ ( $p$-value $=0.05)$

The focus group discussions were held to explore community perceptions of the $\mathrm{CHW}$ program. The results are reported by main themes: Awareness of $\mathrm{CHWs}$ in the communities and source of information, utilization and perceptions of CHW Services in the communities, perceived benefits of the $\mathrm{CHW}$ work in the community, learnings from campaign messages and recommendations for program improvement. Direct quotes from participants are shown in Table 4.

Awareness of $\mathrm{CHWs}$ in the communities and source of information: Awareness of the $\mathrm{CHW}$ program though widespread among participants, differed in depth between female and male groups. Females appeared more 
Table 3: Logistic Regression of Utilization of CHW Service by Care givers of children Under Five by Exposure

\begin{tabular}{|c|c|c|c|}
\hline Variable & OR & P-Value & $95 \% \mathrm{CI}$ \\
\hline Exposure to $\mathrm{CHW}$ program-Yes & 3.79 & $0.000 * * *$ & $(2.62,5.49)$ \\
\hline \multicolumn{4}{|l|}{ Age } \\
\hline \multicolumn{4}{|l|}{ (Ref: $15-25)$} \\
\hline $26-45$ & 0.85 & NS & $(0.54,1.35)$ \\
\hline 46 plus & 0.62 & NS & $(0.22,1.75)$ \\
\hline Number of Children & 1.16 & $0.02 * *$ & $(1.03,1.31)$ \\
\hline Sex (Female) & 2.32 & NS & $(0.35,15.46)$ \\
\hline \multicolumn{4}{|l|}{ Education } \\
\hline \multicolumn{4}{|l|}{ (No education) } \\
\hline Primary & 1.10 & NS & $(0.67,1.81)$ \\
\hline JSS/Middle school & 1.23 & NS & $(0.75,2.01)$ \\
\hline Secondary/SSS & 0.89 & NS & $(0.31,2.51)$ \\
\hline \multicolumn{4}{|l|}{ Ethnicity } \\
\hline \multicolumn{4}{|l|}{ (Ga Adangme) } \\
\hline Akan & 1.00 & NS & $(0.11,9.30)$ \\
\hline Ewe & 1.31 & NS & $(0.87,1.97)$ \\
\hline Northern & 1.13 & NS & $(0.52,2.46)$ \\
\hline Marital Status (Single) & 1.04 & NS & $(0.63,1.72)$ \\
\hline \multicolumn{4}{|l|}{ Married } \\
\hline \multicolumn{4}{|l|}{ Occupation (Unemployed) } \\
\hline Farmer & 1.84 & $0.05^{* *}$ & $(1.00,3.39)$ \\
\hline Artisan & 0.87 & NS & $(0.39,1.93)$ \\
\hline Trader & 1.19 & NS & $(0.65,2.17)$ \\
\hline Civil Servant & 0.86 & NS & $(0.26,2.84)$ \\
\hline Constant & 0.13 & NS & $(0.02,1.09)$ \\
\hline
\end{tabular}

Note: Values are odds ratios

$* * *, * *$ denote significant at $1 \%$ and $5 \%$ levels respectively. NS: Not significant 
knowledgeable on the different programs and reported personal involvement in various meetings and activities. On the other hand, men mostly indicated their wives, friends or other community members as their source of information. Further, female participants demonstrated a better understanding of services rendered by $\mathrm{CHWs}$ than males. This knowledge was apparent as they explained the role and activities of $\mathrm{CHWs}$ in the community.

Utilization and perception of CHW services in the communities: More female participants than males reported ever use of $\mathrm{CHW}$ services for treatment of their child's fever. A recount of care givers' last visit to the CHWs suggested a general satisfaction with the quality of service. Specifically participants made reference to prompt treatment, friendliness and counseling on medication adherence.

On the other hand, reasons care givers gave for non-utilisation of the services of CHWs were mostly, perceived poor attitude of CHWs, existing interpersonal conflict between care givers and CHWs, lack of trust and perception of ineffectiveness such as CHWs' refusal to treat ineligible children (above 5 years), CHWs refusal to administer additional medicines within the same month on account of relapse.

Perceived benefits of the CHW work: the most cited benefit by care givers was that of the efficacy of the medicine in treating fever resulting in a reduction in reported fever cases among children in the community compared to the time before the intervention. Other benefits included easy access or proximity to the $\mathrm{CHW}$ which reduced or led to the elimination of costs related to care seeking and the need for transportation. In addition care givers reported some change in community perceptions about the cause of some illnesses for example convulsion. 
Learnings from campaign messages: Though various strategies were used for information dissemination, the video seems to have been readily recollected more than the talks and audio messages via the mobile van.Participants reported that scenes from the video drama made lasting impressions on them, especially those who attended the sessions. The messages were easy to understand and lessons from video scenes easy to recollect.

Recommendations for Improving CHW program: Most discussants indicated the intention and willingness to recommend the services of the $\mathrm{CHWs}$ to other care givers. However others were reluctant. The common trend in the responses was that the $\mathrm{CHWs}$ ' work in the communities should be maintained despite the challenges. However, solutions recommended by discussants to the perceived challenges were mostly external to the discussants as almost all their recommendations were directed at government.

When asked why they, as a beneficiary community, did not keep their promise about motivating $\mathrm{CHWs}$, they responded that they were as equally in need of help as the CHWs since they were all living in the same community and had similar needs.

Table 4: Responses from Focus Group Discussions

Themes

Awareness of

CHW work in the

community

\section{Quotes from care givers}

"The CHWs were selected by us (the community) and they went for training to give medication to children with fever in the community. When they finished the training, they were introduced to the community for us to know" (female participant)

"It was my wife who made me know about them (the CHWs)..." (Male participant)

"Yes, I know (about CHWs) but I don't deal with them" (male participant). 
Utilization and perception

of CHW services in the

communities
Reasons for not using

CHWs: Care Givers'

Perspective
"... The CHW attended to me and my wife quickly and after few questions he gave us the drugs. After 3 days the child's fever subsided." (Male participant)

"When I went he was in the kitchen and as soon as he saw me he stopped. He sells biscuits so he gave my child a biscuit to stop crying and he attended to us. He later came to my house to see the child's condition" (Female participant)

"I sent the child myself to the CHW and narrated what was happening to the child. The CHW asked questions and then gave us the drugs and explained to us how to give the drugs". (Male participant)

"I personally have nothing against them, but few community members who have problems with them refused to go there for treatment... also people complain that some (CHWs) behave as if they know it all (Female participant);

"Some may prefer the clinic to the CHWs because of lack of trust". (Female Participant)

"My wife told me she sent our six year old sick child there but was told the boy was above age." (Male participant).

$\mathrm{He}$ (CHW) told me to give it morning and evening for three days, when I gave the child the drug, the following day the hedola was the same, so I sent the child to the clinic." (Female participant) 
Perceived benefits of the CHW work

Learnings from campaign messages

Recommendations for Improving CHW program
"Before the introduction of the drugs, children frequently fell sick, especially with hedola, but now the hedola has reduced in the community." (Female Participant)

"We used to spend money sending our children to the clinic, but now we have free access to drugs and we don't travel long distances again." (Female participant)

"Some of us had beliefs that evil forces were the cause of fever and convulsion in children but with the education, that belief has changed" (Male participant"

"I learned that when CHW gives medicine for the child's ailment, the child should complete the full course."(Female participant).

"What I learned is that when a child has fever, not to tepid sponge from the head but from the feet upwards."(Female participant)

"Since I watched the video I always remember what I saw and never forget because it is like a picture in my mind" (Female participant)

The government should pay some allowances to keep CHWs motivated. "(Male participant)

"They (government) should re-consider the age limit... age restriction on the eligibility of children should be extended to cover 10 year olds, as children at older ages also largely depended on their parents. (Male participant)

"CHWs should not be engaged in other paying jobs so that they can be available to the community all the time (Female Participant) 


\section{Discussion}

This study assessed community utilization and related factors as well as community perceptions of the CHW program in the Dangme West District. Female participants appeared to be more aware of $\mathrm{CHWs}^{\prime}$ existence and knowledgeable about CHW activities in the communities than the males. Utilization of CHW services for children under five with fever was fairly high among caregivers in the study with over $50 \%$ having used the services of the $\mathrm{CHWs}$ at least once. Care giver Perceptions of the program were generally positive; most care givers expressed satisfaction with the $\mathrm{CHW}$, citing prompt treatment, friendliness and free medicines.

The level of knowledge about CHWs in the communities was very high (93.06\%) among care givers in the communities included in this study. Evidence from a recent review [34]showed that awareness campaigns to improve care giver knowledge of appropriate medications for illnesses were associated with use of $\mathrm{CHWs}$ for treatment of childhood illnesses. This might have explained the fairly high utilization rate of $59.43 \%$ of $\mathrm{CHW}$ services by care givers of children under five found in this study. Awareness and knowledge of the program was more prevalent among female participants in the focus groups than their male counterparts. Given that women have traditionally been responsible for care of the sick child at the household level, it is possible the men in these communities were less inclined to participate in such activities; a finding reported by others. [147, 148]

Utilization of CHWs for treatment of fever episodes four weeks prior to our study is satisfactory and falls within the range of $2 \%$ to $59 \%$ reported in the literature. $[22,81,82,149,151]$ In the study in Western Uganda where a lower rate was reported than our study, the authors attribute the reason to their inability to implement the behaviour change communication component of their intervention. [81] On the other hand, a study in the Dangme west district conducted prior to this study reported a higher rate of 96\%. [86] However, the study was limited to one out of the four sub districts, unlike the present study which covered the entire district. The level of overall 
utilization founding our study is acceptable and promising and suggests that effective communication and engagement of community members are important factors that can influence utilization of $\mathrm{CHW}$ services. Consequently, even with limited package in the delivery of $\mathrm{CHW}$ services, care givers may still utilize such services when adequate efforts are put in place to generate demand; underscoring the fact that, successful dissemination leads to exposure which in turn facilitates utilization. It is, thus, not surprising that our study found awareness (exposure) to be significantly related with utilization of $\mathrm{CHW}$ services. Care givers who reported being aware of the communications were about four times more likely to use services of the CHWs compared with non-exposed care givers (OR=3.79, 95\% Cl (2.62, 5.49)), ( $P<0.001)$. Further, utilization of $\mathrm{CHW}$ services was significantly associated with occupation as shown in Table 3. The finding that farmers were four times more likely to utilize CHW services for their child's fever compared with care givers who are unemployed might be due to the fact that the farmer is more available and stable in the community after returning from farm in the day time, and therefore more likely to access CHWs services in their communities. Comparatively, the unemployed living in the community; may be commuting daily or often to nearby urban areas seeking job opportunities for income to meet daily needs. [38] As such, other household members may be playing the role of care seeking for the sick child.

From our focus groups, factors that facilitated utilization of $\mathrm{CHW}$ services include proximity to $\mathrm{CHW}$ location, perceived quality of care and availability of free medicine. Similar findings have been reported in a study in a rural district in Uganda where caregivers who lived closer to $\mathrm{CHWs}$ were more likely to use CHWs; conversely, caregivers who lived closer (within a kilometer) to a health facility were less likely to use $\mathrm{CHWs}$ compared to those who resided farther away from a health facility. [22] 
Suggested modifications by focus group participants included treatment for more diseases, extension of eligibility to cover children aged up to 10 years and an increase in the range of medicines to cover other childhood illnesses. On one hand, while the recommendation could be a sign that care givers see CHWs as being effective and therefore want them to address further needs, on the other hand, this could undermine the rationale for targeting under-fives as the most vulnerable group to "fever". This may have policy and program implications especially in the face of limited supply and costs.

Findings indicate positive changes including improvements in management of fevers in children under five and particularly changes in the perceptions and knowledge about causes and treatment of convulsions. These are consistent with findings reported in a study in Tanzania [152] where community members reported positive changes in knowledge and management of convulsion episodes as a result of educational campaigns held in the communities. This finding is encouraging as several previous studies found that care givers associated cause of convulsion with supernatural factors and therefore delayed or sought inappropriate care. [59, 153].

A general observation by care givers suggested that there was a decrease in the episodes of fever in children under five years leading to a reduction in childhood deaths in their communities and the whole district. This perception is corroborated by the overall outcome of our study intervention that showed a reduction in all-cause mortality among the children studied. [40] Perceptions such as these can be important for public health interventions. Communities having confidence in such interventions by the health care system could provide a strong foundation to roll out other effective community based interventions. It also means it is more likely to promote early care seeking from these CHWs to prevent complications caused by delays in seeking appropriate care. 
Finally, majority of care givers found the messages disseminated understandable, appropriate and acceptable. This could be attributed to the level of community involvement in the design and production of the communication materials. Further, the added elements of entertainment to its educational value, may have sustained their interest. Similar communication approaches have been used effectively in rural settings for example in Tanzania. [154] .

\section{Limitations}

The study limitations included limited variables in assessing care giver utilization of CHWs. Care seeking practices are multifaceted and influenced by various factors including distance to $\mathrm{CHW}^{\mathrm{s}}$ location and household poverty. Given that respondents and $\mathrm{CHWs}$ lived in the same communities, a possible reporting bias from respondents in the face- to- face interviews could have occurred. Respondents may have provided socially desirable responses rather than a true reflection of the real life situation for fear of offending CHWs or their relatives; resulting in incomplete and socially biased information. Furthermore recall bias was a possibility given that care givers were asked to remember issues about events that took place in the past. However, the use of triangulation through both quantitative and qualitative data may have minimized such biases. The authors recognize that the study was cross sectional thus, causal inferences cannot be made. Nonetheless, the study findings provide useful insights informing program planning and implementation in other similar settings. Particularly for Ghana, this information is useful for scaling up the home based care involving CHWs. 


\section{Conclusion}

Communities were largely exposed to the program through involvement in various program related activities. These included selecting CHWs from and for their own communities, information sharing on the training and skills acquired by the CHWs, the expected role of care givers themselves and other stakeholders including the community at large, project staff and professional health staff. The use of a multimedia approach especially the video drama acted by community members to promote the role model story of prompt and appropriate care seeking for childhood fevers may have enhanced exposure leading to utilization of $\mathrm{CHW}$ services.

The expression of satisfaction among the few men who showed interest in the services of the CHWs can be acknowledged in comments of willingness to recommend services of $\mathrm{CHWs}$ to others; and also allowing their wives to utilise $\mathrm{CHW}$ services for the sick child.

This paper contributes to the understanding of factors that are related to utilization of CHWs in community-based health volunteer programs; however, further research is needed to explore issues from the perspective of both men and women care givers of under-fives to gain in depth understanding on their views on male involvement. Such information could be useful in planning appropriate strategies to get men more involved in community based child health programs. 


\section{Chapter 8}

General Discussion 

In developing countries, especially in rural areas in Sub Saharan Africa (SSA), malaria and pneumonia are major causes of morbidity and mortality among children under five [1] Many of these deaths occur at home or within the community due to poor access to health care $[1,54]$.

Factors contributing to this poor access are many and include on one hand: lack of policy, supply issues and high costs of health care [7] and on the other, poor geographic access to health care facilities, financial barriers; Care giver perceived poor attitudes of health care providers, care giver understanding of the illness, and the practice of self-medication [3, 7-9].

To improve access to care, community-based interventions for common childhood illnesses have been introduced to complement formal health care services. For example the Home Management of Malaria (HMM) strategy, introduced in the 1990s aimed to provide treatment close to homes or within communities especially in areas that lacked diagnostic facilities [10] . Under this strategy, all children with fever were treated presumptively as having malaria using anti malarials alone [11).

Reviews have shown the feasibility and effectiveness of involving CHWs in HMM and have reported substantial reductions in childhood mortality and severe morbidity. For instance, a trial in Ethiopia reduced mortality by $40 \%$ [14] and in Burkina Faso, prompt treatment of children with uncomplicated malaria with pre-packaged anti- malarials reduced progression to severe malaria by 50\% [12]. However, the HMM approach was ineffective against other non-malaria febrile conditions or illnesses such as pneumonia (which symptoms similar to malaria), were often inappropriately treated with anti-malarials only, resulting in delayed treatment for pneumonia $[15,16]$.

In 2004, WHO and UNICEF recommended community treatment of pneumonia as part of integrated community case management (iCCM) of common childhood illnesses. This approach enables treatment for multiple 
common childhood illnesses including malaria, pneumonia and diarrhoea [19] and is increasingly adopted by many developing countries based on evidence of its effectiveness in achieving high treatment coverage and improved access to prompt treatment. [11, 17, 82, 156] For example $69 \%$ of under-fives in Nepal are reported to have access to treatment due to experience with community based management of childhood illnesses [17]. In addition, initial studies conducted in Sub Saharan Africa on iCCM concur on the feasibility, acceptability, and usefulness of the iCCM approach. $[40,81$, 157]

In 2010 (after the completion of the present study) malaria case management policy changed from the presumptive to test-based approach using a rapid diagnostic test (RDT) before initiating drug treatment. [13]. Using a test based approach enables parasitological confirmation to differentiate malaria from other common causes of childhood illnesses [21].

Between 2006 and 2009, a cluster randomized controlled trial was implemented in the Dangme West district of Ghana to train CHWs for the treatment of fever among children 2-59 months of age [40]. Recognizing the importance of demand generation activities to promote and ensure adequate use of services for program success, the present study, guided by the Intervention Mapping (IM) protocol [41] designed a health communication program to complement the trial. The program (reported in chapter 4 of this thesis) was implemented in all communities and had a wide reach of about 16844 (Abbey et al; in press).

This thesis is based on the health communication component of the trial and this final chapter provides a discussion of the results of the main studies presented in this thesis. It also raises important methodological and practical issues that should guide interpretation of the results. Finally, the chapter discusses implications of the findings for programmatic action and further research. 


\section{Main Results}

The role of Community Health Workers in improving access to health care

Community Health Workers (CHWs) play a crucial role in the provision of very basic health services in remote areas in many developing countries particularly in areas with limited access to health care facilities [22]. Evidence from several country reviews have shown that $\mathrm{CHWs}$ provided with adequate training, logistics supply and supervision can identify and appropriately treat childhood illnesses including malaria and pneumonia [17].

The term "community health worker" generally refers to lay persons selected and trained to carry out one or several functions related to health care. CHWs are known by different names in different countries such as Village Health Volunteers (VHWs), Community Drug Distributers (CDDs), and Community Based Agents (CBAs). They are often of varied demographic backgrounds such as age, sex, marital status and education[22] . A common definition proposed by the WHO is that: "Community health workers should be members of the communities where they work, should be selected by the communities, should be supported by the health system but they are not necessarily a part of its organization, and have shorter training than professional workers"[23].

Typically, after selection, CHWs are trained using a simplified version of the Integrated Management of Childhood Illness curriculum to , identify, and treat sick children or refer them if they have danger signs [140].

Involving CHWs in the provision of health programs has been in existence for many years [22] and is based on the philosophy endorsed in the Alma Ata Declaration of 1978 that emphasized among other things, Universal primary health care (PHC) and 'bringing health care as close as possible to where people live and work'[23] CHWs gained much prominence internationally with their involvement in $\mathrm{PHC}$ programs established by many countries post Alma Ata as a means of attaining "Health for All". 
Although some trials involving $\mathrm{CHWs}$ in health care delivery contributed to substantial reductions in childhood mortality and severe morbidity, $[12,14,24,25]$ the problem of high rates of $\mathrm{CHW}$ attrition varying between $3.2 \%$ and $77 \%$ [24-26] coupled with other program related factors including poor selection criteria and training, inadequate financial motivation, lack of community support, heavy workload and sociocultural environments [25, 27-30] have raised concerns about the sustainability of programs involving $\mathrm{CHWs}$. The negative effect of high rates of attrition on the continuity of established relationships between $\mathrm{CHWs}$, the community they serve and the health system as well as increased costs involved in the selection and training of new $\mathrm{CHW}$ s have been noted [22, 25].

Due to the important role of CHWs in health care delivery, it is critical to adapt strategies to improve the retention and motivation of $\mathrm{CHWs}$ in low income areas. CHW programmes can be a good investment though they are not cheap or easy to maintain [25].

\section{Selection and retention of $\mathrm{CHWs}$ in community based programmes}

The effectiveness of the work of CHWs is largely influenced by their relationship with the communities in which they work. The selection, training and supervision of $\mathrm{CHWs}$ should therefore be done with the involvement of the community [26].

In the present study, CHW attrition rate in a district in Ghana in a 30 month period was $21.2 \%$ [38] which is lower than that reported for community based interventions in Senegal, Nigeria and Kenya [26, 29]. This low attrition rate may have been achieved due to the high level of community involvement in the selection process such as consultations between project staff, health workers and the communities with the community playing the lead role in proposing criteria as well as in nominating persons whom they thought could better perform the role of the CHWs. The selection was done transparently at community meetings with traditional and opinion leaders 
present in most communities. The participation of all stakeholders improved the credibility of the selection process leading to subsequent acceptance of CHWs and thereby reducing attrition rates. In addition, involvement of the community by the project team in other programme activities such as the development and implementation of the communication programme may have sustained their interest.

Our strategy of re-introducing CHWs after their training back to their communities; and subsequently done on a continuing basis as part of the awareness creation programme was useful and served as a source of motivation for CHWs. This was revealed in the focus group discussions with CHWs who remained till project end. Further, the monitoring visits conducted once every two weeks by project field coordinators to provide continuous education and to restock $\mathrm{CHW}$ supplies; as well as the periodic refresher training offered to improve $\mathrm{CHWs}^{\prime}$ skills, served as a platform for addressing various concerns for the $\mathrm{CHWs}$; similar to the findings elsewhere [103].

A community's active and comprehensive involvement in $\mathrm{CHW}$ programmes facilitates the achievement of programme objectives. The direct involvement of communities in the selection of $\mathrm{CHWs}$ has demonstrated improvement in community participation in $\mathrm{CHW}$ programmes and uptake of the services provided by CHWs. [12, 25, 30] Furthermore, community participation influences the motivation and retention of $\mathrm{CHWs}$ and contributes to programme sustainability $[26,158]$.

The factors that influence $\mathrm{CHW}$ selection are varied and the process of selecting CHWs involves several steps such as setting a criteria, nomination by the community, self-volunteerism of a candidate, and open acceptance by the selected candidate [26]. Despite the importance of community roles in the selection process, evidence from CHW programmes show community's involvement has been mostly limited to identifying and nominating $\mathrm{CHW}$. 
Though programme staff may have a predefined selection criteria, community inputs in the criteria are critical due to their extensive knowledge of the community and what factors may improve $\mathrm{CHW}$ retention and sustainability. For instance, the evaluation of a project in Ethiopia revealed that project staff consultations with intervention communities yielded a 16 step criteria for selection of CHWs whereas the programme staff in their planning prior to meeting the communities had predefined "literacy" as the only selection criteria. In another instance, availability of the selected individual at all times and being responsible were deemed by local communities in Guatemala as the critical attributes for persons to qualify as a $\mathrm{CHW}[26]$.

The CHW selection process as simple as it may seem, is complicated particularly when communities are not well informed about the role and functions of the CHWs. In some cases, the decision on the $\mathrm{CHW}$ candidate may be taken by only community leaders or a unanimous decision by all community members. For example, an evaluation study found that $45 \%$ of CHWs selected by community leaders in a programme were all kinsmen of a chief or sub-chief. Furthermore, in Swaziland where the choice was made by the local chief and his council, an evaluation revealed favouritism and greed shrouded the CHW selection process. This is in contrast to the experience in the Saradidi community in Kenya where selecting a CHW was done collectively by the community and in a transparent manner (As reported by Kaseje (1987).

In some settings however, conflicts do arise in this process due to family, religious and ethnic allegiances. Not only are social marketing, communication and community participation embedded in $\mathrm{CHW}$ programmes to mitigate conflicts in misinformation and misunderstanding of the $\mathrm{CHW}$ selection process but they also serve to create demand and manage community expectations of a trained $\mathrm{CHW}$. CHW program staff knowledge of local contexts and settings is critical in averting compromising of the $\mathrm{CHW}$ selection process by communities. This is crucial because communities 
without adequate understanding of the role of the $\mathrm{CHWs}$ are less likely to give the CHWs the necessary support and "may not understand their own role in improving their health" [26].

Attrition rate reported in a Community Health Volunteer programme in Senegal was 60 percent over a two year period mainly because community leaders had disqualified women and representatives of community groups at community meetings held to select $\mathrm{CHWs}$. The disqualification of these groups of people substantially reduced the pool of eligible persons qualified for the role of $\mathrm{CHW}$. Subsequently, in the next round of selection, programme staff ensured extensive consultations with and among all community level stakeholders. This resulted in a drastic reduction of $\mathrm{CHW}$ attrition over five years [26]

\section{Planning and developing health promotion programs}

Health promotion interventions are often implemented as part of efforts to change people's behaviour to improve their health and or quality of life. Many authors have argued for a systematic approach for development and reporting of theory and evidence based interventions [41, 101, 103]. Systematic programme planning makes for better understanding of the processes and also easier for replication by other scientists $[41,101]$.

Intervention Mapping (IM) [41] is a framework that offers a systematic approach to intervention planning, development, implementation, and evaluation. IM is a six-step process for the systematic planning of health promotion programs using theory and evidence. The protocol has guided the planning and development of health promotion programs for many different health problems. Recent examples include cancer screening [42], smoking [44], obesity [113], chronic disease selfmanagement [46]; sexuality and HIV/AIDS, [47, 48] hearing loss [49], antiretroviral treatment adherence [50] and physical activity. [51]. 
Each step of the IM approach systematically guides planners through producing an intervention and evaluation that is based on theory and evidence. Though the steps are linear, the process is cyclical and therefore allows for adaptation between steps throughout the process. Each of the six steps of IM comprises several tasks. The completion of the tasks in each step leads to products that inform the subsequent step, and the completion of all steps creates a "blueprint" for designing, implementing, and evaluating the intervention. The six steps of IM are: 1 . needs assessment, 2. formulation of change objectives matrices, 3 . selection of theory-based methods and practical applications, 4 . creation of intervention components and materials, 5. development of an adoption and implementation plan, and 6 . development of an evaluation plan.

Step 1: Needs Assessment: This step comprises of collecting, analyzing, and interpreting available data that may possibly contribute to program planning and development. The process here also involves describing the problem, the behaviours and environmental factors that cause the problem, among whom, and in what context. In step 2, the specific behaviours required (performance objectives) to solve the identified problem are described and crossed with their determinants (personal and external) in matrices to create a logic model of change for the intervention. In step 3 , the change objectives in the matrices are linked to practical applications derived from theoretical methods (i.e., a general technique, derived from theory for behaviour change). In step 4, actual development of program is achieved. The practical applications listed previously are organized into one program with regard to the intended participants and context. Program producers (e.g. graphic artists, communication specialists) are notified of their tasks and program is pretested and piloted. In Step 5 potential users of the program including decision makers to ensure program success are identified. In step 6, the final step of IM, an evaluation plan is completed. This plan allows planners to assess whether or not a program was successful in achieving set goals. 
To promote prompt and appropriate care seeking for fever in children under five, we planned and designed a multi component program that comprises elements to influence behaviour of care givers of children, community health workers (CHWs), professional health care providers and the wider community.

Application of the IM process [41] provided a useful framework for the systematic development, implementation and process evaluation of our program. Whether the same results would have been achieved without a systematic process is doubtful. The formative study results in step 1, provided insight into the problem of a community knowledge gap on pneumonia as a potentially deadly disease and the seeming absence of a local name for it. The results also showed inadequate response to fever as well as the related factors at the individual and external levels. For example, factors contributing to the inappropriate response to fevers were found to be inadequate understanding by care givers and parents that fever can be related to either malaria or pneumonia and that both need urgent care.

Care givers reported that malaria is a serious disease, but the local language did not appear to have a single word for pneumonia. The household survey showed high intention to seek care for childhood fevers from trained CHWs and perceived benefits and behavioural control(confidence) [110] about their ability to take a sick child to a $\mathrm{CHW}$ if available as well as positive subjective norms regarding use of a $\mathrm{CHW}$ for childhood fever.

It became apparent that our campaign or message focus should be on fevers rather than on pneumonia or disease specific messages; given that community knowledge about pneumonia was inadequate and further that they had no local name for pneumonia. On the other hand, fever is a wellknown common overlapping symptom for both malaria and pneumonia 
$[20,56]$ therefore it was appropriate to use "fever" in our program to represent both malaria and pneumonia or to refer to febrile illnesses in general; Moreover, the community was not required to diagnose the type of febrile illness at their level given that the two diseases of focus (malaria and pneumonia) are not easily distinguishable in the absence of appropriate diagnostic tools.

Our use of video tape recorded messages facilitated the reach of a wider audience in a shorter time and with standardised messages than the commonly used health education strategy of face - to -face oral presentations commonly used in the Dangme West communities. Oral deliveries are more prone to dilution by the implementers as compared with audio or video tape recorded messages. Further the video shows were appropriate because its target audience captures those who did not own TV sets and could have missed out on the messages if they were aired by television stations. The video shows were not encumbered by lack of electric power in the rural communities and the shows facilitated immediate post video show audience surveys. Given the low literacy level among the care givers, face to face interviews were better suited. The strategy of playing music via the mobile van also served as a form of entertainment and attracted many to gather around to listen and dance, making it easy to recruit participants and to sustain their interest for the activity.

Our continuous involvement of relevant stakeholders in various aspects of the program fostered a sense of ownership among the community. It also enabled us to obtain feedback on processes during program development and implementation. Working with a local drama troupe to produce the drama/video role model story ensured that the characters and issues were of cultural relevance and created identifiable (credible) characters dealing with familiar day to day issues. These processes involving the dramatization of issues made it more acceptable to the community because they could easily relate with the people and the issues. 
Through the application of IM, we were able to establish a logical planning process for the design, implementation and process evaluation of a community based program for community management of childhood fevers in a rural district in Ghana.

As revealed through our post intervention community survey, a majority, $93.06 \%$ (523/562) of care givers had knowledge about CHWs in their communities. More than half, $59.4 \%$ of care givers had used $\mathrm{CHW}$ services at least once for management of fever in their under-fives. Further, Care givers who were exposed to the communication intervention were about four times more likely to use the services of the CHWs compared to those who were not exposed [39].

The systematic and detailed planning could account for the success in achieving our program goals. Finally, our description of the process in the public domain (Open access peer reviewed Journal) provides insights that may be replicated by other scientists interested in planning theory and evidence-based interventions in community settings.

\section{Methodological considerations}

The studies reported in this thesis have various strengths and limitations that should be noted when interpreting the results. A reflection on the quality of the methodological issues pertaining to these studies can also guide future research where appropriate.

\section{Strengths}

Several of the studies reported in this thesis adopted a mixed methods design comprising both quantitative and qualitative data collection approaches (reported in chapters 2, 4, 6 and 7) ; providing a broader perspective on the issues under investigation. Triangulation, or the use of multiple methods, helps to overcome the limitations implicit in each individual type of method and also helps to validate the research findings based on the different approaches. 
The qualitative approach used in the formative studies and in particular the use of video enhanced access to more terminologies and words in the local dialect [66]. Such terminologies are useful for incorporation into design of effective intervention programs [75] (reported in chapters 2 and 3) of this thesis. Further the mixed methods design proved useful in confirming perceptions expressed in the quantitative and qualitative responses about pneumonia and treatment practices in the study among community care givers (also reported in Chapter 2 ) and about community perceptions of $\mathrm{CHW}$ services reported in chapter 7. Furthermore, the In-depth interviews and focus group discussions provided detailed explanation of the quantitative responses, which validated knowledge gathered from the responses as true reflections of opinions and beliefs of the respondents.

\section{Limitations}

One key limitation of the studies reported in this thesis is that they focused more on exploring community perceptions of care seeking rather than behaviors and practices. Perceptions are in reality different from practices; thus those studies may have under/over reported on treatment seeking behaviors and practices of care givers for children with fever. The survey questions administered through face-to-faceinterviews; may have been subject to interviewer-respondent interaction effects on responses to some questions. There is a possibility that respondents provided socially desirable responses rather than what they actually thought or did; however, our inability to use the self- administered questionnaire method which may have reduced this form of bias was due to the high levels of illiteracy in the rural communities. Regarding the use of the video, one common weakness is the tendency of captivating the study participants by what they see to the extent that they can be distracted from the main issues [66]. 
A limitation that transcends the various studies is the fact that our study (the communication component) was designed to complement and run in tandem with a larger study whose design was predetermined such that we could not choose a design that would have been more suitable for our purposes. Ideally, an experimental or quasi-experimental design would have made it possible to assess the impact of our program on care seeking behaviour for childhood fever; however, as we worked within a larger study that was already designed with a step wedged approach, the other option for us would have been to follow up the care givers recruited at time intervals. We were unable to use such a design because the sample for each subsequent survey changed and therefore it was not possible to deal with the same group of care givers to enable comparison.

As a consequence, our studies were cross-sectional making it impossible to draw conclusions on whether the underlying beliefs mentioned by care givers in the initial studies caused subsequent behaviour regarding care seeking or whether they are merely related. However, results from process evaluation studies conducted soon after implementation of program activities, indicated positive results.

\section{Conclusion}

The various studies contribute on one hand to the understanding of the factors involved in designing effective programs for community involvement in community based interventions to improve treatmentseeking in rural settings and on the other hand, factors contributing to motivation and retention of $\mathrm{CHWs}$ in community health programs. Many authors have argued for a systematic approach for development and reporting of theory and evidence based interventions [41, 101-103] Providing adequate information about the design process and intervention implementation could promote the understanding of how effective interventions are made and further enables other scientists and practitioners to replicate such interventions. 


\section{Implications for policy, programs and future research}

The findings of the studies reported here are of immediate relevance to public health advancement. The potential of $\mathrm{CHWs}$ to contribute to public health services in general and improvement in access to community health care has been documented for malaria and pneumonia control in Ghana $[18,19]$ as in other SSA countries. The success of this trial as demonstrated by the outcome of the various intervention components provides useful information for scaling up more active engagement of the community and the relevant stakeholders. In Ghana's bid to increase access to health care through the use of CHWs particularly in rural areas where majority of the population reside.

This study was conducted in a period just preceding the implementation of the national Home-Based Care programme for childhood illnesses involving CHWs in Ghana, thus, lessons and findings from this study informed some aspects of the national program including criteria setting for selection of CHWs, community mobilization activities and development and implementation of demand generation activities to enhance utilization of services. Further, some of the studies may serve as baseline for future assessments of participation and retention of CHWs in community based health programmes.

Factors affecting health seeking behaviours are multifaceted. Further research is needed to explore issues from the perspective of both men and women care givers of under-fives to gain in depth understanding on their views on male involvement. Such information could be useful in planning appropriate strategies to get men more involved in community based child health programs as highlighted in chapter 6 of the present thesis. 
Valorization 
This section highlights the societal relevance of the findings of this thesis for communities, organizations, policy and programs. It also discusses implications for improved management of childhood illnesses at the community level and proposes areas for future research.

\section{Relevance and knowledge value}

In developing countries with high childhood morbidity and mortality rates and poor accessibility to health care, utilisation of community members to manage childhood illnesses such as fevers within their communities can contribute to the reduction of morbidity and mortality among children. In Ghana as in other parts of the developing world, malaria and pneumonia constitute a huge public health challenge with children under-five being the most vulnerable. To reduce mortality from febrile illnesses, integrated community case management (i-CCM) of childhood illnesses including malaria and pneumonia has been introduced to provide easy access to treatment in areas with difficult access to health care facilities [72].

Community perceptions of malaria and treatment seeking behaviour have been widely studied in Ghana and elsewhere and have shown that mothers had knowledge to recognize symptoms suggestive of malaria [3, 59, 61]. However, in Ghana, little has been documented about community awareness, knowledge, perceptions and management of childhood pneumonia particularly in the study district. Therefore, we assessed community perceptions of pneumonia for the purpose of informing the design and implementation of context specific health communication strategies for appropriate care seeking behaviour for childhood pneumonia.

Through the use of a mixed method approach we gained a comprehensive perspective of care givers knowledge and management of childhood fever illnesses including pneumonia. The study revealed that majority of respondents had never heard the name pneumonia and therefore did not know about the signs and symptoms.

The low awareness and inadequate recognition of pneumonia implies that affected children may not receive prompt and appropriate treatment as their caregivers may misdiagnose the illness. Based on the study findings, and 
guided by the Intervention Mapping protocol, we were able to design and implement a multi component health communication program that aimed at influencing behavior of care givers of under-fives, community health workers, health care providers and the wider community towards improved care seeking to reduce morbidity and mortality among children under five.

\section{Innovation}

\section{The areas of innovation include:}

The use of the Intervention Mapping (IM) protocol to guide our program design and implementation was novel in our study district. IM, a six- step tool enabled the systematic planning, development and implementation of our multi- component health promotion program. We used theory, evidence from the literature, formative research, and community participation in the design and implementation that led to the realization of our program goals. Whether the same goals would have been obtained without a systematic process is doubtful.

\section{Program implementation}

Our use of video tape recorded messages and drama in the communities facilitated the coverage of a wider audience in a shorter time and with standardised messages than the commonly used strategy of to face-to-face oral presentations sometimes used in the study district and elsewhere. Oral deliveries are more prone to dilution by the implementers as compared with audio or video tape recorded messages.

Further, the video shows were appropriate because its target audience captures those who did not own TV sets and could have missed out on the messages if they were aired by television stations. The video shows were not encumbered by lack of electric power in the rural communities and the shows facilitated immediate post video show audience surveys. The strategy of playing music via the mobile van also served as a form of entertainment and 
attracted many to gather around to entertain themselves through dancing, making it easy to recruit participants and to sustain their interest for the activity.

Overall, Working with a local drama troupe to produce the drama/video role model story ensured that the characters and issues were of cultural relevance and created identifiable (credible) characters dealing with familiar day to day issues. These processes involving the dramatization of issues made it more acceptable to the community because they could easily relate with the people and the issues.

\section{Target}

Our findings are targeted at various stakeholders including International organisations that support child health such as the World Health Organization and UNICEF. Local Health policy makers and program managers of child health and malaria control programs, District Directors of health services and the community level, chiefs and elders and NGO executives.

\section{Implications for implementation and research}

Our study served as a pilot which preceded the implementation of the national Home-Based Care (HBC) programme for childhood illnesses. The $\mathrm{HBC}$ programme uses a model that is similar to our trial in using $\mathrm{CHWs}$ to implement the programme. As $\mathrm{HBC}$ is being integrated as part of the health system, particularly in rural areas, lessons from this study were drawn to help shape the national program.

The researcher became a member of the National Coordinating Committee for Malaria Control in Ghana and has contributed to the development of the National Implementation Guidelines for Malaria Control in Ghana; as well as other educational materials for malaria control. 
Socio- economic value and risk

The effectiveness of the educational aids produced by the project in communicating the messages is being further tested for adoption by the National Malaria Control Programme of Ghana for scaling up home management of fevers in the country. 



\section{Summary}

To improve access to care, integrated community case management (iCCM) of common childhood illnesses have been introduced to complement formal health care services.

The iCCM approach enables treatment for multiple common childhood illnesses including malaria, pneumonia and diarrhoea and is being adopted by many countries.

Following WHO's recommendation on community management of childhood pneumonia, the Ghana Health Service implemented a pilot randomized controlled trial between 2006 and 2009, in the Dangme West district. The trial aimed to operationalize the approach of using CHWs to manage malaria and pneumonia at the community level and to assess the impact of the intervention on under-five mortality in the study district.

Community based interventions can yield useful results, however demand generation activities are needed alongside to ensure adequate utilization and success. Therefore, to complement this trial, the present study, guided by the Intervention Mapping (IM) protocol for systematic planning of programs, developed and implemented health promotion interventions targeted at household caregivers/parents of children under five and other stakeholders to create community awareness of, and promote prompt and appropriate care seeking for fever in under- fives. The current thesis is based on the health communication component of the trial. This section summarizes the various studies reported in this thesis.

Chapters 2and 3 present findings from formative studies conducted for the purpose of informing the design and implementation of context specific health communication messages/strategies for appropriate and prompt care seeking behaviour for childhood fever illnesses in the study district. In Chapter 2, we assessed community perceptions and practices of treatment seeking for childhood pneumonia in children under-five. 
A mixed methods design was adopted for the study. Data were obtained from eight focus group discussions with 56 caregivers of underfives; A caregiver was defined as the person whom household members regarded as having primary responsibility of caring for a child under five. Eight in-depth interviews with community Key Informants (KIIs) and a cross sectional household surveys among 501 care givers. The caregivers were randomly selected through a multi-stage sampling technique.

The qualitative study was conducted by a social scientist together with a note taker and the Principal Investigator while the quantitative study was conducted using an interviewer-administered questionnaire. Questions included socio-demographic variables (age, sex, parity, education, marital status, religion, occupation and ethnicity) as well as caregiver recognition of childhood pneumonia and its treatment seeking practices. (Assessment of pneumonia was based on the criteria used by Integrated Management of Childhood Illnesses criteria i.e. the presence of cough, difficult or fast breathing with or without fever).

Findings from the quantitative study showed majority of the respondents were inadequately informed about pneumonia. Few indicated they had ever heard the name pneumonia and could neither state any symptoms of pneumonia. Very few suggested a word in Dangme for pneumonia and each name mentioned, varied.

Results from the FGDs and key Informant interviews also showed little knowledge of the disease pneumonia and its treatment seeking practices among the participants. Pneumonia or breathing difficulties were not mentioned or perceived as leading causes of Under-five mortality in the district. There appeared to be no common or single word for pneumonia in the local dialect.

However, the intention to use CHWs services for treatment of childhood fever was high . Intention was positively associated with marital status and birth parity. Married respondents were more likely than the unmarried to use services of the CHWs. The use of these services also increases with an increasing parity. 
In chapter 3, we sought to explore caregivers' salient beliefs about seeking care for children Under 5 with fever from a CHW.The study reported in chapter 3 was nested within the household cross sectional survey on community perceptions and practices of treatment seeking for pneumonia (reported in chapter 2). In the present study we conducted a belief elicitation study (based on the Reasoned Action Theory) [76] among the 501 caregivers sampled for the larger formative study. In line with the RAA, we selected and stated the behaviour of interest in terms of action, target, context and time. The behaviour selected for elicitation was "taking your child under 5 with fever to the CHW immediately you notice that the child has fever". The phrase: "taking your child" reflects action, "child under 5" is the target, "with fever" is the context and "immediately" relates to the time frame communicating the urgency with which action needs to be taken. This is in line with "prompt care seeking" defined by WHO as adequate treatment received within 24 hours of onset of illness; recommended to prevent the illness from progressing from mild symptoms to severe complications. [72]

Subsequently, as recommended by the authors of the theory, six open-ended questions were asked, two on each of the determinants of intention; to identify the underlying beliefs about: salient consequences (related to attitude), underlying beliefs about social referents (related to perceived norms) and beliefs underlying salient circumstances of performing the selected behaviour (related to perceived behavioural control):

The results showed that parents of the child were predominantly perceived as the referents for seeking immediate care for the child's fever with the $\mathrm{CHW}$. Almost all respondents reported that no one will disapprove of their decision to utilize CHWs except where the people are not sure of the ability of the $\mathrm{CHW}$ and the efficacy of the drugs. Distance to the location of the CHW expressed as "proximity" or "nearness" was perceived as the main facilitator for using $\mathrm{CHW}$ services for the child's fever. On the other hand, financial constraint, or unfriendly $\mathrm{CHWs}$ were seen to be a hindrance. The 
findings suggest that factors including prompt treatment, proximity, cost and inter-personal aspects of care are key to caregiver's expectations. The findings reported in chapters two and three formed part of the building blocks for our program development and demand generation for prompt and appropriate care seeking and treatment utilization for childhood fever.

Chapter 4 describes the application of the IM protocol to design and implement a multi component program, designed with elements to influence the determinants of the behaviour of caregivers of children under five, $\mathrm{CHWs}$, professional health workers and community leaders regarding management of childhood fevers through theoretically based methods that included modeling, persuasion and skills training; and strategies including video and audio recordings and training.

Process evaluation results of various intervention components implemented were positive. For example communication activities reached a wide audience who also found the messages communicated acceptable, appropriate and understandable. Further, more $\mathrm{CHWs}$ were retained on the program, with a moderate rate of attrition of $21.2 \%$ over the 30 month period of intervention.

In Chapter 5, the study aimed to assess the adherence of CHWs to dosing and referral guidelines. We reviewed and analyzed records of consultations of children with fever, managed by CHWs in the study district. Appropriate use of drugs was defined as the provision of the correct drug pack(s) for the child's age group. Symptoms requiring referral were categorized into: danger signs; respiratory distress and symptoms indicating other illnesses. Multivariate logistic regression examined symptoms most likely to be noted as requiring a referral and those associated with a provision of written referral. The study found that most children received the appropriate drug and CHWs' adherence to dosing guidelines was high. Adherence to referral guidelines was however inadequate. 
Chapter 6 presents findings from a mixed methods study that examined CHW attrition and correlates of attrition. Attrition rates were abstracted from the $\mathrm{CHW}$ database built as part of the project. Information contained in the database included socio demographic characteristics of CHWs such as age, sex, educational level attained, marital status, occupation, and total number of children ever had. The reasons for, or correlates of, attrition were analysed from data from face to face interviews $(N=520)$ and focus group discussions ( $\mathrm{N}=5$ ) among $\mathrm{CHWs}$ who stayed till end of the project.

The findings showed a relatively moderate rate of attrition over the intervention period of 30 months. Attrition was comparatively higher in younger age groups than the older ones. The approval of a $\mathrm{CHW}$ by community and the CHW's immediate family were positively related to the probability of remaining in the programme. Results of the focus group discussions revealed that motivation for retention was related to the desire to serve their communities, humanitarian and religious reasons.

Chapter 7 assessed Caregiver Perceptions of Community Health Worker Services in the study district using a mixed methods design. The results showed that a majority, 93.06\% (523/562) of caregivers had knowledge about CHWs in their communities. More than half, $59.4 \%$ of care givers had used $\mathrm{CHW}$ services at least once for management of fever in their under-fives. Further, Caregivers who were exposed to the communication intervention were about four times more likely to use the services of the $\mathrm{CHWs}$ compared to those who were not exposed (OR=3.79, $95 \% \mathrm{Cl}(2.62$, 5.49)), ( $P<0.001)$.

More female participants than males reported ever use of $\mathrm{CHW}$ services for treatment of their child's fever. A recount of caregivers' last visit to the CHWs suggested a general satisfaction with the quality of service. Specifically participants made reference to prompt treatment, friendliness and counseling on medication adherence. On the other hand, reasons some 
caregivers gave for non-utilisation of the services of CHWs were mostly, perceived poor attitude of $\mathrm{CHWs}$, existing interpersonal conflict between caregivers and $\mathrm{CHWs}$.

Chapter 8 provides a general discussion of the main studies presented in this thesis. It also discusses the results in the light of the existing literature and highlights the strengths and limitations of these studies. The implications of the research findings for policy, program and further research are discussed. 
References 
1. Black RE, Cousens S, Johnson HL, Lawn JE, Rudan I, Bassani DG, Jha P, Campbell $\mathrm{H}$, Walker $\mathrm{CF}$, Cibulskis R: Global, regional, and national causes of child mortality in 2008: a systematic analysis. The Lancet 2010, 375(9730):1969-1987.

2. Ghana Statistical Service (GSS), Ghana Health Service (GHS), Macro International Inc (MII): Ghana Demographic and Health Survey. In. Calverton, Maryland: Ghana Statistical Service, GHS, MI Inc.; 2008: 136.

3. Ruebush TK, Kern MK, Campbell CC, Oloo AJ: Self-treatment of malaria in a rural area of western Kenya. Bull World Health Organ 1995, 73(2):229-236.

4. World Health Organization: The Roll Back Malaria strategy for improving access to treatment through home management of malaria: World Health Organisaztion; 2005.

5. Black RE, Morris SS, Bryce J: Where and why are $\mathbf{1 0}$ million children dying every year? The Lancet 2003, 361(9376):2226-2234.

6. Garg R, Omwomo W, Witte JM, Lee LA, Deming MS: Care Seeking During Fatal Childhood Illnesses: Siaya District, Kenya, 1998. American Journal of Public Health 2001, 91(10):1611-1613.

7. Whitty C, Chandler C, Ansah E, Leslie T, Staedke SG: Deployment of ACT antimalarials for treatment of malaria: challenges and opportunities. Malar J 2008, 7.

8. Gill CJ, Young M, Schroder K, Carvajal-Velez L, McNabb M, Aboubaker $S$, Qazi S, Bhutta ZA: Bottlenecks, barriers, and solutions: results from multicountry consultations focused on reduction of childhood pneumonia and diarrhoea deaths. Lancet 2013, 381(9876):14871498.

9. World Health Organization: Scaling up home-based management of malaria: from research to implementation. In: Geneva: World Health Organization. 2004.

10. Justice Nonvignon, Moses K Aikins, Margaret A Chinbuah, Mercy Abbey, Margaret Gyapong, Bertha N A Garshong, and SF, John O Gyapong: Treatment choices for fevers in children under-five years in a rural Ghanaian district. Malaria Journal 2010, 9(188). 
11. Pagnoni F: Malaria treatment: no place like home. Trends in parasitology 2009, 25(3):115-119.

12. Gyapong M, Garshong B: Lessons learned in home management of malaria: implementation research in four African countries. Geneva: WHO/TDR; 2007.

13. Sirima SB, Konate A, Tiono AB, Convelbo N, Cousens S, Pagnoni F: Early treatment of childhood fevers with pre packaged antimalarial drugs in the home reduces severe malaria morbidity in Burkina Faso. Tropical Medicine \& International Health 2003, 8(2):133-139.

14. Kidane $\mathrm{G}$, Morrow RH: Teaching mothers to provide home treatment of malaria in Tigray, Ethiopia: a randomised trial. The lancet 2000, 356(9229):550-555.

15. Källander K, Nsungwa-Sabiiti J, Peterson S: Symptom overlap for malaria and pneumonia-policy implications for home management strategies. Acta tropica 2004, 90(2):211-214.

16. Kallander K, Hildenwall H, Waiswa P, Galiwango E, Peterson S, Pariyo $G$ : Delayed care seeking for fatal pneumonia in children aged under five years in Uganda: a case-series study. Bull World Health Organ 2008, 86(5):332-338.

17. World Health Organization: WHO/UNICEF joint statement: management of pneumonia in community settings: UNICEF; 2004.

18. Theodoratou E, Al-Jilaihawi S, Woodward F, Ferguson J, Jhass A, Balliet M, Kolcic I, Sadruddin S, Duke T, Rudan I: The effect of case management on childhood pneumonia mortality in developing countries. International journal of epidemiology 2010, 39(suppl 1):i155-i171.

19. Young M, Wolfheim C, Marsh DR, Hammamy D: World Health Organization/United Nations Children's Fund Joint Statement on Integrated Community Case Management: An Equity-Focused Strategy to Improve Access to Essential Treatment Services for Children. The American journal of tropical medicine and hygiene 2012, 87(5 Suppl):6-10. 
20. Yeboah-Antwi K, Pilingana P, Macleod WB, Semrau K, Siazeele K, Kalesha P, Hamainza B, Seidenberg P, Mazimba A, Sabin L: Community case management of fever due to malaria and pneumonia in children under five in Zambia: a cluster randomized controlled trial. PLoS Medicine 2010, 7(9):e1000340.

21. World Health Organization: Guidelines for the treatment of Malaria Second edition. Geneva, . 2010.

22. Mukanga D, Tibenderana JK, Peterson S, Pariyo GW, Kiguli J, Waiswa P, Babirye R, Ojiambo G, Kasasa S, Pagnoni F: Access, acceptability and utilization of community health workers using diagnostics for case management of fever in Ugandan children: a cross-sectional study. MalarJ 2012, 11:121.

23. Lehmann $U$, Sanders D: Community health workers: What do we know about them? The state of the evidence on programmes, activities, costs and impact on health outcomes of using community health workers. World Health Organization 2007:41.

24. WHO: Strenthening the performance of community health workers in primary health care In: Technical report series. Geneva: WHO; 1989.

25. Haines A, Sanders D, Lehmann U, Rowe A.K, Lawn J.E, Jan S, Walker D.G, Z B: Achieving child survival goals: potential contribution of community health workers. The Lancet 2007, 369(9579):2121-2131.

26. Bhattacharyya $K$, Winch $\mathrm{P}$, LeBan $\mathrm{K}$, Tien $\mathrm{M}$ : Community health worker incentive and disincentives: How they affect motivation, retention, and sustainability. In. Arlington, Virginia: BASICS II; 2001.

27. Walt $G$, Perera $M$, Heggenhougen $K$ : Are large-scale volunteer community health worker programmes feasible? The case of Sri Lanka. Social Science \& Medicine 1989, 29(5):599-608.

28. Khan SH, Chowdhury A, Karim F, Barua MK: Training and retaining shasthyo shebika: reasons for turnover of community health workers in Bangladesh. The Health Care Manager 1998, 17(1):37. 
29. Olang'o CO, Nyamongo IK, Aagaard-Hansen J: Staff attrition among community health workers in home-based care programmes for people living with HIV and AIDS in western Kenya. Health Policy 2010, 97(2-3):232-237.

30. Ofosu-Amaah V: National experience in the use of community health workers. A review of current issues and problems. . In. Geneva: WHO 1983: 70:71-49.

31. Syed Moshfiqur Rahman, Nabeel Ashraf Ali, Larissa Jennings, M Habibur R Seraji, Ishtiaq Mannan, Rasheduzzaman Shah, Arif Billah AlMahmud, Sanwarul Bari, Daniel Hossain, Milan Krishna Das et al: Factors affecting recruitment and retention of community health workers in a new born care intervention in Bagladesh. Human Resourcesfor Health 2010, 8(12).

32. Lehmann $U$, Sanders D: Community health workers: what do we know about them: The state of the evidence on programmes, activities, costs and impact on health outcomes of using community health workers. In. Geneva: World Health Organization; 2007: 1-42.

33. Kok MC, Dieleman M, Taegtmeyer M, Broerse JE, Kane SS, Ormel H, Tijm MM, de Koning KA: Which intervention design factors influence performance of community health workers in low-and middleincome countries? A systematic review. Health policy and planning 2015, 30(9):1207-1227.

34. iCCM: Integrated Community Case Management (iCCM) Evidence Review Symposium 3-5 March 2014, Accra Ghana. In.; 2014.

35. McCollum R, Gomez W, Theobald S, Taegtmeyer M: How equitable are community health worker programmes and which programme features influence equity of community health worker services? A systematic review. BMC public health 2016, 16(1):1.

36. Mukanga D, Tibenderana JK, Peterson S, Pariyo GW, Kiguli J, Waiswa P, Babirye R, Ojiambo G, Kasasa S, Pagnoni F: Access, acceptability and utilization of community health workers using diagnostics for case management of fever in Ugandan children: a cross-sectional study. MalarJ 2012, 11. 
37. Kiwanuka S, Ekirapa E, Peterson S, Okui O, Rahman MH, Peters D, Pariyo G: Access to and utilisation of health services for the poor in Uganda: a systematic review of available evidence. Transactions of the Royal Society of Tropical Medicine and Hygiene 2008, 102(11):1067-1074.

38. Abbey M, Bartholomew LK, Nonvignon J, Chinbuah MA, Pappoe M, Gyapong M, Gyapong JO, Bart-Plange $C$, van den Borne B: Factors related to retention of community health workers in a trial on community-based management of fever in children under 5 years in the Dangme West District of Ghana. International health 2014.

39. Abbey M, Bartholomew LK, Pappoe M, van den Borne B: Treating fever in children under five: caregiver perceptions of community health worker services in Dangme West district, Ghana. International health 2015:ihv027.

40. Chinbuah MA, Kager PA, Abbey M, Gyapong M, Awini E, Nonvignon J, Adjuik M, Aikins M, Pagnoni F, Gyapong JO: Impact of Community Management of Fever (Using Antimalarials With or Without Antibiotics) on Childhood Mortality: A Cluster-Randomized Controlled Trial in Ghana. The American Journal of Tropical Medicine and Hygiene, 87(5 Suppl):11-20.

41. Bartholomew LK, Parcel GS, Kok G, Gottlieb NH, Fernandez ME: Planning health promotion programs: an intervention mapping approach: Jossey-Bass; 2011.

42. Scarinci IC, Bandura L, Hidalgo B, Cherrington A: Development of a Theory-Based (PEN-3 and Health Belief Model), Culturally Relevant Intervention on Cervical Cancer Prevention Among Latina Immigrants Using Intervention Mapping. Health Promotion Practice 2012, 13(1):29-40.

43. Suzuki R, Peterson JJ, Weatherby AV, Buckley DI, Walsh ES, Kailes JI, Krahn GL: Using Intervention Mapping to Promote the Receipt of Clinical Preventive Services Among Women With Physical Disabilities. Health Promotion Practice 2012, 13(1):106-115.

44. Dalum P, Schaalma H, Kok G: The development of an adolescent smoking cessation intervention-an Intervention Mapping approach to planning. Health education research 2012, 27(1):172-181. 
45. Lloyd JJ, Logan S, Greaves CJ, Wyatt KM: Evidence, theory and context-using intervention mapping to develop a school-based intervention to prevent obesity in children. Int J Behav Nutr Phys Act 2011, 8:73.

46. Detaille SI, van der Gulden JW, Engels JA, Heerkens YF, van Dijk FJ: Using intervention mapping (IM) to develop a self-management programme for employees with a chronic disease in the Netherlands. BMC public health 2010, 10(1):353.

47. Mkumbo K, Schaalma H, Kaaya S, Leerlooijer J, Mbwambo J, Kilonzo G: The application of Intervention Mapping in developing and implementing school-based sexuality and HIV/AIDS education in a developing country context: The case of Tanzania. Scandinavian journal of public health 2009, 37(2 suppl):28-36.

48. Mikolajczak J, Kok G, Hospers HJ: Queermasters: Developing a Theory and Evidence? Based Internet HIV? Prevention Intervention to Promote HIV?Testing among Men who have Sex with Men (MSM). Applied Psychology 2008, 57(4):681-697.

49. Fernandez $M$, Bartholomew $L$, Alterman $T$ : Planning a multilevel intervention to prevent hearing loss among farmworkers and managers: a systematic approach. J Agric Saf Health 2009, 15(1):4974.

50. Bruin MD, Hospers H, Borne HVD, Kok G, Prins J: Theory-and evidence-based intervention to improve adherence to antiretroviral therapy among HIV Infected patients in the Netherlands: A pilot study. AIDS Patient Care \& STDs 2005, 19(6):384-394.

51. Brug J, Oenema A, Ferreira I: Theory, evidence and Intervention Mapping to improve behavior nutrition and physical activity interventions. International Journal of Behavioral Nutrition and Physical Activity 2005, 2(1):2.

52. Fishbein $M$, Ajzen I: Predicting and changing behavior: The reasoned action approach: Taylor \& Francis; 2011.

53. Unicef, WHO: Pneumonia the forgotten killer of children. New York, Geneva: The United Nations Children's Fund (UNICEF). World Health Organization (WHO) 2006. 
54. Schellenberg J, Victora C, Mushi A, de Savigny D, Schellenberg D, Mshinda H, Bryce J: Tanzania Integrated Management of Childhood Illness MCE Baseline Household Survey Study Group. Inequities among the very poor: health care for children in rural southern Tanzania. Lancet 2003, 361(9357):561-566.

55. Winch PJ, Gilroy KE, Wolfheim C, Starbuck ES, Young MW, Walker LD, Black RE: Intervention models for the management of children with signs of pneumonia or malaria by community health workers. Health Policy Plan 2005, 20(4):199-212.

56. Kallander K, Nsungwa-Sabiiti J, Peterson S: Symptom overlap for malaria and pneumoniaâ€"policy implications for home management strategies. Acta Tropica 2004, 90(2):211-214.

57. Brown ENL: Early appropriate home management of fevers in children aged 6 months to 6 years in Ghana. Geneva: WHO-TDR 2001.

58. Hausmann Muela S: Community understanding of malaria, and treatment-seeking behaviour, in a holoendemic area of southeastern Tanzania. University of Basel; 2000.

59. Ahorlu CK, Dunyo SK, Afari EA, Koram KA, Nkrumah FK: Malaria related beliefs and behaviour in Southern Ghana: Implications for treatment, prevention and control. Tropical Medicine \& International Health 1997, 2(5):488-499.

60. Obol J, David Lagoro K, Christopher Garimoi O: Knowledge and Misconceptions about Malaria among Pregnant Women in a PostConflict Internally Displaced Persons' Camps in Gulu District, Northern Uganda. Malaria Research and Treatment 2011, 2011.

61. Asante KP, Abokyi L, Zandoh C, Owusu R, Awini E, Sulemana A, Amenga-Etego S, Adda R, Boahen O, Segbaya S: Community perceptions of malaria and malaria treatment behaviour in a rural district of Ghana: implications for artemisinin combination therapy. BMC Public Health 2010, 10(1):409.

62. Hussain R, Lobo MA, Inam B, Khan A, Qureshi AF, Marsh D: Pneumonia perceptions and management: an ethnographic study in urban squatter settlements of Karachi, Pakistan. Social Science \& Medicine 1997, 45(7):991-1004.

63. Irimu G, Nduati R, Wafula $E$, Lenja J: Community understanding of pneumonia in Kenya. African health sciences 2008, 8(2). 
64. Gálvez CA, Modeste N, Lee JW, Betancourt H, Wilkins RL: Peruvian mothers' knowledge and recognition of pneumonia in children under 5 years of age. Revista Panamericana de Salud Pública 2002, 11(2):99-108.

65. Monique Hennink, Inge Hutter, Bailey A: Qualitative Research Methods. London: Sage publishers; 2011.

66. Ryan $\mathrm{GW}$, Martinez $\mathrm{H}$, Pelto $\mathrm{GH}$ : Methodological issues for eliciting local signs/symptoms/illness terms associated with acute respiratory illnesses. Archives of medical research 1995, 27(3):359365.

67. Hildenwall H, Rutebemberwa E, Nsabagasani X, Pariyo G, Tomson G, Peterson S: Local illness concepts-implications for management of childhood pneumonia in eastern Uganda. Acta tropica 2007, 101(3):217-224.

68. Källander K, Tomson G, Nsabagasani X, Sabiiti JN, Pariyo G, Peterson S: Can community health workers and caretakers recognise pneumonia in children? Experiences from western Uganda. Transactions of the Royal Society of Tropical Medicine and Hygiene 2006, 100(10):956-963.

69. Agyepong IA: Malaria: Ethnomedical perceptions and practice in an Adangbe farming community and implications for control. Social Science \&amp; Medicine 1992, 35(2):131-137.

70. Bryce J, Boschi-Pinto C, Shibuya K, Black RE: WHO estimates of the causes of death in children. The lancet 2005, 365(9465):1147-1152.

71. Malaria [http://www.who.int/mediacentre/factsheets/fs094/en/]

72. Young $M$, Wolfheim C, Marsh DR, Hammamy D: World Health Organization/United Nations Children's Fund joint statement on integrated community case management: an equity-focused strategy to improve access to essential treatment services for children. American Journal of Tropical Medicine and Hygiene 2012, 87(5):6.

73. Breman JG, Egan A, Keusch GT: The intolerable burden of malaria: a new look at the numbers. 2001.

74. Agyepong IA: Malaria: ethnomedical perceptions and practice in an Adangbe farming community and implications for control. Social Science \& Medicine 1992, 35(2):131-137. 
75. Middlestadt SE, Bhattacharyya K, Rosenbaum J, Fishbein M, Shepherd $M$ : The use of theory based semistructured elicitation questionnaires: formative research for CDC's Prevention Marketing Initiative. Public Health Reports 1996, 111(Suppl 1):18.

76. Fishbein $M$, Ajzen I: Predicting and changing behavior: The reasoned action approach. 2010.

77. Bai Y, Middlestadt S, Joanne Peng CY, Fly A: Psychosocial factors underlying the mother's decision to continue exclusive breastfeeding for 6 months: An elicitation study. Journal of human Nutrition and dietetics 2009, 22(2):134-140.

78. Herath CS: Eliciting Salient Beliefs are Critical to Predict Behavioral Change in Theory of Planned Behavior. In: International Scientific Ph D and Post Docs Conference 2010: 2010; 2010: 1-6.

79. Downs DS, Hausenblas HA: Elicitation studies and the theory of planned behavior: a systematic review of exercise beliefs. Psychology of sport and exercise 2005, 6(1):1-31.

80. Abbey M, Chinbuah MA, Gyapong M, Bartholomew LK, van den Borne $B$ : Community perceptions and practices of treatment seeking for childhood pneumonia: a mixed methods study in a rural district, Ghana. BMC Public Health 2016, 16(1):1-10.

81. Kalyango JN, Lindstrand A, Rutebemberwa E, Ssali S, Kadobera D, Karamagi $C$, Peterson S, Alfven $\mathrm{T}$ : Increased use of community medicine distributors and rational use of drugs in children less than five years of age in Uganda caused by integrated community case management of fever. The American journal of tropical medicine and hygiene 2012, 87(5 Suppl):36-45.

82. Ajayi IO, Browne EN, Garshong B, Bateganya F, Yusuf B, Agyei-Baffour $P$, Doamekpor L, Balyeku A, Munguti K, Cousens S: Feasibility and acceptability of artemisinin-based combination therapy for the home management of malaria in four African sites. Malaria Journal 2008, 7(1):6. 
83. Kemble SK, Davis JC, Nalugwa T, Njama-Meya D, Hopkins H, Dorsey G, Staedke SG: Prevention and treatment strategies used for the community management of childhood fever in Kampala, Uganda. American Journal of Tropical Medicine and Hygiene 2006, 74(6):999.

84. Dunyo SK, Afari EA, Koram KA, Ahorlu CK, Abubakar I, Nkrumah FK: Health centre versus home presumptive diagnosis of malaria in southern Ghana: implications for home-based care policy. Transactions of the Royal Society of Tropical Medicine and Hygiene 2000, 94(3):285-288.

85. Sirima SB, Konate A, Tiono AB, Convelbo N, Cousens S, Pagnoni F: Early treatment of childhood fevers with pre packaged antimalarial drugs in the home reduces severe malaria morbidity in Burkina Faso. Tropical Medicine \& International Health 2003, 8(2):133-139.

86. Chinbuah AM, Gyapong JO, Pagnoni F, Wellington EK, Gyapong M: Feasibility and acceptability of the use of artemether lumefantrine in the home management of uncomplicated malaria in children 6 59 months old in Ghana. Tropical Medicine \& International Health 2006, 11(7):1003-1016.

87. Halwindi $H$, Siziya $S$, Magnussen $P$, Olsen A: Factors perceived by caretakers as barriers to health care for under-five children in Mazabuka district, Zambia. ISRN Tropical Medicine 2013, 2013.

88. Bazzano AN, Kirkwood BR, Tawiah Agyemang C, Owusu Agyei S, Adongo PB: Beyond symptom recognition: care seeking for ill newborns in rural Ghana. Tropical Medicine \& International Health 2008, 13(1):123-128.

89. Nsungwa Sabiiti J, Källander K, Nsabagasani X, Namusisi K, Pariyo G, Johansson A, Tomson G, Peterson S: Local fever illness classifications: implications for home management of malaria strategies. Tropical Medicine \& International Health 2004, 9(11):1191-1199.

90. Huber $\mathrm{H}$ : The Krobo: Traditional social and religious life of a West African people, vol. 16: Anthropos institute; 1963. 
91. Sharkey AB, Martin S, Cerveau T, Wetzler E, Berzal R: Demand generation and social mobilisation for integrated community case management (iCCM) and child health: Lessons learned from successful programmes in Niger and Mozambique. Journal of global health 2014, 4(2).

92. Mbiti JS: African religions \& philosophy: Heinemann; 1990.

93. Christopher JB, Le May A, Lewin S, Ross DA: Thirty years after AlmaAta: a systematic review of the impact of community health workers delivering curative interventions against malaria, pneumonia and diarrhoea on child mortality and morbidity in sub-Saharan Africa. Hum Resour Health 2011, 9(1):27.

94. Lozano R, Wang H, Foreman KJ, Rajaratnam JK, Naghavi M, Marcus JR, Dwyer-Lindgren L, Lofgren KT, Phillips D, Atkinson C: Progress towards Millennium Development Goals 4 and 5 on maternal and child mortality: an updated systematic analysis. The Lancet 2011, 378(9797):1139-1165.

95. Rajaratnam JK, Marcus JR, Flaxman AD, Wang $H$, Levin-Rector A, Dwyer L, Costa M, Lopez AD, Murray CJL: Neonatal, postneonatal, childhood, and under-5 mortality for 187 countries, 1970-2010: a systematic analysis of progress towards Millennium Development Goal 4. The lancet 2010, 375(9730):1988-2008.

96. Laínez YB, Wittcoff A, Mohamud Al, Amendola P, Perry HB, D'Harcourt $E$ : Insights from community case management data in six subSaharan African countries. The American journal of tropical medicine and hygiene 2012, 87(5 Suppl):144-150.

97. Sreeramareddy C, Shankar R, Sreekumaran B, Subba S, Joshi H, Ramachandran $\mathrm{U}$ : Care seeking behaviour for childhood illness-a questionnaire survey in western Nepal. BMC international health and human rights 2006, 6(1):7.

98. Perez $\mathrm{F}, \mathrm{Ba} \mathrm{H}$, Dastagire $\mathrm{S}$, Altmann $\mathrm{M}$ : The role of community health workers in improving child health programmes in Mali. BMC international health and human rights 2009, 9(1):28. 
99. Thiede $M$, Akweongo $P$, Mclntyre $D$ : Exploring the dimensions of equity. In.: The Economics of Health Equity, Cambridge: Cambridge University Press; 2007.

100. Chinbuah MA, Abbey M, Kager PA, Gyapong M, Nonvignon J, Ashitey P, Akpakli J, Appiatse S-AA, Kubi D, Gyapong JO: Assessment of the adherence of community health workers to dosing and referral guidelines for the management of fever in children under 5 years: a study in Dangme West District, Ghana. International Health 2013, 5(2):148-156.

101. Craig P, Dieppe P, Macintyre S, Michie S, Nazareth I, Petticrew M: Developing and evaluating complex interventions: the new Medical Research Council guidance. International journal of nursing studies 2013, 50(5):587-592.

102. Glanz K, Bishop DB: The role of behavioral science theory in development and implementation of public health interventions. Annu Rev Public Health 2010, 31:399-418.

103. Strachan DL, Kallander K, Ten Asbroek AH, Kirkwood B, Meek SR, Benton L, Conteh L, Tibenderana J, Hill Z: Interventions to improve motivation and retention of community health workers delivering integrated community case management (iCCM): stakeholder perceptions and priorities. Am J Trop Med Hyg 2012, 87(5 Suppl):111119.

104. Belansky ES, Cutforth N, Chavez RA, Waters E, Bartlett-Horch K: An adapted version of intervention mapping (AIM) is a tool for conducting community-based participatory research. Health promotion practice 2011, 12(3):440-455.

105. Bartholomew LK, Mullen PD: Five roles for using theory and evidence in the design and testing of behavior change interventions. Journal of public health dentistry 2011, 71(s1):S20-S33.

106. Brendryen $\mathrm{H}$, Kraft $\mathrm{P}$, Schaalma $\mathrm{H}$ : Looking inside the black box: Using intervention mapping to describe the development of the automated smoking cessation intervention 'happy ending'. Journal of Smoking Cessation 2010, 5(01):29-56.

107. Green LW, Kreuter MW: Health program planning: an educational and ecological approach: McGraw-Hill New York; 2005. 
108. Michie S, Johnston M, Francis J, Hardeman W, Eccles M: From theory to intervention: mapping theoretically derived behavioural determinants to behaviour change techniques. Applied psychology 2008, 57(4):660-680.

109. Bandura A: Social foundations of thought and action. Englewood Cliffs, NJ 1986.

110. Ajzen I: The theory of planned behavior. Organizational behavior and human decision processes 1991, 50(2):179-211.

111. Kreuter MW, McClure SM: The role of culture in health communication. Annu Rev Public Health 2004, 25:439-455.

112. Gans KM, Kumanyika SK, Lovell HJ, Risica PM, Goldman R, OdomsYoung A, Strolla LO, Decaille DO, Caron C, Lasater TM: The development of SisterTalk: a cable TV-delivered weight control program for black women. Preventive Medicine 2003, 37(6):654-667.

113. Mann CM, Ward DS, Vaughn A, Benjamin Neelon SE, Long Vidal LJ, Omar S, Namenek Brouwer RJ, Østbye T: Application of the Intervention Mapping protocol to develop Keys, a family child care home intervention to prevent early childhood obesity. BMC Public Health 2015, 15(1):1-13.

114. WHO: Community health workers: What do we know about them? The State of the evidence on programmes, activities, costs and impact on health outcomes of using community health workers: Evidence and information for policy. In. Geneva: WHO, Department of Human Resources for Health; 2007.

115. Haines A SD, Lehmann U, Rowe AK, Lawn JE, Jan S et al.: Achieving child survival goals: potential contribution of community health workers. Lancet, 369: 2121-2131 2007.

116. Lewin S, Munabi Babigumira S, Glenton C, Daniels K, Bosch Capblanch $X$, van Wyk BE, Odgaard Jensen J, Johansen M, Aja GN, Zwarenstein M: Lay health workers in primary and community health care for maternal and child health and the management of infectious diseases. The Cochrane Library 2010.

117. Dawson P, Pradhan $Y$, Houston R, Karki S, Poudel D, Hodgins S: From research to national expansion: 20 years' experience of community-based management of childhood pneumonia in Nepal. Bulletin of the World Health Organization 2008, 86(5):339-343. 
118. Hadi A: Diagnosis of pneumonia by community health volunteers: experience of BRAC, Bangladesh. Tropical doctor 2001, 31(2):75-77.

119. Kelly JM, Osamba B, Garg RM, Hamel MJ, Lewis JJ, Rowe SY, Rowe AK, Deming MS: Community health worker performance in the management of multiple childhood illnesses: Siaya District, Kenya, 1997-2001. American journal of public health 2001, 91(10):16171624.

120. World Health Organization, United Nations Children's Fund: Integrated Management of Childhood Illnesses: Sick Child Modules A-E, G and video; Geneva. . 2004.

121. Ghana Health Service, BASICS U, Concern Ghana: Caring for the sick child. A manual for community based agents. Accra; . 2003. .

122. El Moussaoui R, De Borgie CA, Van den Broek P, Hustinx WN, Bresser P, Van den Berk GE, Poley J-W, Van den Berg B, Krouwels FH, Bonten MJ: Effectiveness of discontinuing antibiotic treatment after three days versus eight days in mild to moderate-severe community acquired pneumonia: randomised, double blind study. Bmj 2006, 332(7554):1355.

123. Fonseca W, Hoppu K, Rey LC, Amaral J, Qazi S: Comparing pharmacokinetics of amoxicillin given twice or three times per day to children older than 3 months with pneumonia. Antimicrobial agents and chemotherapy 2003, 47(3):997-1001.

124. Ansah E, Gyapong J, Agyepong I, Evans D: Improving adherence to malaria treatment for children: the use of pre? packed chloroquine tablets vs. chloroquine syrup. Tropical Medicine \& International Health 2001, 6(7):496-504.

125. Yeboah-Antwi K, Gyapong J, Asare I, Barnish G, Evans D, Adjei S: Impact of prepackaging antimalarial drugs on cost to patients and compliance with treatment. Bulletin of the World Health Organization 2001, 79(5):394-399.

126. Pagnoni F, Convelbo N, Tiendrebeogo J, Cousens S, Esposito F: A community-based programme to provide prompt and adequate treatment of presumptive malaria in children. Transactions of the Royal Society of Tropical Medicine and Hygiene 1997, 91(5):512-517. 
127. Hazir T, Fox L, Nisar YB, Fox M, Ashraf Y, MacLeod W, Ramzan A, Maqbool S, Masood T, Hussain W: New Outpatient Short-Course Home Oral Therapy for Severe Pneumonia Study Group. Ambulatory short-course high-dose oral amoxicillin for treatment of severe pneumonia in children: a randomised equivalency trial. Lancet 2008, 371(9606):49-56.

128. Thomson A, Khogali M, de Smet M, Reid T, Mukhtar A, Peterson S, von Schreeb J: Low referral completion of rapid diagnostic test-negative patients in community-based treatment of malaria in Sierra Leone. MalarJ 2011, 10:94.

129. Källander K, Tomson G, Nsungwa-Sabiiti J, Senyonjo Y, Pariyo G, Peterson S: Community referral in home management of malaria in western Uganda: a case series study. BMC International Health and Human Rights 2006, 6(1):2.

130. Winch P, Bagayoko A, Diawara A, Kane M, Thiero F, Gilroy K, Daou Z, Berthe $Z$, Swedberg $E$ : Increases in correct administration of chloroquine in the home and referral of sick children to health facilities through a community-based intervention in Bougouni District, Mali. Transactions of the Royal Society of Tropical Medicine and Hygiene 2003, 97(5):481-490.

131. Arifeen SE, Hoque DE, Akter T, Rahman M, Hoque ME, Begum K, Chowdhury EK, Khan R, Blum LS, Ahmed S: Effect of the Integrated Management of Childhood Illness strategy on childhood mortality and nutrition in a rural area in Bangladesh: a cluster randomised trial. The Lancet 2009, 374(9687):393-403.

132. WHO /UNICEF: Management of sick children by community health workers: intervention models and programme examples. 2006.

133. Dovlo D: The brain drain and retention of health professionals in Africa. In: 2003; 2003: 23-25.

134. Clarke E: The brain drain of health workers in Ghana. In: 27th International Conference on Occupational Health Brazil, Iguassu Falls; 2003. 
135. Martineau T, Decker K, Bundred P: "Brain drain" of health professionals: from rhetoric to responsible action. Health Policy 2004, 70(1):1-10.

136. Ahorl C, Koram K, Seake-Kwawu A, M W: Two Year Evaluation of Intermittent Preventive Treatment for Children (IPTC) combined with timely Home Treatment for malaria control in Ghana. Malaria Journal 2011, 10(1):127.

137. Bugri Sam: Community-Based Surveillance In Ghana. In. Accra: Ministry of Health, Ghana; 2005.

138. Bronfenbrenner $\mathrm{U}$ : The ecology of human development. cambridge ma: Harvard University Press; 1979.

139. Chevalier C, Lapo A, O'Brien J, Wierzba TF: Why do village health workers drop out. In: 1993; 1993: 258-261.

140. Lambrechts T, et al: Integrated Management of Childhood Illness: A Summary of First Experiences. Bulletin of the World Health Organization 1999, 77(7):582-594.

141. Jones AM: Applied econometrics for health economists: A practical guide. Oxford: Radeliffe Publishing Ltd; 2007.

142. Oliver D, Serovich J, Mason T: Constraints and opportunities with interview transcription: Towards reflection in qualitative research. Social Forces 2005, 84(2):1273-1289.

143. Marsh DR, Hamer DH, Pagnoni F, Peterson S: Introduction to a special supplement: Evidence for the implementation, effects, and impact of the integrated community case management strategy to treat childhood infection. The American journal of tropical medicine and hygiene 2012, 87(5 Suppl):2.

144. Strachan DL, Källander K, ten Asbroek AH, Kirkwood B, Meek SR, Benton L, Conteh L, Tibenderana J, Hill Z: Interventions to improve motivation and retention of community health workers delivering integrated community case management.(iCCM): Stakeholder perceptions and priorities. American Journal of Tropical Medicine and Hygiene 2012, 87(5):111. 
145. MOH/NMCP: Home Management of Malaria, ARI and Diarrhoea in Ghana: Implementation Guidelines. 2010.

146. Chinbuah MA, Adjuik M, Cobelens F, Koram KA, Abbey M, Gyapong M, Kager PA, Gyapong JO: Impact of treating young children with antimalarials with or without antibiotics on morbidity: a clusterrandomized controlled trial in Ghana. International health 2013, 5(3):228-235.

147. Onyango MA, Owoko S, Oguttu M: Factors that influence male involvement in sexual and reproductive health in Western Kenya: a qualitative study: original research article. African journal of reproductive health 2010, 14(4):33-43.

148. Olang'o CO, Nyamongo IK, Aagaard-Hansen J: Staff attrition among community health workers in home-based care programmes for people living with HIV and AIDS in western Kenya. Health Policy 2010, 97(2):232-237.

149. Nsungwa-Sabiiti J, Peterson S, Pariyo G, Ogwal-Okeng J, Petzold MG, Tomson G: Home-based management of fever and malaria treatment practices in Uganda. Transactions of the Royal Society of Tropical Medicine and Hygiene 2007, 101(12):1199-1207.

150. Das A, Ravindran T: Factors affecting treatment-seeking for febrile illness in a malaria endemic block in Boudh district, Orissa, India: policy implications for malaria control. Malar J 2010, 9:377.

151. Rutebemberwa E, Pariyo G, Peterson S, Tomson G, Kallander K: Utilization of public or private health care providers by febrile children after user fee removal in Uganda. Malaria journal 2009, $8(1): 45$.

152. Comoro C, Nsimba S, Warsame M, Tomson G: Local understanding, perceptions and reported practices of mothers/guardians and health workers on childhood malaria in a Tanzanian districtimplications for malaria control. Acta tropica 2003, 87(3):305-313. 
153. Winch PJ, Makemba AM, Kamazima SR, Lurie M, Lwihula GK, Premji Z, Minjas JN, Shiff CJ: Local terminology for febrile illnesses in Bagamoyo District, Tanzania and its impact on the design of a community-based malaria control programme. Social Science \& Medicine 1996, 42(7):1057-1067.

154. Hetzel MW, Iteba N, Makemba A, Mshana C, Lengeler C, Obrist B, Schulze A, Nathan R, Dillip A, Alba S: Understanding and improving access to prompt and effective malaria treatment and care in rural Tanzania: the ACCESS Programme. Malaria journal 2007, 6(1):83.

155. Ajayi I, Browne EN, Garshong B, Bateganya F, Yusuf B, Agyei-Baffour P: Feasibility and acceptability of artemisinin-based combination therapy for the home management of malaria in four African sites. MalarJ 2008, 7.

156. Elmardi KA, Malik EM, Abdelgadir T, Ali SH, Elsyed AH, Mudather MA, Elhassan $\mathrm{AH}$, Adam I: Feasibility and acceptability of home-based management of malaria strategy adapted to Sudan's conditions using artemisinin-based combination therapy and rapid diagnostic test. Malaria journal 2009, 8(1):39.

157. Seidenberg PD, Hamer DH, lyer H, Pilingana P, Siazeele K, Hamainza B, MacLeod WB, Yeboah-Antwi K: Impact of integrated community case management on health-seeking behavior in rural Zambia. The American journal of tropical medicine and hygiene 2012, 87 (5 Suppl):105-110.

158. Abbey M, Bartholomew LK, Nonvignon J, Chinbuah MA, Pappoe M, Gyapong M, Gyapong JO, Bart-Plange C, van den Borne B: Factors related to retention of community health workers in a trial on community-based management of fever in children under 5 years in the Dangme West District of Ghana. International health 2014:ihu007. 

Acknowledgements 
I am grateful to all the individuals and institutions that supported me in the process of working on this dissertation. I offer my deepest gratitude to God Almighty who sustained me and by whose help I have leaped over this "wall". My Special thanks to my 3 supervisors from whom I learned so much in the course of this journey:

To my lead supervisor Professor Bart van den Borne, who visited Ghana to work on the project and provided technical support during the intervention mapping workshop. Who also reviewed and critically revised my manuscript drafts for important intellectual content. I am also thankful for his magnanimity, constant support, patience and encouragement throughout the whole study period.

To Prof L Kay Bartholomew-Eldridge, my co-supervisor who came to Ghana to guide the intervention mapping phase of the project. You were a great mentor who demanded nothing less than excellence in the work of your students. Thanks for all that you shared with me. I am grateful also for your friendship and your kindness in hosting me in your house when I visited Houston for my short courses. How I wish you were around to see my defense of this thesis and to share this time with you. Kay, rest in perfect peace.

I am equally grateful to $\mathrm{Dr}$ Matilda Pappoe, my third supervisor who supported and guided me through the doctoral journey. She provided the expertise during the field implementation of the health education component of the project. Thanks for the constant encouragement and also for facilitating my position as a part time lecturer at the department of social and behaviuoral sciences of the school of public health, University of Ghana; a position that made it possible for closer supervision and which also granted me access to study facilities there.

I am especially grateful to the Netherlands Organization for International Cooperation in Higher Education (NUFFIC) for the financial support that made it possible for me to complete my PhD. I also appreciate the funding from the UNDP/WHO/Special programme for Tropical Diseases Research (TDR) and the Knowledge Enriches Programme of the Netherlands Foundation for the Advancement of Tropical Research (WOTRO) that supported the implementation of the entire trial. 
My appreciation goes to Lori Mees, my scholarship coordinator for helping and sorting out my scholarship issues, keeping me abreast of related current issues and helping make my time in the school enjoyable. Furthermore, I express my appreciation to the staff of the Department of Health Promotion, Maastricht University. In particular, I am most grateful to Marja Vissers for her exceptional administrative and organizational skills that made everything seem so easy. I am grateful for all the support she provided until her retirement. To Patricia von Schenckendorff who took over from Marja, I am most grateful for her role in facilitating the preparations towards the defense of my dissertation and for helping me to finish well. I am very grateful to Leon Kolenburg who provided all the IT support the entire duration of my study. Leon was always reliable and his great sense of humor made it easy to learn from him. My sincere gratitude goes to the members of my dissertation committee for the time spent assessing my thesis.

During my study in Maastricht, there were many people I met who enriched my life in diverse ways:

Many thanks to Monique Willigers my first hostess, for taking care of me shortly after my arrival and helping me start off well. Thank you for instilling in me the discipline of having breakfast every morning which you always ensured we had together before I would leave the house and thank you for introducing me to the Segers family who became my hosts for the rest of my study in Maastricht.

To you Jo Segers and your caring wife Mieke Segers, together with your lovely daughters: Elian, Jolanda and Monique, accept my gratitude for making my stay so enjoyable that Gronsveld has become my second home. You provided me not just accommodation but with your friendship, and an atmosphere of belonging. My gratitude is extended to sons -in-law to the Segers: Marc, Harold and Maarten and to their children: Sanne, Stan, Gus, Fons and Raf. The times we spent together will never be forgotten. 
I also want to thank Aziza Mukhayer, a colleague from Sudan, and with whom I shared an office in the department of health promotion and who became a special friend and a sister. Aziza, together with your sweet daughters: Madena, Amna and Nafisa, you shared the warmth of your home with me and it was always an atmosphere of love. Thanks for your generosity and the great times we spent together, your friendship has truly enriched my life.

Back in Ghana: I would like to express gratitude to the larger study team: Prof. John Gyapong, Dr. Margaret Gyapong, Dr. Margaret Amanua Chinbuah, Dr. Justice Nonvignon and Dr. Moses Aikins for the wealth of knowledge they brought on board from their various disciplines and from which I benefitted a lot. Gratitude also goes to Prof Piet Kager of the University of Amsterdam for his coordinating role which facilitated the successful completion of the trial.

My gratitude also goes to the data collection team for their hard work in obtaining the needed data and to the community members, opinion leaders, the Community Health Workers and all those who patiently answered our many questions, many times over the years

I owe much thanks to the research assistants and field coordinators especially: Saviour Fia, David Kubi, Evelyn Lotsu and Jonas Akpakli who worked tirelessly to ensure the successful completion of the project. Special thanks to Evelyn Lotsu for the tremendous work you did in creating and directing the drama and helping to produce all the communication materials; as well as implementing the programme in the communities sometimes even before and beyond working hours. Your enthusiasm and dedication to the program was admirable. Jonas Akpakli, your stamina to meet the high demands of the entire team's data needs was impressive. We could always rely on you and your data entry team - Ruby and Sheila.

I wish to express much appreciation to Dr. Isaiah Teye Awidi - you have been a brother and a friend. I cannot thank you enough for all the support you gave me over the years in the areas of statistical analysis and data interpretation, interpretation of the Dangme dialect and critically reviewing drafts of my 
manuscripts for journal publications. In this regard, I also like to thank $\mathrm{Dr}$ Godwin Afenyadu, Dr Alex Nazzar, Dr Ivy Osei, Dr Bertha Garshong and Dr Eric Arthur for reviewing drafts of my manuscripts and to Fuseini Sataru for contributing materials essential for my write ups. To Dr Abraham Hodgson, Director of the Research and Development Division I am thankful for the support granted me to complete the thesis.

I am most grateful to Reverend Benjie Djin my Pastor in Ghana for his wisdom and great insight (for pushing me out of my comfort zone) and for inspiring me to aim high. My sincere thanks to Mrs Djin and all the associate Pastors of my local church for their prayer support. I am also grateful to the leadership and members of the Redeemed Christian Church of God in Maastricht for their support and great fellowship times on Sundays. I also thank my parents and siblings for their interest in my work and for their well wishes and support throughout the years until the end of the thesis.

Finally, my sincere appreciation goes to my dear husband, Emmanuel Kofi Abbey for being so patient and kind. Your support has been great and your unconditional love covered my guilt for being away for those extended periods! It could not have been easier without your kindness. I am truly grateful for having you in my life. 

Curriculum Vitae 
Mercy Abbey is one of nine children born to Mr. and Mrs. John Ablordey in the Volta Region of Ghana, but grew and lived in Accra. She is married to Mr. Emmanuel Kofi Abbey and the family lives together in Tema, in the Greater Accra region of Ghana.

Mercy studied Journalism and Mass Communications at the Ghana Institute of Journalism in 1987 and did her internship in the Radio News Room of the Ghana Broadcasting Corporation and later with the National Newspaper - The Daily Graphic. Subsequently she did her national service at the North Ridge Lyceum where she taught for a year. In 1989 she joined the Operations Research Unit of the Ghana Ministry of Health to work on a joint collaborative project on Traditional Birth Attendants with the University of Columbia. In 1990, she obtained a grant from the then Overseas Development Agency (ODA), now DFID, to pursue an MSc degree in Population Policies and Programmes at the College of Cardiff, University of Wales. Subsequently she participated in a professional development training program in Research at the University of Exeter in England. She returned to the Ministry of Health in 1992.

Over the years, Mercy has been involved in the development and implementation of health and health related research, coordination of field research projects and capacity building among regional and district staff of the Ghana Health Service. She has also collaborated with both national and international institutions / organizations for research and development projects.

In 1994- 1995 Mercy participated in the development and field testing of guidelines for the design and implementation of Health Education for the national Safe-Motherhood program of the Ghana Ministry of Health. Subsequently, between 1995 and 2000, she was part of the national trainer of trainers' team that facilitated series of workshops to train Health Workers in the regions for district staff in the use of the revised Guidelines for implementation. 
Between 1999 and2000, Mercy collaborated with Family Care International ( $\mathrm{FCl}$ ), an international NGO to Pre-test a set of health education materials produced by $\mathrm{FCl}$ for adolescents: "You, your life your dreams". She also field-tested tools developed by $\mathrm{FCl}$ to support community education about unsafe abortion, as well as the provision of high-quality counselling and care to women who receive treatment for abortion complications. Further she evaluated the use of a set of safe motherhood-related publications: "Healthy Women, Healthy Mothers"; "Getting the Message Out"; and "Strengthening Communications"

From 2000 to 2003, Mercy worked as a Research Fellow on a multi-centred research initiative called SAFE (Skilled Attendance for Everyone) which aimed to improve the knowledge base on skilled attendance at delivery in developing countries. This Research Partnership involved five countriesBangladesh, Ghana, Jamaica, Malawi and Mexico; with the coordinating centre at the University of Aberdeen in Scotland and funded by the European commission and the Department for International Development, UK. On this project, she conducted and also coordinated a number of studies and activities that culminated in the development of a strategy development tool for safe motherhood and also a number of publications.

Mercy was one of two research coordinators for the Ghanaian-Dutch collaboration (GDC) for Health Research and Development implemented between 2000 and 2005. It was an innovative partnership for health research through which over 70 health research projects were funded across the country; that applied principles of local stewardship. Besides coordination and monitoring of the various projects, Mercy also helped to design and edited a newsletter for the GDC titled: Partners for Health Research and Development.

Between 2006 and 2009, she worked on a collaborative project that was supported by the UNDP/WHO/Special programme for Tropical Diseases Research (TDR) and the Knowledge Enriches Programme of the Netherlands Foundation for the Advancement of Tropical Research (WOTRO) on Home 
and community management of fevers in children under five in the Dangme West district. Her role on the project included, but not limited to the development of appropriate communication strategies/messages for improved care seeking for fever in children under five. Data generated for the project formed the basis for this thesis. In 2010 she was awarded the Dutch Government Fellowship (NUFFIC) to pursue doctoral studies at the Department of Health Promotion, University of Maastricht.

Mercy is currently Deputy Chief Health Research Officer and has disseminated her research work in local and international meetings and conferences and written a number of publications.

\section{Publications}

M Abbey, MA Chinbuah, M Gyapong, L.K Bartholomew, B van den Borne (2016) Community perceptions and practices of treatment seeking for childhood pneumonia: a mixed methods study in a rural district, Ghana. BMC Public Health 16(1), 848

Mercy Abbey, L. Kay Bartholomew, Matilda Pappoe and Bart van den Borne (2015) Treating fever in children under five: caregiver perceptions of community health worker services in Dangme West district, Ghana. International health 7(6), 455-463

Mercy Abbey, L Kay Bartholomew, Justice Nonvignon, Margaret A. Chinbuah, Matilda Pappoe, Margaret Gyapong, John O. Gyapong, Constance Bart-Plange and Bart van den Borne (2014).Factors Related to Retention of Community Health Workers in a Community Based Management of Fevers in Children under Five years in the Dangme West District of Ghana. International health 6 (2), 99-105

MA Chinbuah, M Abbey, PA Kager, M Gyapong, J Nonvignon, P Ashitey, J Akpakli Assessment of the adherence of community health workers to dosing and referral guidelines for the management of fever in children under 5 years: a study in Dangme West District, Ghana. International Health. Advance Access published January 24, 2013 
MA Chinbuah, PA Kager, M Abbey, M Gyapong, E Awini, J Nonvignon, M Adjuik, M. Impact of community management of fever (using antimalarials with or without antibiotics) on childhood mortality: a cluster-randomized controlled trial in Ghana.The American journal of tropical medicine and hygiene 87 (5 Suppl), 11-20 (2012)

J Nonvignon, MA Chinbuah, M Gyapong, M Abbey, E Awini, JO Gyapong, M Aikins Is home management of fevers a cost-effective way of reducing under-five mortality in Africa? The case of a rural Ghanaian District. Tropical Medicine \& International Health 17 (8), 951-957 2012

J Nonvignon, M K S Aikins, MA Chinbuah, M Abbey, M Gyapong, BNA Garshong, Saviour F. Gyapong J. Treatment choices for fevers in children under-five years in a rural Ghanaian district Malaria Journal 2010, 9:188

Lucia D'Ambruoso, Mercy Abbey, Julia Hussein. Please understand when I cry out in pain: women's accounts of maternity services during labour and delivery in Ghana. BMC Public Health 2005, 5:140 (22 December 2005)

Hussein J, Hundley V, Bell J, Abbey M, Quansah Asare G and, Graham WJ How do women identify health professionals at birth in Ghana? Midwifery, Volume 21, Issue 1, March 2005, Elsvier Pages 36-43

J Hussein, J Bell, ANazzar, M Abbey, S Adjei, W Graham. The skilled attendance index: proposal for a new measure of skilled attendance at delivery. Reproductive Health Matters 12 (24), 2004 pages 160-170

Agyepong IA, Wellington EK, Abbey M. A comparative study of clinical and socio-cultural aspects of anaemia among adolescent girls in rural Ghana. Acta Trop. 1997 May 30;65(3):123-38.

In Press: $\mathrm{BMCPH}$

Mercy Abbey, L Kay Bartholomew, Margaret A. Chinbuah, Margaret Gyapong, John O. Gyapong, and Bart van den Borne: Development of a theory and evidence based program to promote community treatment of fevers in children under five in a rural district in Southern Ghana: An Intervention Mapping Approach. 